\title{
Maniraptoran pelvic musculature highlights evolutionary patterns in theropod locomotion on the line to birds
}

\author{
Matthew M Rhodes ${ }^{\text {Corresp., } 1}$, Donald M Henderson ${ }^{2}$, Philip J Currie ${ }^{1}$ \\ ${ }^{1}$ Department of Biological Sciences, University of Alberta, Edmonton, Alberta, Canada \\ 2 Royal Tyrrell Museum of Palaeontology, Drumheller, Alberta, Canada \\ Corresponding Author: Matthew M Rhodes \\ Email address: mmrhodes@ualberta.ca
}

Locomotion is a fundamental aspect of palaeobiology and often investigated by comparing osteological structures and proportions. Previous studies document a stepwise accumulation of avian-like features in theropod dinosaurs that accelerates in the clade Maniraptora. However, the soft tissues that influenced the skeleton offer another perspective on locomotory adaptations. Examination of the pelvis for osteological correlates of hind limb and tail musculature allowed reconstruction of primary locomotory muscles across theropods and their closest extant relatives. Additionally, the areas of pelvic muscle origins were quantified to measure relative differences within and between taxa, to compare morphological features associated with cursoriality, and offer insight into the evolution of locomotor modules. Locomotory inferences based on myology often corroborate those based on osteology, although they occasionally conflict and indicate greater complexity than previously appreciated. Maniraptoran pelvic musculature underscores previous studies noting the multifaceted nature of cursoriality and suggests that a more punctuated step in caudal decoupling occurred at or near the base of Maniraptora. 


\section{Maniraptoran pelvic musculature highlights}

2 evolutionary patterns in theropod locomotion on the

\section{3 line to birds}

5 Matthew M. Rhodes ${ }^{1}$, Donald M. Henderson ${ }^{2}$, Philip J. Currie ${ }^{1}$

6

$7{ }^{1}$ Department of Biological Sciences, University of Alberta, Edmonton, Alberta, Canada

$8 \quad 2$ Royal Tyrrell Museum of Palaeontology, Drumheller, Alberta, Canada

10 Corresponding Author:

11 Matthew Rhodes ${ }^{1}$

12 CW 405 Biological Sciences Building, University of Alberta, Edmonton, Alberta T6G 2E9,

13 Canada

14 Email address: mmrhodes@ualberta.ca 


\section{Abstract}

16 Locomotion is a fundamental aspect of palaeobiology and often investigated by comparing

17 osteological structures and proportions. Previous studies document a stepwise accumulation of

18 avian-like features in theropod dinosaurs that accelerates in the clade Maniraptora. However, the

19 soft tissues that influenced the skeleton offer another perspective on locomotory adaptations.

20 Examination of the pelvis for osteological correlates of hind limb and tail musculature allowed

21 reconstruction of primary locomotory muscles across theropods and their closest extant relatives.

22 Additionally, the areas of pelvic muscle origins were quantified to measure relative differences

23 within and between taxa, to compare morphological features associated with cursoriality, and

24 offer insight into the evolution of locomotor modules. Locomotory inferences based on myology

25 often corroborate those based on osteology, although they occasionally conflict and indicate

26 greater complexity than previously appreciated. Maniraptoran pelvic musculature underscores

27 previous studies noting the multifaceted nature of cursoriality and suggests that a more

28 punctuated step in caudal decoupling occurred at or near the base of Maniraptora. 


\section{Introduction}

30 Locomotion is a vital component of palaeobiology as it determines how individuals acquire

31 resources and escape predators, and is inherently linked to other aspects such as body size and

32 physiology (Hutchinson, 2004a,b). Of particular interest is locomotion in theropod dinosaurs,

33 whose fossil record documents the gradual but steady assembly of the avian body plan

34 (Hutchinson \& Allen, 2009; Brusatte et al., 2014; Xu et al., 2014). Non-avian theropods achieved

35 global distribution and striking diversity while experimenting with locomotion at large body

36 sizes encroaching on biomechanical limits for bipeds (Hutchinson \& Garcia, 2002; Henderson \&

37 Snively, 2004; Therrien \& Henderson, 2007; Hutchinson et al., 2011; Persons \& Currie, 2016;

38 Persons, Currie \& Erickson, 2020; Dececchi et al., 2020), flight and wing-based locomotion

39 (Burgers \& Chiappe, 1999; Chatterjee \& Templin, 2007; Alexander et al., 2010; Evangelista et

40 al., 2014a,b; Palmer, 2014; Xu et al., 2015; Heers et al., 2016; Dececchi, Larsson \& Habib, 2016;

41 Sullivan, Xu \& O’Connor, 2017; Segre \& Banet, 2018; Talori et al., 2018, 2019; Pei et al.,

42 2020), and ventilatory structures (Carrier \& Farmer, 2000; Codd et al., 2008; Macaluso \&

43 Tschopp, 2018), among other features. Without the ability to directly observe locomotion in

44 extinct theropods, it is typically examined via osteological features, skeletal proportions, and

45 trackway sites (Gatesy, 1991; Gatesy \& Middleton, 1997; Carrano, 1998, 2000; Paul, 1998;

46 Gatesy et al., 1999; Day et al., 2002; Milner, Lockley \& Kirkland, 2006). These methods are

47 useful for inferring certain conditions but each has drawbacks as well. For example, although

48 trackways directly record the motions of individual organisms, they may not represent

49 characteristic behaviours or functional traits (e.g., speed, stride length, maneuverability).

50 However, accounting for soft tissues that anchor and control the skeleton provides an additional

51 viewpoint on locomotory adaptations.

Peer) reviewing PDF | (2020:07:51271:2:0:NEW 27 Dec 2020) 
early twentieth century, which used comparative methods grossly similar to extant phylogenetic

bracketing but without categorical confidence levels that constrain speculation and improve

55

consistency (Romer, 1923a,b,c, 1927; Russell, 1935). Comparisons with close living relatives

provided data on muscles and their osteological landmarks that were then used to infer attachment sites on scarred surfaces, tubercles, and processes of fossil bones. Substantial research on patterns in locomotory evolution has been conducted since those foundational studies to reconstruct the musculature for various clades: abelisaurids (Persons \& Currie, 2011b), allosauroids (Bates \& Schachner, 2011; Bates, Benson \& Falkingham, 2012), dromaeosaurids (Perle, 1985; Hutchinson et al., 2008; Persons \& Currie, 2012), herrerasaurids (Grillo \& Azevedo, 2011), ornithomimids (Russell, 1972), oviraptorosaurs (Persons, Currie \& Norell, 2014), troodontids (Bishop et al., 2018a), tyrannosaurids (Walker, 1977; Tarsitano, 1983; Perle, 1985; Carrano \& Hutchinson, 2002; Hutchinson et al., 2005; Persons \& Currie, 2011a), and broadly among theropods (Gatesy, 1990, 1995; Gatesy \& Dial, 1996; Carrano \& Biewener, 1999; Carrano, 2000; Farlow et al., 2000; Jones et al., 2000; Hutchinson \& Gatesy, 2000; Persons \& Currie, 2017). Although reconstructing muscles in extinct taxa poses challenges (McGowan, 1979; Bryant \& Seymour, 1990), proper phylogenetic context and categorization of confidence levels provide a stronger, more explicit framework for reconstruction (Bryant \& Russell, 1992; Witmer, 1995). Hutchinson (2001a, 2001b) used these more rigorous methods to produce a pair of thorough studies with a homology-based approach that documented osteological correlates of pelvic and femoral soft tissues in archosauromorphs. These two studies - plus follow-up summaries of hind limb muscle evolution in the same group (Hutchinson, 2002; Hutchinson \& Allen, 2009) — all documented a stepwise accumulation of 
75 avian-like traits on the evolutionary line to birds. They have become oft-cited references for

76 locomotory muscle reconstruction in dinosaurs, including musculoskeletal models that go

77 beyond description of muscle scars to provide another dimension on locomotion studies (Langer,

78 2003; Maidment \& Barrett, 2011, 2012; Bates et al., 2012; Maidment, Bates \& Barrett, 2014;

79 Maidment et al., 2014; Bishop et al., 2018a).

80 In theropods, many studies seem to corroborate the hypothesis that they represent a

81 gradual continuum of morphological change regarding hind limb anatomy and locomotor

82 function (Hutchinson \& Allen, 2009). However, some have noted that anatomical changes (e.g.,

83 whole-body proportions, centre of mass position, size and scaling of appendicular skeleton

84 relative to body mass) underwent significant evolutionary rate shifts in morphological evolution

85 within Maniraptora that continued into early birds (Allen et al., 2013; Dececchi \& Larsson, 2013;

86 Brusatte et al., 2014), coincident with the development of feathers, opisthopuby, and other

87 features (Foth, Tischlinger \& Rauhut, 2014; Xu et al., 2014; Sullivan, Xu \& O’Connor, 2017;

88 Macaluso \& Tschopp, 2018). To further complicate matters, locomotor abilities inferred from

89 skeletal proportions and foot morphology indicate that convergence is common, such as the

90 acquisition of relatively long distal limb elements (Gatesy \& Middleton, 1997; Carrano, 1998,

91 1999; Persons \& Currie, 2016) or proximally compressed metatarsals (Holtz, 1994; Snively \&

92 Russell, 2001, 2003; Snively, Russell \& Powell, 2004; White, 2009). Nevertheless, soft tissue

93 reconstruction provides another perspective on these issues. In eudromaeosaurians, reduced

94 extensor musculature corroborates osteological inferences suggesting reduced pursuit ability

95 (Carrano, 1999; Persons \& Currie, 2012, 2016). Conversely, tyrannosaurids exhibit several

96 skeletal features associated with enhanced running and/or agility (Holtz, 1994; Paul, 1998;

97 Snively \& Russell, 2001, 2003; Henderson \& Snively, 2004; Persons \& Currie, 2016), but 
98 musculoskeletal models accounting for soft tissues suggest that running was improbable in large

99 adults (Hutchinson \& Garcia, 2002; Hutchinson, 2004b; Hutchinson et al., 2005; Sellers et al.,

100 2017; Dececchi et al., 2020). Despite these advances, the locomotory musculature of many

101 theropods is unknown, and recent discoveries of new theropods - particularly within

102 Maniraptora - may require revisions of evolutionary patterns in light of previously unidentified 103 conditions.

104 Given that soft tissue inferences may corroborate or conflict with osteological ones, how

105 well does the myology of maniraptorans conform to the purported stepwise accumulation of

106 avian-like features? To address this question, maniraptoran pelvic anatomy was inspected for

107 osteological correlates of soft tissues, focusing on caenagnathids, therizinosaurs, and troodontids

108 as taxa with understudied or unstudied pelvic myology (Fig. 1). Subsequently, the area of each

109 muscle origin may be quantified and compared, with functional inferences inferred from

110 previous studies or the most closely related taxa. Examination of the hip focuses on proximal

111 hind limb muscles with a primary relationship to locomotion that protract and retract the entire

112 leg, and flex and extend joints of the leg (Dilkes, 2000; Meers, 2003; Maidment \& Barrett,

113 2011). Furthermore, the pelvis of a biped is the junction between the axial body and the

114 locomotory system. In particular, the pelvis sits at the junction of the hind limb and tail, and

115 provides key information on caudal locomotory musculature and its degree of integration with

116 the thigh (Gatesy, 1990; Gatesy \& Dial, 1996; Persons \& Currie, 2011a,b).

117 However, there is evidence that the morphology of an attachment site (an enthesis) does

118 not correspond muscular excursion, force production, or other attributes of its associated muscle

119 (Zumwalt, 2006; Rabey et al., 2015). Because of this, the area of attachment data here may be

120 unsuitable for reconstruction of other muscle properties including but not limited to muscle 
121 volume, physiological cross-section area, force production, or activity level. Instead, the area of

122 attachment for homologous muscles is herein presented as an opportunity to examine relative

123 changes in a comparative context and investigate potential relationships with other aspects of

124 palaeobiology. Shifts in the relative areas of each muscle or muscle group should not be used to

125 directly infer muscle volume, force production, or other physiological attributes.

126

127 Institutional abbreviations

128 AMNH, American Museum of Natural History, New York City, New York, United States of

129 America; BYUVP, Brigham Young University Museum of Paleontology, Provo, Utah, United

130 States of America; CEUM, College of Eastern Utah Prehistoric Museum, Price, Utah, United

131 States of America; CM, Carnegie Museum of Natural History, Pittsburgh, Pennsylvania, United

132 States of America; CMN, Canadian Museum of Nature, Ottawa, Ontario, Canada; DLXH,

133 Dalian Xinghai Museum, Dalian, Liaoning, China; IVPP, Institute for Vertebrate Paleontology

134 and Paleoanthropology, Beijing, China; RM, Redpath Museum, Montréal, Québec, Canada;

135 ROM, Royal Ontario Museum, Toronto, Ontario, Canada; TMP, Royal Tyrrell Museum of

136 Palaeontology, Drumheller, Alberta, Canada; UALVP, University of Alberta Laboratory for

137 Vertebrate Palaeontology, Edmonton, Alberta, Canada; UAMZ, University of Alberta Museum

138 of Zoology, Edmonton, Alberta, Canada; UMNH, Natural History Museum of Utah, Salt Lake

139 City, Utah, United States of America.

140

\section{Materials \& Methods}

142 Pelvic material of non-avian maniraptorans was examined, along with comparisons to that of

143 other theropods, and to that of extant avians, crocodylians, and squamates (Table 1). In addition, 
144 a savannah monitor (Varanus exanthematicus), a spectacled caiman (Caiman crocodilus), and a

145 common raven (Corvus corax) were dissected and inspected for pelvic and hind limb soft tissues

146 (all UAMZ). Literature review provided a guide for dissection of pelvic musculature in

147 squamates (Russell \& Bauer, 2008; Dick \& Clemente, 2016), crocodylians (Romer, 1923a;

148 Otero, Gallina \& Herrera, 2010; Allen et al., 2015), and birds (Shufeldt, 1890; Hudson,

149 Lanzillotti \& Edwards, 1959; Halvorson, 1972; Gheţie, 1976; Jacobson \& Hollyday, 1982;

150 Baumel, Wilson \& Bergren, 1990; Baumel et al., 1993; Mellett, 1994; Patak \& Baldwin, 1998;

151 Verstappen, Aerts \& De Vree, 1998; Gangl et al., 2004; Smith et al., 2006, 2007; Paxton et al.,

152 2010; Lamas, Main \& Hutchinson, 2014; Hutchinson et al., 2015). The homologies of pelvic

153 musculature are summarized in Table 2. Material was photographed with a digital camera and

154 illustrations were created in Adobe Photoshop or Illustrator CS6 using a Wacom tablet.

155 A guiding principle of the present study is the Extant Phylogenetic Bracket (Bryant \&

156 Russell, 1992; Witmer, 1995). This approach utilizes the closest extant representatives of an

157 extinct focal taxon as the best evidence for soft tissue inferences. Dissections and comparative

158 anatomy of skeletonized specimens provided data on soft tissues and their osteological correlates

159 in living relatives of non-avian maniraptorans. Following previous studies (Hutchinson, 2001a;

160 Carrano \& Hutchinson, 2002; Hutchinson et al., 2005, 2008; Maidment, Bates \& Barrett, 2014;

161 Bishop et al., 2018a), these data were used to examine pelvic material of non-avian

162 maniraptorans for osteological correlates of soft tissues, which were then mapped onto a

163 reconstructed pelvis in each taxon. For taxa in which an articulated pelvis was unavailable or

164 non-existent, the reconstruction was derived from associated material where possible, or from

165 contact surfaces (i.e., joints between peduncles of pelvic bones) using well-preserved, closely

166 related taxa for reference. It is unclear which subspecies is represented by the specimen of Gallus 
167 used in this study (Table 1); specimens influenced by artificial selection or commercialization

168 may affect how accurately they represent galliform morphology compared to ancestral Gallus

169 stock, which is perhaps better embodied by junglefowl (Paxton et al., 2010; 2014). Previous

170 studies note variation in body mass, muscle mass and architecture, locomotor ability, and force-

171 generating capacity between junglefowl and commercial chickens (Paxton et al., 2010, 2014;

172 Rose et al., 2016). However, these breeds tend to exhibit comparable limb muscle masses when

173 each is expressed as a proportion of body mass (Paxton et al., 2010; Rose et al., 2016).

174 Moreover, it is not clear how these behavioural and physiological differences are related to

175 enthesis morphology, if at all (Zumwalt, 2006; Rabey et al., 2015). Therefore, these potential

176 differences between specimens of Gallus are not expected to substantially influence our

177 myological reconstruction or quantitative comparisons that account for body mass.

178 For Therizinosauria, published descriptions of various taxa were reviewed (Xu, Tang \&

179 Wang, 1999; Kirkland et al., 2005; Li, You \& Zhang, 2008; Zanno et al., 2009; Zanno, 2010a,b;

180 Pu et al., 2013; Yao et al., 2019), but only specimens pertaining to Falcarius were used in

181 muscle reconstruction. There exists the potential that some of these specimens are taxonomically

182 different at the specific or even generic level (Zanno, 2010a), but limited variation was observed

183 in the osteological correlates of the specimens examined; the taxonomic differences therefore are

184 not expected to significantly influence the results.

185 Caenagnathids exhibit some variation, chiefly among the ilia (Funston \& Currie, 2020;

186 Rhodes, Funston \& Currie, 2020). The relatively poor preservation of their pelvic elements

187 required comparison to previous descriptions for reconstruction, including those of closely

188 related oviraptorosaurs (Currie \& Russell, 1988; Sues, 1997; Barsbold et al., 2000; Clark, Norell

189 \& Barsbold, 2001; Lü, 2002; Lü et al., 2004, 2013, 2017; Sullivan, Jasinski \& van Tomme, 2011; 
190 Xu et al., 2013; Lamanna et al., 2014; Funston et al., 2018). The reconstructed pelvis and

191 musculature presented here relies heavily on material of Chirostenotes (Currie \& Russell, 1988;

192 Funston \& Currie, 2020) but serves as a general blueprint for Caenagnathidae given the minor

193 pelvic variation within the family.

194 In troodontids, variation in pelvic morphology warranted two separate reconstructions

195 based on observed fossils. More basal, Early Cretaceous troodontids, such as Sinovenator (Xu et

196 al., 2002), exhibit similar morphology and osteological correlates with each other (Russell \&

197 Dong, 1993; Currie \& Dong, 2001; Xu et al., 2017; Pei et al., 2020), but differ substantially from

198 those of Late Cretaceous forms (Norell et al., 2009; Zanno et al., 2011; Tsuihiji et al., 2014; van

199 der Reest \& Currie, 2017; Pei et al., 2017). Basal and derived troodontids were reconstructed and

200 are herein treated separately based on these differences. However, basal members are

201 paraphyletic with respect to derived taxa (Xu et al., 2002, 2011, 2017; Zanno et al., 2011;

202 Tsuihiji et al., 2014; Hendrickx, Hartman \& Mateus, 2015; Shen et al., 2017b) and thus useful to

203 polarize anatomical changes within the family. They are intended to represent subsequent

204 stages — not equivalent taxonomic groups — within Troodontidae (Fig. 1).

205 Although the areas of pelvic muscle origins may not be an ideal or even suitable method

206 to determine other properties of muscles (Zumwalt, 2006; Rabey et al., 2015), it does allow for

207 examination of relative changes that occurred across non-avian theropods. Other methods, such

208 as analysis of cancellous bone architecture (Bishop et al., 2018a), can produce dynamic models

209 and informative results, but are limiting because sampling is not possible for many specimens.

210 Comparison of origin areas can provide data across a wide range of taxa but this only represents

211 one aspect of locomotion. Accordingly, these data are limited and cannot unequivocally

212 determine locomotory adaptations or directly inform on other attributes of muscle function. 
213 Nevertheless, these data can be incorporated into a more holistic analysis of locomotion and

214 behaviour in theropods. The areas of pelvic muscle origins (Supplemental Figs. S1-14) were

215 calculated using two methods. In the first method, the image of a pelvis with its associated

216 muscle regions was imported into the illustration program Corel DRAW!, and the perimeters of

217 each origin were traced counter-clockwise using the polyline tool to generate a contour with a

218 positive (right hand) sense of curl. Each contour was then exported as an AutoCAD DXF file and

219 the area enclosed by the contour was then calculated with some custom software. More details of

220 this method can be seen with the determination of the areas of theropod orbits (Henderson,

221 2002). In the second method, diagrams of pelvic muscles were imported to ImageJ, the scale set,

222 and then each area of origin measured using the wand (tracing) tool under default settings. In

223 both methods, a muscle origin that appeared in multiple views had its portions summed. This

224 relies on the assumption that using standard anatomical views, which present each view rotated

$22590^{\circ}$ from one another, adequately captures the surface area covered by the origin if flattened to a

226 2-dimensional shape. In addition, the pubes in a non-avian theropod are fused together, so the

227 anterior and posterior views of these bones display both the anatomical left and right sides of the

228 pelvis (Supplemental Figs. S4-11). This was mimicked in the figures of the crocodylians for

229 consistency and more anatomically realistic diagrams. However, only the origins appearing on

230 one anatomical side of the pelvis were measured. This is because pelvic musculature only affects

231 the hind limb on the same side of the body, and is identical on the contralateral side of a

232 bilaterally symmetric organism.

233 R statistical software (R Core Team, 2020) was used to test whether the muscle area

234 results from the Corel DRAW! tracings and ImageJ measurements were significantly different.

235 The absolute areas of pelvic muscle origins measured by each method (Supplemental Table S1) 
236 were compared using a two-sample t-test for each taxon individually and all taxa collectively. To

237 measure the similarity between results from Corel DRAW! and ImageJ, these matrices

238 (Supplemental Tables S2-3) were subjected to a RV coefficients analysis (Robert \& Escoufier,

239 1976) performed in R using the 'MatrixCorrelation' package (Liland, Næs \& Indahl, 2017;

240 Indahl, Næs \& Liland, 2018). A sensitivity analysis was conducted by performing a one-way

241 ANOVA on measurements of Albertosaurus gathered in ImageJ under a variety of tolerance

242 levels (thresholds; 0 [default], 16, 32, 48, 64) to examine the effect of tolerance level on

243 measured origin areas (Supplemental Table S4). Albertosaurus was chosen because its total area

244 of pelvic origins was greatest in absolute value and included origins of small and large areas, and

245 thus was expected to show the highest variation under different tolerance levels.

246 Functional groups were compared in antagonistic pairs (flexor/extensor,

247 abductor/adductor, medial/lateral rotator) by the proportion of combined origin areas in each

248 functional group (e.g., flexors) to the total area of both antagonistic functions (e.g., flexors +

249 extensors). Muscles were assigned to functional groups based on previous studies of locomotion

250 and their function(s) were averaged. The inferred functions were determined in a "consensus"

251 framework in which the functions of each muscle were compared and amalgamated across these

252 studies. In each of the extant groups, one study or review was used as the primary source as it

253 examined functions in all three spatial dimensions by directly measuring activity or by using

254 detailed musculoskeletal models to measure moment arms. This was given preference over

255 studies that hypothesized or estimated actions based on gross anatomy, which provided

256 complementary data but tended to assess fewer spatial dimensions and comprised subsets of the

257 functions presented in the primary source in nearly all cases. Conflicts were rare, but if they

258 arose, preference was given to studies that directly measured function, then to moment arm 
259 analyses, and then to estimation from gross anatomy. Within this framework, locomotion in 260 squamates primarily followed Russell \& Bauer (2008) alongside other sources (Rewcastle, 1983;

261 Higham \& Jayne, 2004; Dick \& Clemente, 2016). In crocodylians, functions were ascertained

262 from Bates \& Schachner (2011) and supplemented by others (Gatesy, 1997; Allen et al., 2015).

263 Among non-avian theropods, data were available for Allosaurus (Bates, Benson \& Falkingham, 264 2012), Tyrannosaurus (Hutchinson et al., 2005), Velociraptor (Hutchinson et al., 2008), and all 265 of these taxa plus Struthiomimus (Bates \& Schachner, 2011). The functions for Struthio relied 266 mainly on Hutchinson et al. (2015) with consideration of Smith et al. (2006), although conflict 267 was noted for the actions of the Mm. obturatorii lateralis et medialis and discussed in the former 268 of these two texts. One detailed study provided data for Dromaius (Lamas, Main \& Hutchinson, 269 2014), and one main paper was used for Gallus (Paxton et al., 2010) alongside a pair of complementary papers (Gatesy, 1999a,b). For any extinct taxon lacking data, functional roles

271 were assigned based on comparison to bracketing taxa with data. To analyze the distributions of cursorial categories, Jenks Natural Breaks optimization in the XRealStats package for Microsoft Excel was used following Powers, Sullivan \& Currie 274 (2020), although the same analysis can be done in R using the 'classInt' package (Bivand, 2020).

275 The distributions were analyzed across four classes $(\mathrm{k}=4)$ to replicate traditional cursorial 276 categories sensu Carrano (1999), and across five classes $(\mathrm{k}=5)$ to test if increasing the number 277 of categories better reflected the data in question. All tests had 1000 iterations regardless of the 278 number of classes. Jenks Natural Breaks optimization calculates a goodness of variance fit 279 (GVF) value in which a result closer to 1 indicates a better fit. The four- and five-class tests from 280 Jenks Natural Breaks optimization were treated as models and compared using the Akaike 281 information criterion (AIC; Akaike, 1973), which evaluates the relative quality of each model. 
282 Because of the sample size of our data, the small-sample corrected version of this analysis was

283 used ( $\mathrm{AIC}_{\mathrm{C}}$; Hurvich \& Tsai, 1989). The difference between the score of each model and the

284 minimum score of all models $\left(\Delta \mathrm{AIC}_{\mathrm{C}}\right)$ allows interpretation of relative model quality wherein

285 lower scores indicate better fit. Models with $\Delta \mathrm{AIC}_{\mathrm{C}} \leq 2$ have substantial support, whereas

286 models with $\Delta \mathrm{AIC}_{\mathrm{C}}>10$ have practically no support (Burnham \& Anderson, 2002, 2004). The

287 potential effects of allometry on the results were explored by comparing body size to the total

288 area of all hip musculature, the area of major extensors only, and the length of the ilium (as a

289 proxy for pelvis size). Body mass estimates were calculated from stylopod circumferences using

290 equation 1 of Campione \& Evans (2012) for quadrupeds and equation 7 of Campione et al.

291 (2014) for bipeds. Wherever possible, the same specimen used for the reconstruction of pelvic

292 musculature was used to estimate body size. In cases where this was not possible, a specimen of

293 similar size was used. For the pair of crocodylians, stylopod circumferences were not measured,

294 but could be estimated based on the equations provided by Dodson (1975) to calculate minimum

295 diameter. Data were already available for some non-avian theropods including Allosaurus (Bates

296 et al., 2009a), Dromiceiomimus (Campione \& Evans, 2020), Falcarius (Campione \& Evans,

297 2020), Chirostenotes (Funston, 2020), Saurornitholestes (Campione \& Evans, 2020), and a

298 derived troodontid (Benson et al., 2014). Body mass estimates using the bipedal formula were

299 significantly higher than the range of each avian species (Dunning Jr., 2007), so these estimates

300 were replaced with species averages. Because of differences in mean body mass depending on

301 sex, either the male or female mean was selected from published sources (Dunning Jr., 2007;

302 Olson \& Turvey, 2013) based on the primary specimen used in myological reconstruction of

303 each palaeognath — an adult male Struthio (UAMZ 7159) and adult female Dromaius (UAMZ B-

304 FIC2014.260). For the chicken, the body mass of the adult Gallus specimen in Allen et al. (2013) 
305 was used because it closely matched adults of other studies (Paxton et al., 2010, 2014). Body

306 mass estimates are provided with a $\pm 25 \%$ range, which seems to generally correspond to the

307 ranges of the extant avian species in this study. All variables were log-transformed to normalize

308 the distribution of the dependent variable (Currie, 2003) and then subjected to a Phylogenetic

309 Generalized Least Squares (PGLS) regression analysis in R. In all of the bivariate comparisons,

310 the dependent variable was set against estimated body mass to standardize the data to body size

311 (Supplemental Table S5). Supplemental files include the R script associated with all calculations

312 and a nexus file containing the tree for PGLS regressions that matches the topology of Fig. 1. All

313 branches were equally weighted; a time-calibrated phylogeny is beyond the scope of this study

314 and may not be very informative given our small sample size and potential skew caused by the

315 shared geologic age of most extinct taxa examined.

316

317 Results

318 The inferred pelvic myology of the therizinosaur, caenagnathid, and troodontid specimens

319 observed here is largely consistent with that of other theropods (Hutchinson, 2001a; Carrano \&

320 Hutchinson, 2002; Hutchinson et al., 2005, 2008; Bishop et al., 2018a). Generally, origins of

321 musculature track morphological changes in the bones, and the number and arrangement of

322 pelvic muscles remain conservative throughout non-avian Maniraptora. However, a few

323 osteological correlates in each of these clades differ — in some cases, notably_from existing

324 literature and the evolutionary continuum on the line to birds (Hutchinson, 2001a; Hutchinson \&

325 Allen, 2009). Novel maniraptoran osteological and myological data are arranged primarily by

326 increasing levels of inference (Witmer, 1995) from osteology to myology to inferred function,

327 and then secondarily by phylogenetic order from stemward to crownward. 
329 Osteological correlates

330 Falcarius. The therizinosaur Falcarius has ilia characterized as altiliac (Zanno, 2010a),

331 not dolichoiliac as in more basal theropod clades such as tyrannosaurids or ornithomimids (Fig.

332 2A). The cuppedicus (= preacetabular) 'fossa' lacks a bony medial wall (Zanno, 2010a), but the

333 medial side of the preacetabular hook has a concavity delineated dorsally by a low, arcuate ridge

334 confluent with a narrow, medially projecting shelf (Fig. 2C-D). This concavity is covered in

335 striae that radiate anteriorly from the shelf in ventrally-concave arcs toward the anterior margin

336 of the ilium and the tip of the preacetabular hook (Fig. 2C). The brevis fossa is narrow and

337 shallow, which strongly contrasts with the wide and deep brevis fossae of more plesiomorphic

338 theropods (Osborn, 1903; Hutchinson, 2001a; Carpenter et al., 2005). Osteological correlates of

339 the pubis are consistent with other theropods (Hutchinson, 2001a). The preacetabular tubercle is

340 reduced but an oval patch of rugose texture is adjacent and lateral to it (Fig. 2A,E), and the pubic

341 apron has longitudinal striations covering its anterior and posterior sides (Fig. 2G-I). The

342 ischium is reduced relative to non-maniraptoran theropods, but exhibits similarity in gross

343 morphology to other maniraptorans (Zanno, 2010a). This includes reduced proximal and distal

344 ischial tuberosities (Fig. 2A) and proximodistally oriented striations on the lateral surface of the

345 obturator process (Fig. 2F).

346 Caenagnathidae indet. The osteological correlates of the pelvic musculature of

347 caenagnathids are detailed in Rhodes et al. (2020), and the morphological variation exhibited

348 within the family does not strongly affect the general layout and arrangement of pelvic muscle

349 correlates. Whereas most of these correlates are congruent with other theropods (Hutchinson,

350 2001a, 2002; Hutchinson et al., 2005, 2008; Bishop et al., 2018a), the general anatomy and

351 noteworthy correlates are emphasized here. Caenagnathids are dolichoiliac as the

Peer) reviewing PDF | (2020:07:51271:2:0:NEW 27 Dec 2020) 
352 postacetabulum is reduced relative to the preacetabulum (Fig. 3A,D) (Currie \& Russell, 1988;

353 Funston \& Currie, 2020; Rhodes, Funston \& Currie, 2020). Much like Falcarius, the cuppedicus

354 'fossa' lacks a bony medial wall—only bordered dorsally by a narrow ridge that merges into the

355 concave medial side of the preacetabular hook (Fig. 3C,F) - and the brevis fossa is narrow,

356 shallow, and reduced compared to non-maniraptoran theropods (Fig. 3E-F) (Osborn, 1903;

357 Gatesy, 1990; Carpenter et al., 2005; Persons \& Currie, 2011a). As identified in Rhodes et al.

358 (2020), the anterior side of the pubic apron possesses longitudinal striations but the posterior

359 surface lacks muscle scars, whereas longitudinal striations cover the posterior edge of the pubic

360 shaft. The ischium is also comparable to Falcarius because it is reduced relative to non-

361 maniraptoran theropods, as are the proximal and distal ischial tuberosities (Fig. 3D).

362 Sinovenator. Basal troodontid characteristics are expressed in Sinovenator (Xu et al.,

363 2002). The pelvic morphology of this troodontid is readily comparable to other basal members

364 such as $\mathrm{Mei}$ (Xu \& Norell, 2004; Gao et al., 2012; Pei et al., 2020). The ilium is small with an

365 anteroposteriorly short preacetabular blade, in which a small portion of the anterior edge is

366 broken away (Fig. 4A-B) that has been reconstructed conservatively based on other basal

367 troodontids (Russell \& Dong, 1993; Currie \& Dong, 2001). A shallow, circular depression sits on

368 the lateral side of the anteroposteriorly long, dorsoventrally deep pubic peduncle at the base of

369 the preacetabular hook (Fig. 4A-B). The rugose dorsal iliac margin continues into the

370 postacetabular blade, which tapers posteriorly and has striae on its posterolateral corner (Fig.

371 4A-B) (Shen et al., 2017a). The brevis fossa is somewhat reduced into a narrow, shallow

372 concavity (Fig. 4C-D). On the pubic apron, both the anterior and posterior sides are covered in

373 longitudinal striae (Fig. 4G-J). Posteriorly, the pubic apron forms a transversely broad trough or

374 embayment that extends laterally so that the posterior margins of the shafts are mediolaterally 
375 compressed into longitudinal ridges (Fig. 4H-J). The ischium is small, has a distally positioned

376 obturator process, and exhibits conspicuous processes along the posterior margin (Fig. 4J-K)

377 (Russell \& Dong, 1993; Currie \& Dong, 2001; Xu et al., 2002, 2017). The lateral surface of the

378 obturator process also shows scars (Fig. 4K).

379 Derived Troodontidae indet. Derived troodontids resemble Gobivenator (Tsuihiji et al.,

380 2014) in their pelvic anatomy. Striations are preserved along the anterior and dorsal margins of

381 the ilium, extending onto a rugose ridge along the dorsolateral edge of the blade (Fig. 5A,C). The

382 postacetabulum tapers slightly and forms a rounded or squared-off posterior edge (Tsuihiji et al.,

383 2014) (Fig. 5A). A triangular patch of striations covers the posterolateral corner of the ilium (Fig.

384 5A). The brevis fossa is moderately expanded — dorsoventrally and transversely—relative to

385 those of more basal troodontids (Fig. 5B-C), but not to the same extent as non-maniraptoran

386 coelurosaurs (Osborn, 1903; Carpenter et al., 2005; Persons \& Currie, 2011a). A prominent

387 preacetabular tubercle projects anterolaterally from the iliac peduncle of the pubis, its

388 anteroventral margin mediolaterally compressed into a spine-like crest with striae oriented

389 parallel to the margin (Fig. 5A,F). Longitudinal striations cover the anterior and posterior

390 surfaces of the pubic apron, which engulf the posterior edges of the shafts as well (Fig. 5G-M).

391 On the lateral side of the pubis of UALVP 55804, this striated region extends distally to a

392 relatively small tubercle that may be the osteological correlate for a pubogastralial ligament (Fig.

$3935 \mathrm{G}-\mathrm{H}, \mathrm{J}-\mathrm{K})$ (Rhodes \& Currie, 2020). The ischium is triangular (Fig. 5A) (Norell et al., 2009;

394 Zanno et al., 2011). Whereas the obturator process is relatively larger than in more basal

395 troodontids, the proximal and distal ischial tuberosities are reduced to low eminences (Fig.

396 5A,D-E). All of these sites have a slightly rugose textures, and between the ischial tuberosities is

397 another longitudinal region along the dorsolateral edge of the shaft (Fig. 5A,C-E). 
399 Inferred myology

400 Falcarius. The origins of pelvic musculature in Falcarius (Fig. 6A) generally correspond 401 to those of other theropods (Fig. 7D-G) (Hutchinson et al., 2005, 2008; Bishop et al., 2018a). On 402 the ilium, the origin of M. puboischiofemoralis internus 1 on the anterolateral side of the pubic 403 peduncle is clearly separate from that of M. puboischiofemoralis internus 2 (Fig. 6A), which is 404 not the case in plesiomorphic relatives such as ornithomimids or tyrannosaurids (Fig. 7E-F) 405 (Russell, 1972; Carrano \& Hutchinson, 2002; Hutchinson et al., 2005). Radiating striations on 406 the medial side of the preacetabular hook indicate that the origin of the M. puboischiofemoralis 407 internus 2 occupied this entire surface (Fig. 6A). The origin of M. caudofemoralis brevis is 408 reduced relative to the same origin in more basal theropod lineages (Figs. 6A, 7D-F) (Carrano \& 409 Hutchinson, 2002; Hutchinson et al., 2005; Persons \& Currie, 2011a), reflecting similar 410 reduction in the brevis fossa, its osteological correlate (Fig. 2B,D). On the pubis, the origin of M. 411 ambiens is not well defined, but nonetheless present on the oval patch of textured bone surface 412 adjacent to the preacetabular tubercle (Fig. 6A). The origins of Mm. flexores tibiales interni 1 et

4133 on the ischium are present but reduced, in turn with the reduction in the distal and proximal

414 ischial tuberosities as their respective osteological correlates. Other origins of pelvic musculature 415 similarly track morphological changes in the bones, but the layout of these origins are similar to 416 other theropods (Figs. 6A, 7D-G) (Hutchinson et al., 2005, 2008; Bishop et al., 2018a). 417 Caenagnathidae indet. Caenagnathid pelvic musculature (Fig. 6B) shows many 418 similarities to that reconstructed for Falcarius. The origin of M. puboischiofemoralis internus 2

419 likewise occupies the entire medial side of the preacetabular hook, and the origin of M.

420 caudofemoralis brevis is also shrunken compared to the conditions in non-maniraptoran

421 theropods (Figs. 6B, 7D-F) (Hutchinson et al., 2005; Persons \& Currie, 2011a). On the pubis, the 
422 origin of M. ambiens is also adjacent to the preacetabular tubercle, and the striated anterior

423 surface of the pubic apron marks the origin of M. puboischiofemoralis externus 1 (Fig. 6B).

424 However, the longitudinal striae on the posterior edges of the pubic shafts - instead of the pubic

425 apron - demarcate the origin of M. puboischiofemoralis externus 2 (Fig. 6B), which exhibits a

426 unique condition among Archosauria (Rhodes, Funston \& Currie, 2020). Muscle attachment sites

427 on the ischium and elsewhere on the pelvis do not vary considerably from those of Falcarius or 428 other theropods (Fig. 6B, 7D-G) (Hutchinson, 2002).

Sinovenator. The organization of most pelvic musculature in Sinovenator (Fig. 6C)

430 corresponds well with the arrangements in other theropods, including previous troodontid

431 reconstructions (Hutchinson, 2001a, 2002; Hutchinson et al., 2008; Bishop et al., 2018a). The

432 relatively small pelvis, and relatively small body size, limit space available for the origins of

433 many muscles compared to more basal theropods such as Falcarius (Fig. 6A) or caenagnathids

434 (Fig. 6B). On the lateral side, the short preacetabular blade restricts origins of deep dorsal

435 musculature, and the shallow postacetabular blade reduces origins of crural flexors (Fig. 6C).

436 Medially, the cuppedicus and brevis fossae, which are both narrower and shallower, housed

437 similarly reduced origins of M. puboischiofemoralis internus 2 and M. caudofemoralis brevis

438 (Fig. 6C). Conversely, the transverse expansion of the pubic apron (Xu et al., 2017) formed a

439 broad space for the origins of Mm. puboischiofemorales externi 1-2 (Fig. 6C). Scarring indicates

440 that the origin of M. puboischiofemoralis externus 2 filled the embayment on the posterior side

441 of the pubic apron, bordered by the mediolaterally narrow edges of the shafts (Fig. 6C).

442 Musculature that arose from the ischium was generally diminished with reduction in the size of

443 the osteological correlates (Fig. 6C). 
445 the pelvis compared to more basal forms, and spaces for muscle attachment tend to track

446

447

448

449

450

451

452

453

454

456 osteological changes within Troodontidae (Fig. 6D). Expansion of the postacetabulum, anteroposteriorly and dorsoventrally, also enlarges the origins of M. iliofibularis and M. flexor tibialis externus on the lateral side (Fig. 6D). Medially, the brevis fossa - and by extension, the origin of M. caudofemoralis brevis — was likewise expanded both dorsoventrally and mediolaterally (Fig. 6D). On the pubis, the hypertrophied preacetabular tubercle appears to also increase the origin of M. ambiens (Fig. 6D). The origin of M. puboischiofemoralis externus 2 envelops the entire pubic apron and posterior sides of the pubic shafts, which is visible in lateral view (Fig. 6D). The scarred region indicates that this origin extends proximally halfway between the top of the apron and the ischiadic peduncle, filling a shallow longitudinal depression on the medial side of the shaft (Figs. 5C,L-M, 6D), and distally to near the pubic boot (Fig. 6D). This differs considerably from the condition reported in any other archosaur (Hutchinson, 2001a, 2002), even from the condition identified in caenagnathids (Fig. 6B). In contrast, musculature on the ischium matches the layouts in other theropods (Fig. 7D-G) (Hutchinson, 2001a, 2002; Bishop et al., 2018a), although the enlarged obturator process increased the origins of M. adductor femoris 1 and M. puboischiofemoralis externus 3 (Fig. 6D).

\section{Area of attachment}

The area of each muscle attachment was quantified (Table 3) and then calculated as a proportion of the total area of pelvic muscle origins (Table 4). This permits comparison of conventional anatomical groups, individual muscles, and functional groups that form antagonistic pairs (e.g., hip flexors and extensors). Relative proportions were favoured over

Peer) reviewing PDF | (2020:07:51271:2:0:NEW 27 Dec 2020) 
467 absolute area to normalize the area of individual muscles or groups to the total area of pelvic 468 musculature.

469 Conventional anatomical muscle groups exhibit notable variation across the sampled taxa 470 (Fig. 8A). The triceps femoris is a relatively small group, occupying $16 \%$ or less of the total area 471 of pelvic muscle origins in any taxon (Table 4). The area of this group peaks in Allosaurus and 472 steadily decreases crownward throughout theropods to Troodontidae (3.5-6\%), whereas extant 473 relatives remain around the middle of this range (3-9\%). More variation is shown by the deep 474 dorsal group, which is largest in Varanus (47\%), dwarfing the same group in crocodylians (18475 19\%) (Fig. 8A). This area gradually rises back to $47 \%$ in Caenagnathidae, steadily falls to $22 \%$ 476 in derived Troodontidae, and then hovers at 15-23\% in birds (Table 4). The flexor cruris group is 477 modest in all taxa (1-9\%) except for Dromaius, which has an exceptionally large area devoted to 478 this group (15\%). Fluctuation occurs across taxa for the external puboischiofemoral group (Fig. 479 8A). Although large in Varanus (34\%) and predominant in crocodylians (52-60\%), the external 480 puboischiofemoral musculature drops in non-maniraptoran Theropoda (11-16\%), spikes in non481 avian Maniraptora (18-49\%), and drops again in birds (27-34\%). In particular, the Mm.

482 puboischiofemorales externi are proportionally largest in Sinovenator (Table 4). Contrasting this 483 pattern, the femoral adductor musculature hovers between $2-7 \%$ across all taxa (Fig. 8A). The 484 remaining area is occupied by miscellaneous musculature, which is relatively small in squamates 485 and crocodylians (7-13\%), of moderate size in non-avian Maniraptora (25-42\%), and rather 486 substantial in non-maniraptoran Theropoda (48-52\%) and in birds (36-54\%).

487 Individual muscles also vary across sampled taxa, although some patterns emerge (Fig.

488 8B). Over half of the area of attachment of the triceps femoris group is comprised of the M.

489 iliotibialis (and its homologues) in nearly every taxon except for Struthio, which instead is 
490 dominated by the origin of M. ambiens 2 (Fig. 8B). This is juxtaposed with other birds; the

491 origin of M. ambiens occupies a small fraction of triceps femoris group and less than $0.2 \%$ of

492 total pelvic muscle origin area in either Dromaius or Gallus (Table 4; Fig. 8B). Comprising the

493 deep dorsal group, derivatives of the M. iliofemoralis and Mm. puboischiofemorales interni are

494 generally similar among most taxa. However, it consists primarily of the Mm.

495 puboischiofemorales interni in Varanus, a pattern reversed in Gallus by the overwhelmingly

496 large origin of M. iliotrochantericus caudalis (Fig. 8B), an important hip flexor in extant birds

497 (Hutchinson \& Gatesy, 2000). The flexor cruris group is occupied mostly by the M. flexor

498 tibialis externus in non-avian theropods, by the M. flexor cruris medialis in palaeognaths, and by

499 both of these muscles roughly equally in Gallus (Fig. 8B). The external puboischiofemoral and

500 femoral adductor groups remain similar across all taxa. However, the M. obturatorius medialis

501 became the dominant muscle in birds after a protracted but steady increase in proportional area

502 spanning Archosauria (Fig. 8B). Among miscellaneous muscles, the M. ischiotrochantericus has

503 the largest relative origin in extant saurians and Gallus (Table 4). This starkly contrasts with non-

504 avian theropods and palaeognaths, in which the area of the M. ischiotrochantericus is eclipsed by

505 the M. caudofemoralis brevis and M. iliofibularis, each accounting for nearly half of all

506 miscellaneous musculature (Fig. 8B). Interestingly, the bulk of taxa examined (crocodylians,

507 non-avian theropods, and palaeognaths) have greater numbers of muscles with osteological

508 correlates on the pelvis than Varanus and Gallus at either end (Fig. 8B). In Varanus, this is due

509 to many muscles remaining undivided in squamates relative to other taxa (Table 2). In Gallus,

510 this is because some muscles have merged or were lost entirely (Table 2). Additionally, many

511 groups in Gallus appear simplified because a single muscle dominates each of them: the M. 
512 iliotibialis lateralis in the triceps femoris, the M. iliotrochantericus caudalis among the deep

513 dorsals, and the M. obturatorius medialis for the obturator muscles (Fig. 8B).

514 Categorizing pelvic muscles according to functional groups revealed a largely

515 conservative pattern among non-avian theropods (Table 5). Even more broadly, this identified

516 muscles involved in the same function across all taxa studied, such as the major extensors

517 comprising parts of the triceps femoris (squamate M. iliotibialis, crocodylian Mm. iliotibiales 2-

518 3, and avian M. iliotibialis lateralis), M. iliofibularis, crural flexors, and M. caudofemoralis

519 brevis. Yet, there is considerable variation across taxa when functions are compared in

520 antagonistic pairs (Fig. 9A). The sum of origin areas for muscles that flex (protract) the leg

521 around the hip joint exceed that for muscles that extend (retract) the leg in squamates and

522 crocodylians. Non-maniraptoran theropods, alongside Saurornitholestes and derived troodontids,

523 maintain a nearly 50:50 split between hip flexors and extensors, whereas Falcarius, the

524 caenagnathid, Sinovenator, and Gallus have relatively more area devoted to hip flexion (Fig.

525 9A). The palaeognaths included here, Struthio and Dromaius, both have more pelvic area for

526 extensors than any other taxon (Fig. 9A), mirroring findings of previous studies noting the

527 adaptations for running in the musculature of these birds (Patak \& Baldwin, 1998; Smith et al.,

528 2006, 2007; Lamas, Main \& Hutchinson, 2014; Hutchinson et al., 2015). Origin areas for

529 musculature that adduct the hind limbs greatly outsize those that perform abduction about the

530 hips in squamates and crocodylians (Fig. 9A). Most theropods seem to favour abduction instead,

531 with the troodontids and Gallus as the only exceptions. This trend is mostly consistent with

532 previous findings (Hutchinson \& Gatesy, 2000), albeit measured using origin areas rather than

533 other methods. Concerning long axis rotation, the pelves of Varanus and all three birds exhibit

534 more area for lateral than medial rotators (Fig. 9A). Crocodylians and non-maniraptoran 
535 theropods hover around an even proportion of each, whereas non-avian maniraptorans appear to

536 favour medial rotators. Lastly, muscles involved in knee flexion and extension are about equal in

537 Varanus (Fig. 9A). Crocodylians have knee extensors with origins that cover much more area

538 than flexors, which is the opposite case in all theropods.

539 Pruning these charts to remove novel muscle reconstructions, using only Alligator and

540 Struthio as traditional extant representatives, show clearer patterns of locomotor evolution that

541 more closely resemble the stepwise changes in function affirmed in previous studies (Gatesy,

542 1990, 1995; Gatesy \& Dial, 1996; Hutchinson \& Gatesy, 2000; Hutchinson, 2002; Hutchinson \&

543 Allen, 2009). Hip flexors and extensors are weighted more heavily toward flexion in Alligator

544 but are nearly equal across non-avian theropods and Struthio (Fig. 9B). Hip abduction and

545 adduction appears less straightforward, although still shows that a large area of pelvic muscle

546 origins involved in abduction appeared early in theropod evolution (Hutchinson \& Gatesy,

547 2000). Long axis rotation is not dramatically different between Alligator and non-maniraptoran

548 theropods. However, the increase in area for medial rotators in Saurornitholestes suggests a

549 pattern of increased lateral rotation on the line to birds (Fig. 9A). Around the knee, the majority

550 of musculature is dedicated to extension in Alligator. This changes to flexion in Allosaurus and

551 continues in a stepwise fashion to derived troodontids and birds, with Saurornitholestes as a

552 single exception (Fig. 9B). Whereas the proportional area of muscle groups varies considerably

553 across taxa (Fig. 9, Table 4), functional groups tend to remain conservative (Fig. 10, Table 5).

554 The inclusion of more data with novel reconstructions of maniraptoran pelvic musculature shows

555 a more complicated pattern in the evolution of functional groups.

556 The origin areas derived from Corel DRAW! and ImageJ yielded similar results. None of

557 the statistical tests showed evidence of significant differences in estimated muscle origin areas, 
$558 \mathrm{t}(506)=0.1723, \mathrm{p}=0.8633$ (Table 6). Comparison of the matrices produced by these two

559 programs in a RV coefficients analysis $(\mathrm{RV}=0.9989)$ further demonstrated the similarity of the

560 measured origin areas (Table 6). Lastly, sensitivity analysis yielded virtually no differences

561 among results measured using ImageJ under five tolerance levels (Fig. 11). This was true

562 regardless of whether the analysis included only Image J results, $F(4,90)=1.006 \times 10^{-3}, \mathrm{p}=$

5630.9999 , or included Corel DRAW! results as well, $F(5,108)=3.661 \times 10^{-3}, p=0.9999$. Thus,

564 method did not significantly affect the results of this study.

565 Body mass estimates for each taxon were compared to the area of attachment of all pelvic

566 musculature, to the area of attachment of major extensors, and to ilium length (Table 7). These

567 values were log-transformed and then subjected to Phylogenetic Generalized Least Squares

568 (PGLS) regressions (Table 8). Regressions of all taxa demonstrated that phylogenetically

569 corrected body size explained much but not all of the variation in the area of attachment for all

570 hip muscles $\left(\mathrm{R}^{2}\right.$ adj $\left.=0.9095\right)$ or major extensors $\left(\mathrm{R}^{2}{ }_{\mathrm{adj}}=0.8495\right)$, or the variation in ilium length

$571\left(\mathrm{R}^{2}{ }_{\text {adj }}=0.8677\right)$. However, regressions of each major group (non-theropod Sauria, non-

572 maniraptoran Theropoda, non-avian Maniraptora, and Aves) or only extinct taxa (non-avian

573 Theropoda) tended to perform better (Table 8). The non-theropod saurians had notably different

574 slopes and intercepts compared to all other taxa, which is presumably related to the differences in

575 posture between these two groups. This is because the regression lines for non-theropod saurians

576 also represent the quadrupedal taxa examined. These data only include the pelvis, ignoring the

577 shoulder and thus half of the quadrupedal locomotory apparatus, which is probably why the

578 results appear as outliers to the bipedal taxa. Regressions that only included the bipeds, or only

579 non-avian theropods, tended to be better predictors than ones that included all taxa (Table 8). 
581 to an increase in body mass. However, all of the bivariate comparisons plot body mass (a three-

582 dimensional property) against area (two-dimensional) or length (one-dimensional), which means

583 scaling principles must be considered when comparing these values (Biewener, 1989;

584 Hutchinson \& Garcia, 2002; Allen et al., 2010, 2015). According to these principles, as body

585 mass increases, area scales as (body mass) $)^{2 / 3}$ and length scales as (body mass) $)^{1 / 3}$. Because the

586 regression lines can be expressed as the power equation $y=b x^{k}(C u r r i e, 2003)$, the slope $(k)$ can

587 be directly compared to its respective scaling factor $\left(\mathrm{k}_{\text {area }}=2 / 3[\approx 0.67] ; \mathrm{k}_{\text {length }}=1 / 3[\approx 0.33]\right)$.

588 Therefore, a slope near or equal to one $(\mathrm{k}=1)$ indicates isometric growth, whereas a slope

589 significantly greater than one $(\mathrm{k}>1)$ signifies positive allometry and a slope significantly less

590 than one $(\mathrm{k}<1)$ denotes negative allometry. For non-theropod Sauria, the regression lines for

591 area of attachment — both total hip muscles and just major extensors — have slopes about double

592 what is expected based on the scaling factor of 0.67 (Table 8). In contrast, the slope for ilium

593 length is close to 0.33 . Non-maniraptoran theropods have slopes much lower than expected

594 across all three comparisons (Table 8). This is likely due to the small sample size that contributes

595 to lower $\mathrm{R}^{2}$ adj values, and the data point for Ornithomimidae indet. with relatively large areas of

596 hip and extensor musculature for its estimated body mass, which skews the left side of this

597 regression line. In non-avian maniraptorans, avians, non-avian theropods, and collectively among

598 bipeds, the slopes for all three comparisons are reasonably close to their scaling factors, although

599 the area of attachment of major extensors is somewhat higher than expected (Table 8).

$600 \quad$ Phylogenetically corrected residual outputs for non-avian theropods and for bipedal taxa

601 were calculated as a percentage of the fitted (predicted) value to examine how they plot relative

602 to each regression line with respect to body size (Table 9). Essentially, this allows clearer 
603 visualization of how far above or below the predicted value each taxon plots for the area of all

604 hip muscles, the area of major extensors, or the size of the hip (Fig. 12). For non-avian

605 Theropoda, these charts show that Ornithomimidae indet. has significantly $(>5 \%)$ higher than

606 predicted values for all three categories at its estimated body mass (Fig. 12). In contrast,

607 Saurornitholestes plots significantly lower than the predicted value in all three aspects, and

608 Sinovenator also scores significantly smaller than average for ilium length (Table 9). No other

609 taxa significantly deviate from the non-avian theropod PGLS regression line. For all bipeds, the

610 results are strikingly different (Fig. 12). Several taxa have residuals greater than $\pm 5 \%$ the bipedal

611 regression line and most of the non-avian theropods have residuals that are greater in magnitude

612 and opposite in direction from those in the non-avian theropod regression (Table 9).

613

614 Discussion

615 Inspection of the pelves of maniraptoran theropods that were previously understudied or

616 unstudied for pelvic myology (Fig. 1) allowed identification of osteological correlates for pelvic

617 soft tissues (Figs. 2-5). Besides documenting some morphological conditions that appear to be

618 unique among Archosauria, these osteological correlates also provided the necessary data for

619 novel reconstructions of pelvic musculature (Fig. 6) for comparison to other theropods and extant

620 relatives (Fig. 7). In turn, the area of each origin was quantified, which permits comparison

621 among taxa for the relative sizes of the areas of attachment of anatomical groups (Fig. 8) and

622 functional groups (Figs. 9-10). This revealed a more complex pattern of evolution than

623 previously appreciated, especially in the broader context of other non-avian theropods and their

624 extant relatives. Whereas non-maniraptoran theropods share similar proportions of pelvic muscle 
625 origin areas in both anatomical and functional aspects (Figs. 8-10), non-avian maniraptorans

626 deviate strongly from these proportions and from one another (Allen et al., 2013).

627 Statistical analysis yielded no significant difference between the sizes of origin areas

628 acquired by Corel DRAW! or ImageJ. This validates the use of either program for measuring the 629 area of osteological correlates and eliminates method choice as a potential source of bias.

630 However, quantifying the area of attachment is only one way to measure muscles. Certain

631 measurements (e.g., physiological cross-sectional area, mass, tendon length), or combinations

632 thereof, may be better predictors of muscle strength or force (Bamman et al., 2000; Jones et al.,

633 2008), although these measurements are generally not feasible in fossilized specimens. There is

634 also debate about the reliability of muscle reconstruction in extinct animals, including the ability

635 to glean relative size or strength from attachment area alone (McGowan, 1979). The current

636 study is not exempt from these issues; for example, the flexor cruris group occupies merely $2-$

$6373 \%$ of pelvic origin areas across extant squamates and crocodylians (Fig. 8A) despite accounting

638 for up to $19 \%$ of hind limb musculature volume in lizards (Russell \& Bauer, 2008). In light of

639 these concerns, it should be clarified that our goal is not to attempt estimation of strength, mass,

640 or any other absolute measurement of muscular capacity. Exploration of potential relationships

641 between the area of attachment of a muscle and other muscular properties exceeds the scope of

642 this study and is deserving of its own investigation. Instead, the proportional areas of muscle

643 origins are simply placed in a comparative framework to examine relative changes and explore

644 how well they align with other methods, such as the proportional lengths of limb bones.

645 Normalizing data to body mass provided an opportunity to explore the effect of body size

646 on the area of attachment and pelvis size. The sampled taxa span three orders of magnitude of

647 body mass and the results follow known scaling principles (Biewener, 1989), which makes this 
648 evaluation applicable to a wide range of body sizes. Nevertheless, these results should be

649 interpreted with caution as they are based on a small sample size and do not consider other

650 attributes that affect locomotion, such as posture or gait (Sellers et al., 2017; Bishop et al.,

651 2018a). Examining these effects is beyond the scope of this study and consequently limits

652 explanatory power. Despite these shortcomings, the area of all pelvic muscle origins and the

653 length of the ilium in non-avian theropods closely follow scaling principles (Table 8) (Biewener,

654 1989; Hutchinson \& Garcia, 2002). Although the regressions for all bipeds tend to follow similar

655 patterns, the phylogenetically corrected residuals casts doubt on how well it represents the data.

656 Many residual values exhibit a higher magnitude and opposite direction, and a greater number of

657 values are outside the $\pm 5 \%$ range, compared to the residuals of the non-avian theropod regression

658 (Table 9). This contrast may stem from the radically different anatomical and locomotory

659 adaptations between non-avian theropods and extant birds, such as postural differences that

660 affect the entire terrestrial locomotory system (Hutchinson \& Gatesy, 2000; Bishop et al.,

661 2018b). Because of these reasons, we henceforth focus on the non-avian theropod PGLS

662 regression results. The regression line for the area of attachment for major extensors is less

663 straightforward, but seems to indicate that major extensors scale with body size at a different rate

664 than the total area of all pelvic musculature. The slope for major extensors in bipeds $(\mathrm{k}=0.7878)$

665 suggests that these muscles increase at a faster rate than all muscles $(\mathrm{k} \approx 0.67)$, which is closer to

666 isometric growth but still negatively allometric. This is consistent with previous studies that

667 suggest large theropods, despite some having multiple adaptations for fast or efficient running,

668 had relatively poorer running abilities due to large body size (Hutchinson \& Garcia, 2002;

669 Dececchi et al., 2020). Large body mass generally requires larger muscles to overcome inertia,

670 but our analysis cannot identify how this affects running ability. Therefore, even though the large 
671 theropods Allosaurus and Albertosaurus each have areas of hip muscles and of major extensors

672 within $5 \%$ of the value predicted from the non-avian theropod regression (Fig. 12) (Table 9),

673 negative allometry may have inhibited attaining the musculature required for rapid locomotion at

674 large body sizes in these taxa (Hutchinson \& Garcia, 2002). Despite this caveat, relative

675 comparisons among the taxa studied can still be investigated.

676 Examining the distribution of the non-avian theropod residuals (Table 9) essentially

677 shows whether each taxon exhibits areas of muscle origins or hip size that are larger or smaller

678 than predicted for its estimated body mass (Fig. 12). The only taxa with residuals significantly

679 above or below average are Ornithomimidae indet., Saurornitholestes, and Sinovenator (Table

680 9). Perhaps unsurprisingly, the "ostrich-mimic" has higher-than-predicted values in all three

681 categories (Fig. 12), consistent with the other adaptations for running seen in ornithomimids

682 (Russell, 1972; Paul, 1998; Carrano, 1999). The residuals in all categories for Saurornitholestes

683 are notably smaller, which is also consistent with its known reduction in cursorial adaptations

684 (Carrano, 1999; Persons \& Currie, 2012, 2016). Sinovenator was significantly smaller in ilium

685 length (Table 9) but the derived troodontid was nearly on the regression line, which reinforces

686 the secondary expansion of the hip in Troodontidae; scaling these measurements to body mass

687 indicates that they are likely not simply an artefact of allometry. The remaining non-avian

688 theropods have residuals within the $\pm 5 \%$ range, indicating that these metrics are within

689 expectations for each taxon based on its body mass after phylogenetic correction (Fig. 12).

690

691 Maniraptoran pelvic myology indicates complex evolutionary patterns

692 Compared to hips of earlier-branching theropods like tyrannosaurids and ornithomimids

693 (Fig. 7) (Russell, 1972; Paul, 1998; Carrano, 2000; Hutchinson, 2001a; Carrano \& Hutchinson,

694 2002; Hutchinson et al., 2005; Macdonald \& Currie, 2019), Falcarius is much smaller in the 
695 postacetabulum and brevis fossa (Fig. 2A-B). These smaller areas available for muscles (Fig.

696 6A) are mirrored by smaller hip extensors with origins in these regions (Fig. 9A). Among these

697 extensors is the M. caudofemoralis brevis, which has implications for the evolution of locomotor

698 modules in theropods (Gatesy \& Dial, 1996). The caudofemoral muscles comprise an important

699 hind limb extensor complex in earlier theropod groups (Gatesy, 1990; Hutchinson \& Gatesy,

700 2000; Persons \& Currie, 2011a, 2017), which can be seen in the relatively large proportion of

701 pelvic musculature taken up by the origin of M. caudofemoralis brevis as a proxy for this

702 complex in Allosaurus and Albertosaurus (Fig. 8). Even ornithomimids retain a comparable

703 origin of M. caudofemoralis brevis (Fig. 8) despite being the earliest group to show decreases in

704 the number of caudal vertebrae and in tail length and, by extension, the caudal locomotor module

705 (Gatesy, 1990; Gatesy \& Dial, 1996). Falcarius, with an estimated 30-35 caudal vertebrae

706 (Zanno, 2010a), has a similar vertebral count and presumably similar tail length to an

707 ornithomimid, but shows a sharp reduction in the origin of M. caudofemoralis brevis (Fig. 8).

708 Rather than a stepwise change, this transition appears rather abrupt, at least for the M.

709 caudofemoralis brevis. It suggests less integration between the caudal and pelvic locomotor

710 modules than in earlier theropod lineages, although not fully decoupled from one another

711 (Gatesy \& Dial, 1996).

712 Caenagnathids resemble Falcarius in having grossly similar osteological and myological

713 features (Figs. 3, 6B, 8) (Zanno, 2010a). The reduced postacetabulum and brevis fossa have the

714 same implications for locomotor modules, which reinforces a strong reduction in the tail and its

715 associated musculature within Maniraptora, perhaps even among its earliest members (Fig. 8)

716 (Allen et al., 2013). Additionally, caenagnathids exhibit a unique osteological correlate for the

717 M. puboischiofemoralis externus 2 on the posterior sides of the pubes, displaced laterally from 
718 the condition in other non-avian theropods (including other oviraptorosaurs) with no evidence of

719 muscle attachment on the pubic apron (Fig. 6B) (Rhodes, Funston \& Currie, 2020).

720 Sinovenator has a small pelvis relative to its body size (Fig. 12) and a transversely broad

721 pubic apron, both of which are representative of other early troodontids (Russell \& Dong, 1993;

722 Currie \& Dong, 2001; Xu et al., 2002, 2017; Shen et al., 2017a). This restricts the area of

723 attachment for most pelvic musculature while increasing the relative area of the $\mathrm{Mm}$.

724 puboischiofemorales externi 1-2 on the pubic apron (Table 4). Surprisingly, this appears as a

725 dramatic change when comparing all pelvic musculature (Fig. 8A) but is almost

726 indistinguishable from bracketing taxa when individual muscles are compared within anatomical

727 groups (Fig. 8B). Derived troodontids underwent a reversal in morphology that is echoed in the

728 myology (Figs. 5-6). Expansion of the postacetabulum, brevis fossa, and ischium (including the

729 obturator process) allowed for respectively enlarged origins of the M. iliofibularis and M. flexor

730 tibialis externus, M. caudofemoralis brevis, and Mm. adductores femorum 1-2 and M.

731 puboischiofemoralis externus 3 (Fig. 6). Many of these muscles are involved in hind limb

732 extension (Fig. 9A), a secondary increase that would have gone unnoticed if Sinovenator had

733 been excluded (Fig. 9B).

734 In derived troodontids, the laterally expanded origin of M. puboischiofemoralis externus

7352 is absolutely larger (Table 3 ) despite becoming proportionately smaller (Table 4). This is likely

736 due, in part, to the relative increase in hip extensors (Figs. 6D, 9). Lateral expansion or migration

737 of the origin of M. puboischiofemoralis externus 2 in troodontids is shared with caenagnathids

738 and birds. However, all three cases appear to arise via convergence, having developed after each

739 clade diverged from other theropods. This origin in caenagnathids does not seem to be shared

740 with other oviraptorosaurs and thus arose independently (Hutchinson, 2001a; Rhodes, Funston \& 
741 Currie, 2020), migrating laterally and leaving no evidence of attachment on the pubic apron

742 (Figs. 3, 6B). The origin of M. puboischiofemoralis externus 2 in troodontids began expanding

743 but remained on the pubic apron in Sinovenator, widening further in derived troodontids (Figs. 4,

744 6C-D). The evolutionary pathway in early birds remains somewhat unclear, although it

745 eventually moved entirely off the bony pelvis and onto the puboischiadic membrane in birds as

746 the M. obturatorius medialis (Hutchinson, 2001a, 2002). Evidently, on three separate occasions,

747 this muscle independently underwent lateral movement in theropods, which may be related to

748 postural or functional changes (Hutchinson \& Gatesy, 2000; Bishop et al., 2018b).

749 Beyond non-avian Maniraptora, modern birds exhibit notable variability in the number of

750 pelvic muscles and their areas of attachment (Tables 3-4; Figs. 8-9). Similarly, there is

751 substantial diversity in the pelvic morphology and myology of extant avians (Fig. 7EE-JJ). The

752 contrast between this observed complexity and previously established hypotheses of prolonged,

753 stepwise change over evolutionary time (Hutchinson, 2002; Hutchinson \& Allen, 2009; Bishop

754 et al., 2018a) may suggest that the latter perspective is an oversimplification to some extent.

755 Others have noted elevated rates of morphological evolution in birds and their stem lineage

756 (Allen et al., 2009; Dececchi \& Larsson, 2013; Brusatte et al., 2014), likely accounting for part

757 of this complexity. Interestingly, Brusatte et al. (2014) found that significantly high rates of

758 morphological change appeared near the origin of Maniraptora and were sustained into early

759 birds. This is generally consistent with our results, which juxtapose gross morphological and

760 myological similarity among the pelves of non-maniraptoran theropods with greater complexity

761 in maniraptorans, including avians (Figs. 6-9). Although the overall pattern of incremental

762 changes seems to hold true, our results emphasize that the rate of change was not as

763 straightforward. 
765 Inferring running ability from musculature

766

767

768

769

770

771

772

773

774

775

776

777

778

779

780

781

782

783

784

785

786

787

Although there is a complex relationship between the area of attachment and the cross-

sectional area, strength, or moment arm of a muscle (McGowan, 1979; Bamman et al., 2000;

Jones et al., 2008), hind limb extensors are fundamental to cursoriality. Broadly defined,

cursoriality is a spectrum of locomotor ability, recognizable by a suite of complementary

morphological features (Carrano, 1999). More cursorial animals are better adapted for fast or

efficient locomotion, although specific cursorial styles (e.g., sprinting vs. endurance running)

cannot usually be elucidated without other means of observation (Carrano, 1999). Cursorial

theropods typically have reduced arms, slender limbs, long distal leg elements relative to the

femur, hinge-like joints, tightly appressed or fused metatarsi, symmetrical feet, lateral pedal digit

reduction or loss, and elongate middle toes (Lull, 1904; Coombs, 1978; de Bakker et al., 2013;

Lovegrove \& Mowoe, 2014; Persons \& Currie, 2016; Dececchi et al., 2020). Additionally, cursorial animals tend to have proximally positioned insertions of locomotory muscles, specifically those involved in hind limb extension (Gatesy, 1990; Gatesy \& Dial, 1996; Carrano, 1999; Hutchinson \& Gatesy, 2000; Hutchinson, 2006; Hutchinson \& Allen, 2009). Although insertion points were not considered in this analysis, the areas of origin of hind limb extensors still offer information. These include muscles that inserted on the femur to directly retract the leg, or knee flexors that inserted on the shin to secondarily cause the same motion. The only muscles that function in hip extension across all taxa are the triceps femoris extensors (squamate

M. iliotibialis, crocodylian Mm. iliotibiales 2-3, and avian M. iliotibialis lateralis), M. iliofibularis, flexor cruris group, and short head of the caudofemoral complex (Table 5).

Presenting traditional cursorial categories sensu Carrano (1999) in parallel with the origin areas of hip extensors show that these two aspects are remarkably well correlated (Fig. 13). 

iliofibularis reflects relative cursorial categories, the M. caudofemoralis brevis suggests that caenagnathids are less cursorial than dromaeosaurids (Fig. 13), which conflicts with the general results of other studies noting decreased running ability in the latter (Carrano, 1999; Fowler et styles, such as sprinting vs. endurance running (Dececchi et al, 2020), but this cannot currently

794 be differentiated by the analysis here. On the other hand, the combination of the M. iliofibularis and M. caudofemoralis brevis better reflects cursoriality across taxa, showing a similar pattern to the inclusion of all hip extensors (Fig. 13). Jenks Natural Breaks optimization performed on the proportion of major extensors recovers five classes with a high goodness of variance fit $(\mathrm{k}=5$, $\mathrm{GVF}=0.9843)($ Fig. 13). The same analysis conducted with four classes to reflect traditional cursorial categories (Carrano, 1999) reveals a slightly lower fit $(\mathrm{k}=4, \mathrm{GVF}=0.9752)$, although

800 relatively small sample size is probably why both values are high. Comparison of these two

801 classifications as models using the small-sample corrected AIC (Hurvich \& Tsai, 1989)

802 recovered the five-class analysis $\left(\mathrm{AIC}_{\mathrm{C}}=-53.95\right)$ as having a better fit than the four-class test

$803\left(\mathrm{AIC}_{\mathrm{C}}=-51.89\right)$. Although the five-class model only scored marginally better $\left(\Delta \mathrm{AIC}_{\mathrm{C}}=2.06\right)$, it

804 is preferred over the four-class model for our data based on these scores (Burnham \& Anderson, 805 2002, 2004). The only difference is that the five-class analysis (Fig. 13) separates derived

806 Troodontidae indet. from Caenagnathidae indet. and Saurornitholestes, whereas the four-class

807 analysis recovers all three of these taxa in the same category (second-highest class overall).

808 Squamates and crocodylians are unsurprisingly recovered as the poorest cursors of all taxa,

809 whereas non-maniraptoran theropods all score highly based on pelvic muscle origin areas (Fig.

810 13). Although expected for tyrannosaurids and ornithomimids (Russell, 1972; Paul, 1998; 
811 Carrano, 1999; Persons \& Currie, 2016), it was unanticipated for allosaurids (Bates, Benson \&

812 Falkingham, 2012). Non-avian maniraptorans vary, though Falcarius and Sinovenator

813 consistently show lower cursoriality than the caenagnathid, Saurornitholestes, and the derived

814 troodontid (Fig. 13). The caenagnathid only slightly exceeds Saurornitholestes, which

815 quantitatively supports the hypothesis that caenagnathids are less cursorial than previously

816 thought (Rhodes, Funston \& Currie, 2020). This result may have previously been masked by

817 categorizing the degree of cursoriality into distinct bins, an issue noted by Carrano (1999) that is

818 applicable to any spectrum. The cursoriality of Saurornitholestes and derived troodontids match

819 predictions, and inclusion of Sinovenator suggests that high cursoriality was gained secondarily

820 in Troodontidae (Fig. 13). Among birds, the contrast between the ostrich and the emu as known

821 high-speed runners that exhibit several cursorial adaptations, and the chicken as a relatively

822 poorer runner, corresponds well with their relative major extensor muscle proportions (Fig. 13)

823 (Patak \& Baldwin, 1998; Smith et al., 2006, 2007; Abourachid \& Renous, 2008; Lamas, Main \& 824 Hutchinson, 2014; Hutchinson et al., 2015).

825 Overall, the results of this study show that the proportion of certain extensor origins is a 826 quantifiable metric that can be used to reasonably infer cursoriality. That being said, cursoriality

827 is multifaceted, reliant on multiple complementary morphological features as supporting lines of 828 evidence (Coombs, 1978; Carrano, 1999; Dececchi et al., 2020). This point is underscored by 829 comparing pelvic musculature with other morphological features associated with cursoriality, 830 which can be averaged for a more comprehensive view on cursorial ability (Fig. 14). Squamates 831 and crocodylians consistently score as the least cursorial taxa in all metrics (Fig. 14B). Within

832 non-maniraptoran Theropoda, Allosaurus superficially appears highly cursorial because $48 \%$ of 833 all pelvic muscle origins are occupied by major hip extensors (Table 4; Fig. 13). However, its 
834 intermediate proportions of distal limb elements (Carrano, 1999), non-arctometatarsalian foot

835 (Holtz, 1994), and three weight-bearing digits with a mostly symmetrical foot (Gilmore, 1920)

836 all indicate more moderate cursoriality (Fig. 14B-C), which better corresponds to previous

837 results on allosaurid locomotion (Bates, Benson \& Falkingham, 2012). Moreover, this may show

838 that theropods attained the musculature necessary for high cursoriality before the acquisition of

839 osteological adaptations like long distal limb proportions, modified metatarsi, or other features

840 (Fig. 14B). However, assessing more basal theropods would help to test this hypothesis. In

841 contrast, both tyrannosaurids and ornithomimids - having large hip extensors, long distal limb

842 bones, and arctometatarsalian feet that are also more symmetrical (Russell, 1972; Holtz, 1994;

843 Paul, 1998; Carrano, 1999; Snively \& Russell, 2001, 2003; Henderson \& Snively, 2004; Persons

844 \& Currie, 2016) - score highly in nearly all aspects (Fig. 14B-C). Although adult tyrannosaurids

845 may have been less adept at running (Hutchinson \& Garcia, 2002; Hutchinson, 2004b;

846 Hutchinson et al., 2005; Sellers et al., 2017), these conditions present in a juvenile are predictive

847 of rapid locomotion (Paul, 1998; Persons \& Currie, 2011a; Dececchi et al., 2020). Non-avian

848 maniraptorans are variable, marked by a substantial reduction in cursorial features already

849 present in Falcarius (Fig. 14B-C) (Zanno, 2010a). Reconstruction of pelvic musculature

850 suggests that caenagnathids are less cursorial than previously predicted (Rhodes, Funston \&

851 Currie, 2020), although they still rank as relatively high in light of other features (Fig. 14B-C).

852 Saurornitholestes and Sinovenator share similar degrees of cursoriality (Fig. 14C). Compared to

853 Sinovenator, derived troodontids show expansion of major hip extensors (Table 4; Fig. 13),

854 elongated distal limb segments (Carrano, 1999), and development of a subarctometatarsus into a

855 full arctometatarsus (Holtz, 1994; White, 2009) that corroborate them as adept runners (Fig.

856 14B-C). Furthermore, it supports previous observations of divergent evolutionary pathways 
857 between eudromaeosaurians and troodontids, and emphasizes that derived troodontids are

858 intermediate in cursoriality between eudromaeosaurians (and all other maniraptorans, in fact) and

859 highly cursorial theropods including tyrannosaurids, ornithomimids, and palaeognaths (Fig. 14C)

860 (Fowler et al., 2011). The area of major hip extensors in each bird is a fair indicator of overall

861 cursoriality based on the taxa included here, separating the palaeognaths from the chicken (Figs.

862 13-14).

863 Jenks Natural Breaks optimization distinguishes five classes $(\mathrm{k}=5, \mathrm{GVF}=0.9957)$ that

864 better reflect cursorial categories based on consideration of multiple adaptations (Fig. 14C). All

865 of the quadrupeds (Varanus, Alligator, and Caiman) comprise the lowest category. The class

866 above includes Falcarius, Saurornitholestes, and Sinovenator, which are inferred as the least

867 cursorial bipeds in this study. Allosaurus and Gallus are recovered in the middle category,

868 whereas the caenagnathid and derived troodontid share the second-highest tier. The highest class,

869 representing the taxa best adapted for cursoriality based on this analysis, includes the

870 tyrannosaurid, ornithomimid, ostrich, and emu (Fig. 14C). However, categorizing the degree of

871 cursoriality into four classes also had strong support $(\mathrm{k}=4, \mathrm{GVF}=0.9885)$. In fact, although the

872 five-class model attains a better fit $\left(\mathrm{AIC}_{\mathrm{C}}=-2.31\right)$ than the four-class analysis $\left(\mathrm{AIC}_{\mathrm{C}}=-1.54\right)$,

873 both have substantial support $\left(\Delta \mathrm{AIC}_{\mathrm{C}}=0.76\right)$. The only difference between these two options is

874 that the middle and second-highest tier (classes 3 and 4) of the five-class model, containing

875 Allosaurus, Gallus, Caenagnathidae indet., and derived Troodontidae indet., collapse into a

876 single bin ranked second-highest (class 3) in the four-class model. Although Jenks Natural

877 Breaks optimization and $\mathrm{AIC}_{\mathrm{C}}$ may not appear to clearly distinguish cursoriality, these methods

878 merit further consideration on a larger, more comprehensive dataset. 
880 2020). Within non-avian Theropoda, the allosaurid, ornithomimid, and tyrannosaurid

881 representatives retain conservative pelvic morphology and myology (Fig. 14A), but their

882 cursoriality differs when accounting for other adaptations (Fig. 14B-C). Additionally, the

883 reconstruction of ornithomimid pelvic musculature (Fig. 7) offers an updated view of the one

884 provided by Russell (1972), which has not been explicitly shown before despite inclusion of this

885 taxon in volumetric reconstructions (Bates et al., 2009b) and musculoskeletal modelling (Bates

$886 \&$ Schachner, 2011). Maniraptorans tend to exhibit wide variation in both osteology and

887 myology (Fig. 14A). The sharp reduction of caudal musculature in early maniraptorans appears

888 to be a shared state; not only is the origin of M. caudofemoralis brevis reduced in Falcarius and

889 the caenagnathid (Figs. 2-3, 6A-B, 8), the insertion point (fourth trochanter) is also shallow or

890 absent in both of these taxa and more plesiomorphic members of their clade (Zanno, 2010a;

891 Rhodes, Funston \& Currie, 2020). This pronounced reduction contrasts strongly with

892 ornithomimids (Gatesy, 1990; Hutchinson, 2001b), which suggests that reduction of the tail and

893 its muscles began conservatively at or near the base of Maniraptora rather than sometime within

894 (Allen et al., 2013). Although the initial stages of caudal decoupling are apparent as early in

895 coelurosaur evolution as Ornithomimidae (Fig. 1) (Gatesy \& Dial, 1996), a similarly punctuated

896 step in caudal decoupling probably occurred at the base of Maniraptora in tandem with tail

897 reduction. Further support for partial caudal decoupling comes from caenagnathids, which share

898 similar pelvic morphology and similar relative area of caudal musculature with Falcarius (Table

899 4; Fig. 8) but have a much higher level of cursoriality achieved through enlargement of pelvic

900 muscles — not tail muscles — along with other morphological adaptations (Figs. 13-14).

901

902 Moving forward 

examination of locomotory adaptations. Of the caudofemoral muscles, only the M. caudofemoralis brevis has an osteological correlate on the pelvis for consideration here, but the M. caudofemoralis longus comprises the bulk of this complex (Gatesy, 1990; Persons \& Currie, 2011a; Hutchinson et al., 2011). Exploring both parts of the Mm. caudofemorales would provide additional insight into the contribution of caudal musculature to cursoriality and the decoupling of pelvic and tail musculature (Gatesy \& Dial, 1996). Including other hind limb musculature of the thigh and lower leg would also allow whole-limb reconstruction that would better

911 complement future analyses. Even with these caveats, the results here are largely consistent with

912 previous studies and show that the combined origin areas of major hip extensors are a reasonable

913 proxy for cursoriality, especially in the context of other metrics (Fig. 14). Further study could

914 evaluate potential relationships between origin areas and known muscles properties such as

915 mass, physiological cross-sectional area, maximal isometric force, and others. On a similar note,

916 selection of specimens with known body masses or associated stylopod elements to estimate

917 body size would refine this analysis and offer better comparisons among taxa. This could be

918 done for multiple specimens of varying body size, within a family or within a species, to better

919 assess potential effects of ontogeny and allometry. Future work could also expand the dataset,

920 including examination of a greater diversity of birds, to better assess potential locomotory trends.

921 A broader dataset would permit a more in-depth analysis of the relationship between major

922 extensors and total hip musculature, which could also incorporate a time-calibrated phylogeny to 923 address questions related to estimated divergence times or ancestral state reconstructions.

924 Furthermore, the methods used here could be applied to other parts of the skeleton to address 925 other myological questions, like how the area of attachment for cranial musculature relates to 
926 bite force and feeding strategies, or integrating shoulder and forelimb muscle attachment sites

927 with pelvic and hind limb ones to analyze patterns in quadrupedal locomotion. The results from

928 our relatively small sample merit additional, more robust investigation into the potential

929 relationships between the area of attachment and cursoriality. Although beyond the scope of this

930 study, the areas of attachment of major hip extensors could be integrated into a more

931 comprehensive analysis with other putative correlates of cursoriality, similar to those done for

932 theropod herbivory and tail weaponry (Zanno \& Makovicky, 2011; Arbour \& Zanno, 2018, 933 2019).

934

935 Conclusions

936 Examination of the pelvis for osteological correlates of locomotory musculature in the

937 maniraptorans Falcarius, Caenagnathidae indet., Sinovenator, and derived Troodontidae indet.

938 documented morphological features and highlighted unique, previously unidentified conditions

939 in these groups. In turn, this allowed for novel reconstructions of pelvic myology that could be

940 quantified to compare within and among taxa. Soft tissue inferences provide an additional

941 perspective on locomotory adaptations that often, but do not always corroborate osteological

942 inferences. In Falcarius, soft tissue inferences generally match the osteological signals all

943 indicating reduced cursoriality. Caenagnathids, though not as cursorial as previously thought

944 based on pelvic muscles alone, still seem to be competent runners given multiple lines of

945 evidence. Sinovenator creates a baseline for the evolution of pelvic musculature in Troodontidae,

946 which supports previous studies noting divergent evolutionary trajectories between this family

947 and eudromaeosaurians (Fowler et al., 2011). Overall, our soft tissue inferences are reasonably

948 consistent with previous results indicating a stepwise accumulation of avian-like traits 
949 (Hutchinson \& Allen, 2009). However, rather than an increased rate of anatomical change

950 occurring sometime within Maniraptora (Allen et al., 2013), our results suggest that it began with

951 a somewhat punctuated step at the base of this clade. Furthermore, this underscores the increased

952 rates of morphological change seen in Maniraptora, suggesting that the assembly of avian

953 features may have been steady but was not always slow.

954 Focusing on the origins of pelvic muscles provided a sufficient basis to explore the

955 primary musculature controlling hind limb function, but would be complemented by examination

956 of other caudal and leg muscles in this manner to flesh out a better understanding of locomotion.

957 Nonetheless, calculating the area of attachment for musculature in a comparative framework

958 offers a quantifiable metric to infer evolutionary patterns and locomotory adaptations. The areas

959 of attachment of major extensors across the taxa examined here are collectively a reasonable

960 proxy for running ability. The hip, as the junction between the hind limb and tail, also provides

961 insight into the integration between locomotor modules (Gatesy \& Dial, 1996). Based on our

962 results, the decoupling of caudal and pelvic locomotor modules seems to follow the same pattern

963 as pelvic morphology and myology, which underwent a substantial advancement early within

964 Maniraptora. That being said, the caudal module remained at least partially integrated with the

965 pelvis and hind limb throughout non-avian Theropoda, partly contributing to the secondary

966 evolution of high cursoriality in troodontids. Future steps could integrate myological data with

967 osteological data and other methods into a more comprehensive analysis of cursoriality as a

968 spectrum of locomotor ability.

969

970 Acknowledgements 
971 For specimen and collections access, we thank R. Esplin and R. Scheetz (BYUVP), K. Corneli

972 and K. Carpenter (CEUM), J. Mallon, K. Shepherd, and M. Currie (CMN), A. Atwater and J.

973 Scannella (MOR), A. Howell (RM), B. Iwama and K. Seymour (ROM), B. Strilisky and D.

974 Brinkman (TMP), C. Coy and H. Gibbins (UALVP), B. Barr (UAMZ), and C. Levitt-Bussain

975 and R. Irmis (UMNH). For specimen acquisition and dissection assistance, MMR thanks A.

976 McIntosh, B. Barr, C. Sullivan, S. Hamilton, and Y.-y. Wang. Additional helpful discussions and

977 constructive feedback came from M. Caldwell, A. Dyer, D. Evans, G. Funston, R. Holmes, E.

978 Koppelhus, T. Miyashita, A. Murray, M. Powers, and S. Persons. Reviewer feedback has been

979 integral to greatly enhancing previous versions of this project.

980

981 References

982 Abourachid A, Renous S. 2008. Bipedal locomotion in ratites (Paleognatiform): examples of 983 cursorial birds. Ibis 142:538-549. DOI: 10.1111/j.1474-919X.2000.tb04455.x.

984 Alexander DE, Gong E, Martin LD, Burnham DA, Falk AR. 2010. Model tests of gliding with

985 different hindwing configurations in the four-winged dromaeosaurid Microraptor gui.

986 Proceedings of the National Academy of Sciences 107:2972-2976. DOI:

987 10.1073/pnas.0911852107.

988 Allen V, Elsey RM, Jones N, Wright J, Hutchinson JR. 2010. Functional specialization and 989 ontogenetic scaling of limb anatomy in Alligator mississippiensis. Journal of Anatomy 990 216:423-445. DOI: 10.1111/j.1469-7580.2009.01202.x.

991 Allen V, Bates KT, Li Z, Hutchinson JR. 2013. Linking the evolution of body shape and 992 locomotor biomechanics in bird-line archosaurs. Nature 497:104-107. DOI:

993 10.1038/nature12059. 
994 Allen V, Molnar J, Parker W, Pollard A, Nolan G, Hutchinson JR. 2015. Comparative

995 architectural properties of limb muscles in Crocodylidae and Alligatoridae and their

996 relevance to divergent use of asymmetrical gaits in extant Crocodylia. Journal of

997 Anatomy 225:569-582. DOI: 10.1111/joa.12245.

998 Akaike H. 1973. Information Theory as an Extension of the Maximum Likelihood Principle. In:

999 Petrov BN, Csaki F eds. Second International Symposium on Information Theory.

$1000 \quad$ Budapest: Akademiai Kiado, 267-281.

1001 Arbour VM, Zanno LE. 2018. The evolution of tail weaponization in amniotes. Proceedings of

1002 the Royal Society B: Biological Sciences 285:20172299. DOI: 10.1098/rspb.2017.2299.

1003 Arbour VM, Zanno LE. 2019. Tail weaponry in ankylosaurs and glyptodonts: an example of a

1004 rare but strongly convergent phenotype. The Anatomical Record 303:988-998. DOI:

$1005 \quad$ 10.1002/ar.24093.

1006 de Bakker MAG, Fowler DA, Oude K den, Dondorp EM, Navas MCG, Horbanczuk JO, Sire J-

1007 Y, Szczerbińska D, Richardson MK. 2013. Digit loss in archosaur evolution and the

1008 interplay between selection and constraints. Nature 500:445-448. DOI:

$1009 \quad 10.1038 /$ nature12336.

1010 Bamman MM, Newcomer BR, Larson-Meyer DE, Weinsier RL, Hunter GR. 2000. Evaluation of

1011 the strength-size relationship in vivo using various muscle size indices. Medicine \&

1012 Science in Sports \& Exercise 32:1307-1313. DOI: 10.1097/00005768-200007000-00019.

1013 Barsbold R, Osmólska H, Watabe M, Currie PJ, Tsogtbaatar K. 2000. A new oviraptorosaur

1014 (Dinosauria: Theropoda) from Mongolia: The first dinosaur with a pygostyle. Acta

1015 Palaeontologica Polonica 45:97-106. 
1016 Bates KT, Falkingham PL, Breithaupt BH, Hodgetts D, Sellers WI, Manning PL. 2009a. How

1017 big was "Big Al”? Quantifying the effect of soft tissue and osteological unknowns on

1018 mass predictions for Allosaurus (Dinosauria: Theropoda). Palaeontologia Electronica

$1019 \quad 12: 1-33$.

1020 Bates KT, Benson RBJ, Falkingham PL. 2012. A computational analysis of locomotor anatomy

1021 and body mass evolution in Allosauroidea (Dinosauria: Theropoda). Paleobiology

$1022 \quad 38: 486-507$. DOI: $10.1666 / 10004.1$.

1023 Bates KT, Maidment SCR, Allen V, Barrett PM. 2012. Computational modelling of locomotor

1024 muscle moment arms in the basal dinosaur Lesothosaurus diagnosticus: assessing

1025 convergence between birds and basal ornithischians. Journal of Anatomy 220:212-232.

1026 DOI: $10.1111 /$ j.1469-7580.2011.01469.x.

1027 Bates KT, Manning PL, Hodgetts D, Sellers WI. 2009b. Estimating Mass Properties of

1028 Dinosaurs Using Laser Imaging and 3D Computer Modelling. PLoS ONE 4:e4532. DOI:

$1029 \quad$ 10.1371/journal.pone.0004532.

1030 Bates KT, Schachner ER. 2011. Disparity and convergence in bipedal archosaur locomotion.

1031 Journal of The Royal Society Interface 9:1339-1353. DOI: 10.1098/rsif.2011.0687.

1032 Baumel JJ, King AS, Breazile JE, Evans HE, Vanden Berge JC (eds.). 1993. Handbook of Avian

1033 Anatomy: Nomina Anatomica Avium. Cambridge: Nuttall Ornithological Club.

1034 Baumel JJ, Wilson JA, Bergren DR. 1990. The ventilatory movements of the avian pelvis and

1035 tail: function of the muscles of the tail region of the pigeon (Columba livia). Journal of

1036 Experimental Biology 151:263-277.

1037 Benson RBJ, Campione NE, Carrano MT, Mannion PD, Sullivan C, Upchurch P, Evans DC.

1038 2014. Rates of Dinosaur Body Mass Evolution Indicate 170 Million Years of Sustained 
Ecological Innovation on the Avian Stem Lineage. PLoS Biology 12:e1001853. DOI:

1040 10.1371/journal.pbio.1001853.

1041 Biewener AA. 1989. Scaling body support in mammals: limb posture and muscle mechanics. Science 245:45-48. DOI: 10.1126/science.2740914.

1043 Bishop PJ, Hocknull SA, Clemente CJ, Hutchinson JR, Farke AA, Barrett RS, Lloyd DG. 2018 a.

1044 Cancellous bone and theropod dinosaur locomotion. Part III-Inferring posture and locomotor biomechanics in extinct theropods, and its evolution on the line to birds. PeerJ 6:e5777. DOI: $10.7717 /$ peerj.5777.

Bishop PJ, Hocknull SA, Clemente CJ, Hutchinson JR, Farke AA, Beck BR, Barrett RS, Lloyd DG. 2018b. Cancellous bone and theropod dinosaur locomotion. Part I - an examination of cancellous bone architecture in the hindlimb bones of theropods. PeerJ 6:e5778. DOI: https://cran.r-project.org/web/packages/classInt/index.html. $10.7717 /$ peerj.5778.

Bivand R. 2020. classInt: Choose Univariate Class Intervals. $R$ package version 0.4-3.

Bryant HN, Russell AP. 1992. The role of phylogenetic analysis in the inference of unpreserved attributes of extinct taxa. Philosophical Transactions of the Royal Society B: Biological Sciences 337:405-418. DOI: 10.1098/rstb.1992.0117.

Bryant HN, Seymour KL. 1990. Observations and comments on the reliability of muscle reconstruction in fossil vertebrates. Journal of Morphology 206:109-117. DOI: 10.1002/jmor.1052060111. 
1062 Burgers P, Chiappe LM. 1999. The wing of Archaeopteryx as a primary thrust generator. Nature

1063

1064

1065

1066

1067

1068

1069

1070

1071

1072

1073

1074

1075

1076

1077

1078

1079

1080

1081

1082

1083 399:60-62. DOI: 10.1038/19967.

Burnham KP, Anderson DR. 2002. Model selection and multimodel inference: a practical information-theoretic approach. New York: Springer.

Burnham KP, Anderson DR. 2004. Multimodel Inference: Understanding AIC and BIC in Model Selection. Sociological Methods \& Research 33:261-304. DOI: $\underline{10.1177 / 0049124104268644 .}$

Campione NE, Evans DC. 2012. A universal scaling relationship between body mass and proximal limb bone dimensions in quadrupedal terrestrial tetrapods. BMC Biology 10:60. DOI: $10.1186 / 1741-7007-10-60$.

Campione NE, Evans DC. 2020. The accuracy and precision of body mass estimation in non-avian dinosaurs. Biological Reviews In Press:1-39. DOI: 10.1111/brv.12638.

Campione NE, Evans DC, Brown CM, Carrano MT. 2014. Body mass estimation in non-avian bipeds using a theoretical conversion to quadruped stylopodial proportions. Methods in Ecology and Evolution 5:913-923. DOI: 10.1111/2041-210X.12226.

Carpenter K, Miles C, Ostrom JH, Cloward K. 2005. Redescription of the small maniraptoran theropods Ornitholestes and Coelurus from the Upper Jurassic Morrison Formation of Wyoming. In: Carpenter K ed. The Carnivorous Dinosaurs. Bloomington: Indiana University Press, 49-71.

Carrano MT. 1998. Locomotion in non-avian dinosaurs: integrating data from hindlimb kinematics, in vivo strains, and bone morphology. Paleobiology 24:450-469. DOI: 10.1017/S0094837300020108. 
1084 Carrano MT. 1999. What, if anything, is a cursor? Categories versus continua for determining 1085 locomotor habit in mammals and dinosaurs. Journal of Zoology 247:29-42. DOI:

1086 10.1111/j.1469-7998.1999.tb00190.x.

1087 Carrano MT. 2000. Homoplasy and the evolution of dinosaur locomotion. Paleobiology 26:4891088 512. DOI: 10.1666/0094-8373(2000)026\%3C0489:HATEOD\%3E2.0.CO;2.

1089 Carrano MT, Biewener AA. 1999. Experimental alteration of limb posture in the chicken (Gallus 1090 gallus) and its bearing on the use of birds as analogs for dinosaur locomotion. Journal of 1091 Morphology 240:237-249. DOI: 10.1002/(SICI)1097-4687(199906)240:3\%3C237::AIDJMOR3\%3E3.0.CO;2-N.

1093 Carrano MT, Hutchinson JR. 2002. Pelvic and hindlimb musculature of Tyrannosaurus rex 1094 (Dinosauria: Theropoda). Journal of Morphology 253:207-228. DOI: 10.1002/jmor.10018.

1096 Carrier DR, Farmer CG. 2000. The evolution of pelvic aspiration in archosaurs. Paleobiology 26:271-293. DOI: 10.1666/0094-8373(2000)026<0271:TEOPAI $>2.0 . C O ; 2$.

1098 Chatterjee S, Templin RJ. 2007. Biplane wing planform and flight performance of the feathered 1099 dinosaur Microraptor gui. Proceedings of the National Academy of Sciences 104:15761100 1580. DOI: 10.1073/pnas.0609975104.

1101 Clark JM, Norell MA, Barsbold R. 2001. Two new oviraptorids (Theropoda: Oviraptorosauria), 1102 Upper Cretaceous Djadokhta Formation, Ukhaa Tolgod, Mongolia. Journal of Vertebrate 1103 Paleontology 21:209-213. DOI: 10.1671/0272-

1104 4634(2001)021[0209:TNOTOU]2.0.CO;2. 
1105 Codd JR, Manning PL, Norell MA, Perry SF. 2008. Avian-like breathing mechanics in

1106 maniraptoran dinosaurs. Proceedings of the Royal Society B: Biological Sciences

275:157-161. DOI: 10.1098/rspb.2007.1233.

1108 Coombs WP. 1978. Theoretical aspects of cursorial adaptations in dinosaurs. The Quarterly

1109 Review of Biology 53:393-418. DOI: 10.1086/410790.

1110 Currie PJ, Dong Z-M. 2001. New information on Cretaceous troodontids (Dinosauria,

1111 Theropoda) from the People's Republic of China. Canadian Journal of Earth Sciences

1112 38:1753-1766. DOI: 10.1139/cjes-38-12-1753.

1113 Currie PJ. 2003. Allometric growth in tyrannosaurids (Dinosauria: Theropoda) from the Upper

1114 Cretaceous of North America and Asia. Canadian Journal of Earth Sciences 40:651-665.

1115 DOI: $10.1139 /$ E02-083.

1116 Currie PJ, Russell DA. 1988. Osteology and relationships of Chirostenotes pergracilis

1117 (Saurischia, Theropoda) from the Judith River (Oldman) Formation of Alberta, Canada.

1118 Canadian Journal of Earth Sciences 25:972-986. DOI: 10.1139/e88-097.

1119 Day JJ, Norman DB, Upchurch P, Powell HP. 2002. Dinosaur locomotion from a new trackway.

$1120 \quad$ Nature 415:494-495. DOI: 10.1038/415494a.

1121 Dececchi TA, Larsson HCE. 2013. Body and limb size dissociation at the origin of birds:

1122 uncoupling allometric constraints across a macroevolutionary transition. Evolution

$1123 \quad 67: 2741-2752$. DOI: $10.1111 /$ evo.12150.

1124 Dececchi TA, Larsson HCE, Habib MB. 2016. The wings before the bird: an evaluation of

1125 flapping-based locomotory hypotheses in bird antecedents. PeerJ 4:e2159. DOI:

$1126 \quad 10.7717$ peerj.2159. 
1127 Dececchi TA, Mloszewska AM, Holtz TR, Habib MB, Larsson HCE. 2020. The fast and the

1128 frugal: Divergent locomotory strategies drive limb lengthening in theropod dinosaurs.

1129 PLoS ONE 15:e0223698. DOI: 10.1371/journal.pone.0223698.

1130 Dick TJM, Clemente CJ. 2016. How to build your dragon: scaling of muscle architecture from

1131 the world's smallest to the world's largest monitor lizard. Frontiers in Zoology 13:1-17.

1132 DOI: $10.1186 / \mathrm{s} 12983-016-0141-5$.

1133 Dilkes DW. 2000. Appendicular myology of the hadrosaurian dinosaur Maiasaura peeblesorum

1134 from the Late Cretaceous (Campanian) of Montana. Transactions of the Royal Society of

1135 Edinburgh: Earth Sciences 90:87-125. DOI: 10.1017/S0263593300007185.

1136 Dunning Jr. JB (ed.). 2007. CRC Handbook of Avian Body Masses. Boca Raton, Florida: CRC

1137 Press. DOI: $\underline{10.1201 / 9781420064452 .}$

1138 Evangelista D, Cam S, Huynh T, Kwong A, Mehrabani H, Tse K, Dudley R. 2014a. Shifts in

1139 stability and control effectiveness during evolution of Paraves support aerial maneuvering

1140 hypotheses for flight origins. PeerJ 2:e632. DOI: 10.7717/peerj.632.

1141 Evangelista D, Cardona G, Guenther-Gleason E, Huynh T, Kwong A, Marks D, Ray N, Tisbe A,

1142 Tse K, Koehl M. 2014b. Aerodynamic characteristics of a feathered dinosaur measured

1143 using physical models. Effects of form on static stability and control effectiveness. PLoS

1144 ONE 9:e85203. DOI: 10.1371/journal.pone.0085203.

1145 Farlow JO, Gatesy SM, Holtz TR, Hutchinson JR, Robinson JM. 2000. Theropod locomotion.

1146 American Zoologist 40:640-663. DOI: 10.1093/icb/40.4.640.

1147 Foth C, Tischlinger H, Rauhut OWM. 2014. New specimen of Archaeopteryx provides insights

1148 into the evolution of pennaceous feathers. Nature 511:79-82. DOI: 10.1038/nature13467. 
1149 Fowler DW, Freedman EA, Scannella JB, Kambic RE. 2011. The predatory ecology of

1150 Deinonychus and the origin of flapping in birds. PLoS ONE 6:e28964. DOI:

$1151 \quad$ 10.1371/journal.pone.0028964.

1152 Funston GF. 2020. Caenagnathids of the Dinosaur Park Formation (Campanian) of Alberta,

1153 Canada: anatomy, osteohistology, taxonomy, and evolution. Vertebrate Anatomy

1154 Morphology Palaeontology 8:105-153. DOI: 10.18435/vamp29362.

1155 Funston GF, Currie PJ. 2020. New material of Chirostenotes pergracilis (Theropoda,

1156 Oviraptorosauria) from the Campanian Dinosaur Park Formation of Alberta, Canada.

1157 Historical Biology:1-15. DOI: 10.1080/08912963.2020.1726908.

1158 Funston GF, Mendonca SE, Currie PJ, Barsbold R. 2018. Oviraptorosaur anatomy, diversity and

1159 ecology in the Nemegt Basin. Palaeogeography, Palaeoclimatology, Palaeoecology

1160 494:101-120. DOI: 10.1016/j.palaeo.2017.10.023.

1161 Gangl D, Weissengruber GE, Egerbacher M, Forstenpointner G. 2004. Anatomical description of

1162 the muscles of the pelvic limb in the ostrich (Struthio camelus). Anatomia, Histologia,

1163 Embryologia 33:100-114. DOI: 10.1111/j.1439-0264.2003.00522.x.

1164 Gao C, Morschhauser EM, Varricchio DJ, Liu J, Zhao B. 2012. A Second Soundly Sleeping

1165 Dragon: New Anatomical Details of the Chinese Troodontid Mei long with Implications

1166 for Phylogeny and Taphonomy. PLoS ONE 7:e45203. DOI:

$1167 \quad$ 10.1371/journal.pone.0045203.

1168 Gatesy SM. 1990. Caudefemoral musculature and the evolution of theropod locomotion.

$1169 \quad$ Paleobiology 16:170-186.

1170 Gatesy SM. 1991. Hind limb scaling in birds and other theropods: implications for terrestrial

1171 locomotion. Journal of Morphology 209:83-96. DOI: 10.1002/jmor.1052090107. 
1172 Gatesy SM. 1995. Functional evolution of the hindlimb and tail from basal theropods to birds. In:

1173 Thomason J ed. Functional Morphology in Vertebrate Paleontology. Cambridge:

1174 Cambridge University Press, 219-234.

1175 Gatesy SM. 1997. An electromyographic analysis of hindlimb function in Alligator during

1176 terrestrial locomotion. Journal of Morphology 234:197-212. DOI: 10.1002/(SICI)1097-

1177 4687(199711)234:2<197::AID-JMOR6>3.0.CO;2-9.

1178 Gatesy SM. 1999a. Guineafowl hind limb function. I: Cineradiographic analysis and speed

1179 effects. Journal of Morphology 240:115-125. DOI: 10.1002/(SICI)1097-

$1180 \quad$ 4687(199905)240:2<115::AID-JMOR3>3.0.CO;2-Y.

1181 Gatesy SM. 1999b. Guineafowl hind limb function. II: Electromyographic analysis and motor

1182 pattern evolution. Journal of Morphology 240:127-142. DOI: 10.1002/(SICI)1097-

1183 4687(199905)240:2<127::AID-JMOR4>3.0.CO;2-Q.

1184 Gatesy SM, Dial KP. 1996. Locomotor modules and the evolution of avian flight. Evolution

1185 50:331-340. DOI: $10.2307 / 2410804$.

1186 Gatesy SM, Middleton KM. 1997. Bipedalism, flight, and the evolution of theropod locomotor

1187 diversity. Journal of Vertebrate Paleontology 17:308-329. DOI:

$1188 \quad 10.1080 / 02724634.1997 .10010977$.

1189 Gatesy SM, Middleton KM, Jenkins Jr. FA, Shubin NH. 1999. Three-dimensional preservation

1190 of foot movements in Triassic theropod dinosaurs. Nature 399:141-144. DOI:

$1191 \quad 10.1038 / 20167$.

1192 Gheţie V. 1976. Atlas de Anatomie a Păsărilor Domestice. Bucharest: Editura Academiei

1193 Republicii Socialiste Romania. 
1194 Gilmore CW. 1920. Osteology of the carnivorous Dinosauria in the United States National

1195 Museum, with special reference to the genera Antrodemus (Allosaurus) and

1196 Ceratosaurus. Bulletin of the United States National Museum 110:1-159.

1197 Grillo ON, Azevedo SAK. 2011. Pelvic and hind limb musculature of Staurikosaurus pricei

1198 (Dinosauria: Saurischia). Anais da Academia Brasileira de Ciências 83:73-98. DOI:

$1199 \quad 10.1590 / \mathrm{S} 0001-37652011000100005$.

1200 Halvorson DB. 1972. Differences in naming muscles of the pelvic limb of chicken. Poultry

$1201 \quad$ Science 51:727-738. DOI: 10.3382/ps.0510727.

1202 Heers AM, Baier DB, Jackson BE, Dial KP. 2016. Flapping before flight: high resolution, three-

1203 dimensional skeletal kinematics of wings and legs during avian development. PLoS ONE

1204 11:e0153446. DOI: 10.1371/journal.pone.0153446.

1205 Henderson DM. 2002. The eyes have it: the sizes, shapes, and orientations of theropod orbits as

1206 indicators of skull strength and bite force. Journal of Vertebrate Paleontology 22:766-

1207 778. DOI: 10.1671/0272-4634(2002)022[0766:TEHITS]2.0.CO;2.

1208 Henderson DM, Snively E. 2004. Tyrannosaurus en pointe: allometry minimized rotational

1209 inertia of large carnivorous dinosaurs. Proceedings of the Royal Society B: Biological

$1210 \quad$ Sciences 271:S57-S60. DOI: 10.1098/rsbl.2003.0097.

1211 Hendrickx C, Hartman SA, Mateus O. 2015. An overview of non-avian theropod discoveries and 1212 classification. PalArch's Journal of Vertebrate Palaeontology 12:1-73.

1213 Higham TE, Jayne BC. 2004. In vivo muscle activity in the hindlimb of the arboreal lizard,

1214 Chamaeleo calyptratus: general patterns and the effects of incline. Journal of

1215 Experimental Biology 207:249-261. DOI: 10.1242/jeb.00745. 
1216 Holtz TR. 1994. The arctometatarsalian pes, an unusual structure of the metatarsus of Cretaceous

1217 Theropoda (Dinosauria: Saurischia). Journal of Vertebrate Paleontology 14:480-519.

1218 DOI: $10.1080 / 02724634.1995 .10011574$.

1219 Hudson GE, Lanzillotti PJ, Edwards GD. 1959. Muscles of the pelvic limb in galliform birds. 1220 American Midland Naturalist 61:1-67. DOI: $10.2307 / 2422340$.

1221 Hurvich CM, Tsai C-L. 1989. Regression and time series model selection in small samples. 1222 Biometrika 76:297-307.

1223 Hutchinson JR. 2001a. The evolution of pelvic osteology and soft tissues on the line to extant 1224 birds (Neornithes). Zoological Journal of the Linnean Society 131:123-168. DOI: $1225 \quad 10.1006 /$ zjls.2000.0254.

1226 Hutchinson JR. 2001b. The evolution of femoral osteology and soft tissues on the line to extant birds (Neornithes). Zoological Journal of the Linnean Society 131:169-197. DOI: 10.1111/j.1096-3642.2001.tb01314.x.

Hutchinson JR. 2002. The evolution of hindlimb tendons and muscles on the line to crown-group birds. Comparative Biochemistry and Physiology Part A 133:1051-1086. DOI:

1232 Hutchinson JR. 2004a. Biomechanical modeling and sensitivity analysis of bipedal running ability. I. Extant taxa. Journal of Morphology 262:421-440. DOI: 10.1002/jmor.10241.

1234 Hutchinson JR. 2004b. Biomechanical modeling and sensitivity analysis of bipedal running ability. II. Extinct taxa. Journal of Morphology 262:441-461. DOI: 10.1002/jmor.10240.

1236 Hutchinson JR. 2006. The evolution of locomotion in archosaurs. Comptes Rendus Palevol 5:519-530. DOI: 10.1016/j.crpv.2005.09.002. 
1238 Hutchinson JR, Allen V. 2009. The evolutionary continuum of limb function from early

1239 theropods to birds. Naturwissenschaften 96:423-448. DOI: 10.1007/s00114-008-0488-3.

1240 Hutchinson JR, Anderson FC, Blemker SS, Delp SL. 2005. Analysis of hindlimb muscle moment

1241 arms in Tyrannosaurus rex using a three-dimensional musculoskeletal computer model:

1242 implications for stance, gait, and speed. Paleobiology 31:676-701. DOI:

$1243 \quad 10.1666 / 04044.1$.

1244 Hutchinson JR, Bates KT, Molnar J, Allen V, Makovicky PJ. 2011. A computational analysis of

1245 limb and body dimensions in Tyrannosaurus rex with implications for locomotion,

1246 ontogeny, and growth. PLoS ONE 6:e26037. DOI: 10.1371/journal.pone.0026037.

1247 Hutchinson JR, Garcia M. 2002. Tyrannosaurus was not a fast runner. Nature 415:1018-1021.

$1248 \quad$ DOI: $10.1038 / 4151018 \mathrm{a}$.

1249 Hutchinson JR, Gatesy SM. 2000. Adductors, abductors, and the evolution of archosaur

$1250 \quad$ locomotion. Paleobiology 26:734-751. DOI: 10.1666/0094-

1251 8373(2000)026<0734:AAATEO >2.0.CO;2.

1252 Hutchinson JR, Miller C, Fritsch G, Hildebrandt T. 2008. The anatomical foundation for multidisciplinary studies of animal limb function: examples from dinosaur and elephant limb imaging studies. In: Endo H, Frey R eds. Anatomical Imaging. Tokyo: Springer

1256 Hutchinson JR, Rankin JW, Rubenson J, Rosenbluth KH, Siston RA, Delp SL. 2015.

1257 Musculoskeletal modelling of an ostrich (Struthio camelus) pelvic limb: influence of limb 1258 orientation on muscular capacity during locomotion. PeerJ 3:e1001. DOI:

1259 $10.7717 /$ peerj.1001. 
1260 Indahl UG, Næs T, Liland KH. 2018. A similarity index for comparing coupled matrices.

$1261 \quad$ Journal of Chemometrics 32:e3049. DOI: 10.1002/cem.3049.

1262 Jacobson RD, Hollyday M. 1982. A behavioral and electromyographic study of walking in the 1263 chick. Journal of Neurophysiology 48:238-256. DOI: 10.1152/jn.1982.48.1.238.

1264 Jones EJ, Bishop PA, Woods AK, Green JM. 2008. Cross-sectional area and muscular strength: a 1265 brief review. Sports Medicine 38:987-994. DOI: 10.2165/00007256-200838120-00003.

1266 Jones TD, Farlow JO, Ruben JA, Henderson DM, Hillenius WJ. 2000. Cursoriality in bipedal 1267 archosaurs. Nature 406:716-718. DOI: $10.1038 / 35021041$.

1268 Kirkland JI, Zanno LE, Sampson SD, Clark JM, DeBlieux DD. 2005. A primitive

1269 therizinosauroid dinosaur from the Early Cretaceous of Utah. Nature 435:84-87. DOI:

$1270 \quad 10.1038 /$ nature03468.

1271 Lamanna MC, Sues H-D, Schachner ER, Lyson TR. 2014. A new large-bodied oviraptorosaurian 1272 theropod dinosaur from the latest Cretaceous of western North America. PLoS ONE 1273 9:e92022. DOI: 10.1371/journal.pone.0092022.

1274 Lamas LP, Main RP, Hutchinson JR. 2014. Ontogenetic scaling patterns and functional anatomy 1275 of the pelvic limb musculature in emus (Dromaius novaehollandiae). PeerJ 2:e716. DOI: $1276 \quad 10.7717 /$ peerj.716.

1277 Langer MC. 2003. The pelvic and hind limb anatomy of the stem-sauropodomorph Saturnalia 1278 tupiniquim (Late Triassic, Brazil). PaleoBios 23:1-30.

1279 Li D, You H, Zhang J. 2008. A new specimen of Suzhousaurus megatherioides (Dinosauria:

1280 Therizinosauroidea) from the Early Cretaceous of northwestern China. Canadian Journal $1281 \quad$ of Earth Sciences 45:769-779. DOI: 10.1139/E08-021. 
1282 Liland KH. 2017. MatrixCorrelation: Matrix Correlation Coefficients. R package version 0.9.2. 1283 https://cran.r-project.org/web/packages/MatrixCorrelation/index.html.

1284 Lovegrove BG, Mowoe MO. 2014. The evolution of micro-cursoriality in mammals. Journal of 1285 Experimental Biology 217:1316-1325. DOI: 10.1242/jeb.095737.

1286 Lü J. 2002. A new oviraptorosaurid (Theropoda: Oviraptorosauria) from the Late Cretaceous of 1287 southern China. Journal of Vertebrate Paleontology 22:871-875. DOI: 10.1671/0272$1288 \quad$ 4634(2002)022[0871:ANOTOF]2.0.CO;2.

1289 Lü J, Li G, Kundrát M, Lee Y-N, Sun Z, Kobayashi Y, Shen C, Teng F, Liu H. 2017. High 1290 diversity of the Ganzhou oviraptorid fauna increased by a new "cassowary-like" crested 1291 species. Scientific Reports 7:6393. DOI: 10.1038/s41598-017-05016-6.

1292 Lü J, Tomida Y, Azuma Y, Dong Z-M, Lee Y-N. 2004. New oviraptorid dinosaur (Dinosauria: Oviraptorosauria) from the Nemegt Formation of southwestern Mongolia. Bulletin of the National Science Museum, Tokyo, Series C 30:95-130.

1295 Lü J, Yi L, Zhong H, Wei X. 2013. A new oviraptorosaur (Dinosauria: Oviraptorosauria) from 1296 the Late Cretaceous of southern China and its paleoecological implications. PLoS ONE 1297 8:e80557. DOI: 10.1371/journal.pone.0080557.

1298 Lull RS. 1904. Adaptations to aquatic, arboreal, fossorial and cursorial habits in mammals. The 1299 American Naturalist 38:1-11. DOI: 10.1086/278375.

1300 Macaluso L, Tschopp E. 2018. Evolutionary changes in pubic orientation in dinosaurs are more 1301 strongly correlated with the ventilation system than with herbivory. Palaeontology 1302 61:703-719. DOI: 10.1111/pala.12362. 
1303 Macdonald I, Currie PJ. 2019. Description of a partial Dromiceiomimus (Dinosauria: Theropoda)

1304 skeleton with comments on the validity of the genus. Canadian Journal of Earth Sciences

1305 56:129-157. DOI: 10.1139/cjes-2018-0162.

1306 Maidment SCR, Barrett PM. 2011. The locomotor musculature of basal ornithischian dinosaurs.

1307 Journal of Vertebrate Paleontology 31:1265-1291. DOI:

$1308 \quad 10.1080 / 02724634.2011 .606857$.

1309 Maidment SCR, Barrett PM. 2012. Does morphological convergence imply functional

1310 similarity? A test using the evolution of quadrupedalism in ornithischian dinosaurs.

1311 Proceedings of the Royal Society B: Biological Sciences 279:3765-3771. DOI:

$1312 \quad 10.1098 / \mathrm{rspb} .2012 .1040$.

1313 Maidment SCR, Bates KT, Barrett PM. 2014. Three-dimensional computational modelling of

1314 pelvic locomotor muscle moment arms in Edmontosaurus (Dinosauria, Hadrosauridae)

1315 and comparisons with other archosaurs. In: Eberth DA, Evans DC eds. Hadrosaurs.

1316 Bloomington: Indiana University Press, 433-448.

1317 Maidment SCR, Bates KT, Falkingham PL, VanBuren C, Arbour V, Barrett PM. 2014.

1318 Locomotion in ornithischian dinosaurs: an assessment using three-dimensional

1319 computational modelling. Biological Reviews 89:588-617. DOI: 10.1111/brv.12071.

1320 McGowan C. 1979. The hind limb musculature of the brown kiwi, Apteryx australis mantelli.

1321 Journal of Morphology 160:33-73. DOI: 10.1002/jmor.1051600105.

1322 Meers MB. 2003. Crocodylian forelimb musculature and its relevance to Archosauria. The

1323 Anatomical Record 274A:891-916. DOI: 10.1002/ar.a.10097.

1324 Mellett FD. 1994. A note on the musculature of the proximal part of the pelvic limb of the 1325 ostrich (Struthio camelus). Journal of the South African Veterinary Association 65:5-9. 
1326 Milner ARC, Lockley MG, Kirkland JI. 2006. A large collection of well-preserved theropod

1327 dinosaur swim tracks from the Lower Jurassic Moenave Formation, St. George, Utah.

$1328 \quad$ New Mexico Museum of Natural History and Science Bulletin 37:315-328.

1329 Norell MA, Makovicky PJ, Bever GS, Balanoff AM, Clark JM, Barsbold R, Rowe T. 2009. A

1330 review of the Mongolian Cretaceous dinosaur Saurornithoides (Troodontidae:

1331 Theropoda). American Museum Novitates 3654:1-63. DOI: 10.1206/648.1.

1332 Olson VA, Turvey ST. 2013. The evolution of sexual dimorphism in New Zealand giant moa (Dinornis) and other ratites. Proceedings of the Royal Society B: Biological Sciences

1335 Osborn HF. 1903. Ornitholestes hermanni, a new comsognathid dinosaur from the Upper 1336 Jurassic. Bulletin of the American Museum of Natural History 19:459-464.

1337 Otero A, Gallina PA, Herrera Y. 2010. Pelvic musculature and function of Caiman latirostris. Herpetological Journal 20:173-184.

1339 Palmer C. 2014. The aerodynamics of gliding flight and its application to the arboreal flight of the Chinese feathered dinosaur Microraptor. Biological Journal of the Linnean Society

1342 Patak AE, Baldwin J. 1998. Pelvic limb musculature in the emu Dromaius novaehollandiae 113:828-835. DOI: $10.1111 /$ bij.12328. (Aves: Struthioniformes: Dromaiidae): adaptations to high-speed running. Journal of

Paul GS. 1998. Limb design, function and running performance in ostrich-mimics and Morphology 238:23-37. DOI: 10.1002/(SICI)1097-4687(199810)238:1<23::AIDJMOR2>3.0.CO;2-O. 
1348 Paxton H, Anthony NB, Corr SA, Hutchinson JR. 2010. The effects of selective breeding on the

1349 architectural properties of the pelvic limb in broiler chickens: a comparative study across

1350 modern and ancestral populations. Journal of Anatomy 217:153-166. DOI:

$1351 \quad 10.1111 / \mathrm{j} .1469-7580.2010 .01251 . x$.

1352 Paxton H, Tickle PG, Rankin JW, Codd JR, Hutchinson JR. 2014. Anatomical and

1353 biomechanical traits of broiler chickens across ontogeny. Part II. Body segment inertial

1354 properties and muscle architecture of the pelvic limb. PeerJ 2:e473. DOI:

$1355 \quad 10.7717 /$ peerj.473.

1356 Pei R, Norell MA, Barta DE, Bever GS, Pittman M, Xu X. 2017. Osteology of a new Late

1357 Cretaceous troodontid specimen from Ukhaa Tolgod, Ömnögovi Aimag, Mongolia.

1358 American Museum Novitates 3889:1-47. DOI: 10.1206/3889.1.

1359 Pei R, Pittman M, Goloboff PA, Dececchi TA, Habib MB, Kaye TG, Larsson HCE, Norell MA,

1360 Brusatte SL, Xu X. 2020. Potential for powered flight neared by most close avialan

1361 relatives, but few crossed its thresholds. Current Biology 30:4033-4046. DOI:

$1362 \quad$ 10.1016/j.cub.2020.06.105.

1363 Perle A. 1985. Comparative myology of the pelvic-femoral region in bipedal dinosaurs.

1364 Paleontological Journal 19:105-109.

1365 Persons WS, Currie PJ. 2011a. The tail of Tyrannosaurus: reassessing the size and locomotive

1366 importance of the M. caudofemoralis in non-avian theropods. The Anatomical Record

1367 294:119-131. DOI: 10.1002/ar.21290.

1368 Persons WS, Currie PJ. 2011b. Dinosaur speed demon: the caudal musculature of Carnotaurus

1369 sastrei and implications for the evolution of South American abelisaurids. PLoS ONE

1370 6:e25763. DOI: 10.1371/journal.pone.0025763. 
1371 Persons WS, Currie PJ. 2012. Dragon tails: convergent caudal morphology in winged archosaurs. $1372 \quad$ Acta Geologica Sinica 86:1402-1412.

1373 Persons WS, Currie PJ. 2016. An approach to scoring cursorial limb proportions in carnivorous 1374 dinosaurs and an attempt to account for allometry. Scientific Reports 6:19828. DOI: $1375 \quad 10.1038 /$ srep 19828.

1376 Persons WS, Currie PJ. 2017. The functional origin of dinosaur bipedalism: cumulative evidence 1377 from bipedally inclined reptiles and disinclined mammals. Journal of Theoretical Biology 420:1-7. DOI: 10.1016/j.jtbi.2017.02.032.

Persons WS, Currie PJ, Erickson GM. 2020. An older and exceptionally large adult specimen of Tyrannosaurus rex. The Anatomical Record 303:656-672. DOI: 10.1002/ar.24118.

1381 Persons WS, Currie PJ, Norell MA. 2014. Oviraptorosaur tail forms and functions. Acta Palaeontologica Polonica 59:553-567. DOI: 10.4202/app.2012.0093.

1383 Powers MJ, Sullivan C, Currie PJ. 2020. Re-examining ratio based premaxillary and maxillary characters in Eudromaeosauria (Dinosauria: Theropoda): Divergent trends in snout morphology between Asian and North American taxa. Palaeogeography,

1387 Pu H, Kobayashi Y, Lü J, Xu L, Wu Y, Chang H, Zhang J, Jia S. 2013. An unusual basal therizinosaur dinosaur with an ornithischian dental arrangement from northeastern China. PLoS ONE 8:e63423. DOI: 10.1371/journal.pone.0063423.

R Core Team. 2020. R: a language and environment for statistical computing. Vienna: $\mathrm{R}$ Foundation for Statistical Computing. https://www.R-project.org.

1392 Rabey KN, Green DJ, Taylor AB, Begun DR, Richmond BG, McFarlin SC. 2015. Locomotor activity influences muscle architecture and bone growth but not muscle attachment site 
1394

1395

1396

1397

1398

1399

1400

1401

1402

1403

1404

1405

1406

1407

1408

1409

1410

1411

1412

1413

1414

1415

morphology. Journal of Human Evolution 78:91-102. DOI:

10.1016/j.jhevol.2014.10.010.

van der Reest AJ, Currie PJ. 2017. Troodontids (Theropoda) from the Dinosaur Park Formation, Alberta, with a description of a unique new taxon: implications for deinonychosaur diversity in North America. Canadian Journal of Earth Sciences 54:919-935. DOI: 10.1139/cjes-2017-0031.

Rewcastle SC. 1983. Fundamental adaptations in the lacertilian hind limb: a partial analysis of the sprawling limb posture and gait. Copeia 1983:476. DOI: 10.2307/1444393.

Rhodes MM, Currie PJ. 2020. The homology, form, and function of the microraptorine lateral pubic tubercle. Journal of Vertebrate Paleontology 40:e1755866. DOI: 10.1080/02724634.2019.1755866.

Rhodes MM, Funston GF, Currie PJ. 2020. New material reveals the pelvic morphology of Caenagnathidae (Theropoda, Oviraptorosauria). Cretaceous Research 114:104521. DOI: 10.1016/j.cretres.2020.104521.

Robert P, Escoufier Y. 1976. A unifying tool for linear multivariate statistical methods: the RVcoefficient. Applied Statistics 25:257-265. DOI: 10.2307/2347233.

Romer AS. 1923a. Crocodilian pelvic muscles and their avian and reptilian homologues. Bulletin of the American Museum of Natural History 48:533-552.

Romer AS. 1923b. The pelvic musculature of saurischian dinosaurs. Bulletin of the American Museum of Natural History 48:605-617.

Romer AS. 1923c. The ilium in dinosaurs and birds. Bulletin of the American Museum of Natural History 48:141-145. 
1416 Romer AS. 1927. The pelvic musculature of ornithischian dinosaurs. Acta Zoologica 8:225-275.

1417 DOI: $10.1111 /$ j.1463-6395.1927.tb00653.x.

1418 Rose KA, Nudds RL, Codd JR. 2016. Variety, sex and ontogenetic differences in the pelvic limb

1419 muscle architectural properties of leghorn chickens (Gallus gallus domesticus) and their

1420 links with locomotor performance. Journal of Anatomy 228:952-964. DOI:

$1421 \quad \underline{10.1111 / \text { joa.12460. }}$.

1422 Russell LS. 1935. Musculature and functions in the Ceratopsia. National Museum of Canada $1423 \quad$ Bulletin 77:39-48. DOI: 10.4095/299139.

1424 Russell DA. 1972. Ostrich dinosaurs from the Late Cretaceous of western Canada. Canadian 1425 Journal of Earth Sciences 9:375-402. DOI: 10.1139/e72-031.

1426 Russell AP, Bauer AM. 2008. The appendicular locomotor apparatus of Sphenodon and normal1427 limbed squamates. In: Gans C, Gaunt AS, Adler K eds. Morphology I. The skull and 1428 appendicular locomotor apparatus of Lepidosauria. Biology of the Reptilia. Ithaca, New 1429 York: Society for the Study of Amphibians and Reptiles, 1-784.

1430 Russell DA, Dong Z-M. 1993. A nearly complete skeleton of a new troodontid dinosaur from the 1431 Early Cretaceous of the Ordos Basin, Inner Mongolia, People's Republic of China. 1432 Canadian Journal of Earth Sciences 30:2163-2173. DOI: 10.1139/e93-187.

1433 Segre PS, Banet AI. 2018. The origin of avian flight: finding common ground. Biological 1434 Journal of the Linnean Society 125:452-454. DOI: 10.1093/biolinnean/bly116.

1435 Sellers WI, Pond SB, Brassey CA, Manning PL, Bates KT. 2017. Investigating the running 1436 abilities of Tyrannosaurus rex using stress-constrained multibody dynamic analysis. 1437 PeerJ 5:e3420. DOI: 10.7717/peerj.3420. 
1438 Shen C, Lü J, Liu S, Kundrát M, Brusatte SL, Gao H. 2017a. A new troodontid dinosaur from

1439 the Lower Cretaceous Yixian Formation of Liaoning Province, China. Acta Geologica

$1440 \quad$ Sinica 91:763-780. DOI: 10.1111/1755-6724.13307.

1441 Shen C, Zhao B, Gao C, Lü J, Kundrát M. 2017b. A new troodontid dinosaur (Liaoningvenator

1442 curriei gen. et sp. nov.) from the Early Cretaceous Yixian Formation in Western Liaoning

1443 Province. Acta Geoscientica Sinica 38:359-371. DOI: 10.3975/cagsb.2017.03.06.

1444 Shufeldt RW. 1890. The myology of the raven (Corvus corax sinuatus): a guide to the study of

1445 the muscular system in birds. London: Macmillan and Company.

1446 Smith NC, Payne RC, Jespers KJ, Wilson AM. 2007. Muscle moment arms of pelvic limb

1447 muscles of the ostrich (Struthio camelus). Journal of Anatomy 211:313-324. DOI:

$1448 \quad 10.1111 / \mathrm{j} .1469-7580.2007 .00762 . x$.

1449 Smith NC, Wilson AM, Jespers KJ, Payne RC. 2006. Muscle architecture and functional

1450 anatomy of the pelvic limb of the ostrich (Struthio camelus). Journal of Anatomy

209:765-779. DOI: 10.1111/j.1469-7580.2006.00658.x.

1452 Snively E, Russell A. 2001. The tyrannosaurid metatarsus: bone strain and inferred ligament

1453 function. Senckenbergiana lethaea 81:73-80. DOI: 10.1007/BF03043771.

1454 Snively E, Russell AP. 2003. Kinematic model of tyrannosaurid (Dinosauria: Theropoda)

1455 arctometatarsus function. Journal of Morphology 255:215-227. DOI:

$1456 \quad 10.1002 /$ jmor.10059.

1457 Snively E, Russell AP, Powell GL. 2004. Evolutionary morphology of the coelurosaurian

1458 arctometatarsus: descriptive, morphometric and phylogenetic approaches. Zoological

1459 Journal of the Linnean Society 142:525-553. DOI: 10.1111/j.1096-3642.2004.00137.x. 
1460 Sues H-D. 1997. On Chirostenotes, a Late Cretaceous oviraptorosaur (Dinosauria: Theropoda)

1461 from western North America. Journal of Vertebrate Paleontology 17:698-716. DOI:

$1462 \quad 10.1080 / 02724634.1997 .10011018$.

1463 Sullivan RM, Jasinski SE, van Tomme MPA. 2011. A new caenagnathid Ojoraptorsaurus

1464 boerei, n. gen., n. sp. (Dinosauria, Oviraptorosauria), from the Upper Cretaceous Ojo

1465 Alamo Formation (Naashoibito Member), San Juan Basin, New Mexico. New Mexico

1466 Museum of Natural History and Science Bulletin 53:418-428.

1467 Sullivan C, Xu X, O’Connor JK. 2017. Complexities and novelties in the early evolution of

1468 avian flight, as seen in the Mesozoic Yanliao and Jehol Biotas of Northeast China.

1469 Palaeoworld 26:212-229. DOI: 10.1016/j.palwor.2016.12.001.

1470 Talori YS, Liu Y-F, Zhao J-S, Sullivan C, O’Connor JK, Li Z-H. 2018. Winged forelimbs of the

1471 small theropod dinosaur Caudipteryx could have generated small aerodynamic forces

1472 during rapid terrestrial locomotion. Scientific Reports 8:17854. DOI: 10.1038/s41598-

$1473 \quad 018-35966-4$.

1474 Talori YS, Zhao J-S, Liu Y-F, Lu W-X, Li Z-H, O’Connor JK. 2019. Identification of avian

1475 flapping motion from non-volant winged dinosaurs based on modal effective mass

1476 analysis. PLOS Computational Biology 15:e1006846. DOI:

$1477 \quad$ 10.1371/journal.pcbi.1006846.

1478 Tarsitano S. 1983. Stance and gait in theropod dinosaurs. Acta Palaeontologica Polonica $1479 \quad 28: 251-264$.

1480 Therrien F, Henderson DM. 2007. My theropod is bigger than yours ... or not: estimating body

1481 size from skull length in theropods. Journal of Vertebrate Paleontology 27:108-115.

1482 DOI: 10.1671/0272-4634(2007)27[108:MTIBTY]2.0.CO;2. 
1483 Tsuihiji T, Barsbold R, Watabe M, Tsogtbaatar K, Chinzorig T, Fujiyama Y, Suzuki S. 2014. An

1484 exquisitely preserved troodontid theropod with new information on the palatal structure

1485 from the Upper Cretaceous of Mongolia. Naturwissenschaften 101:131-142. DOI:

$1486 \quad 10.1007 / \mathrm{s} 00114-014-1143-9$.

1487 Verstappen M, Aerts P, De Vree F. 1998. Functional morphology of the hindlimb musculature of 1488 the black-billed magpie, Pica pica (Aves, Corvidae). Zoomorphology 118:207-223. DOI: $1489 \quad 10.1007 / \mathrm{s} 004350050070$.

1490 Walker AD. 1977. Evolution of the pelvis in birds and dinosaurs. In: Andrews SM, Miles RS, $1491 \quad$ Walker AD eds. Problems in Vertebrate Evolution. Linneaen Society Symposium Series. $1492 \quad$ New York: Academic Press, 319-358.

1493 White MA. 2009. The subarctometatarsus: intermediate metatarsus architecture demonstrating 1494 the evolution of the arctometatarsus and advanced agility in theropod dinosaurs.

1495 Alcheringa 33:1-21. DOI: 10.1080/03115510802618193.

1496 Witmer LM. 1995. The Extant Phylogenetic Bracket and the importance of reconstructing soft 1497 tissues in fossils. In: Functional Morphology in Vertebrate Paleontology. New York: 1498 Cambridge University Press, 19-33.

1499 Xu X, Currie PJ, Pittman M, Xing L, Meng Q, Lü J, Hu D, Yu C. 2017. Mosaic evolution in an 1500 asymmetrically feathered troodontid dinosaur with transitional features. Nature

$1501 \quad$ Communications 8:14972. DOI: 10.1038/ncomms14972.

1502 Xu X, Norell MA. 2004. A new troodontid dinosaur from China with avian-like sleeping posture. 1503 Nature 431:838-841. DOI: $10.1038 /$ nature02898.

$1504 \mathrm{Xu}$ X, Norell MA, Wang X, Makovicky PJ, Wu X. 2002. A basal troodontid from the Early 1505 Cretaceous of China. Nature 415:780-784. DOI: 10.1038/415780a. 
1506 Xu X, Tan Q, Sullivan C, Han F, Xiao D. 2011. A short-armed troodontid dinosaur from the

1507 Upper Cretaceous of Inner Mongolia and its implications for troodontid evolution. PLoS

1508 ONE 6:e22916. DOI: 10.1371/journal.pone.0022916.

1509 Xu X, Tan Q-W, Wang S, Sullivan C, Hone DWE, Han F-L, Ma Q-Y, Tan L, Xiao D. 2013. A

1510 new oviraptorid from the Upper Cretaceous of Nei Mongol, China, and its stratigraphic

1511 implications. Vertebrata PalAsiatica 51:85-101.

1512 Xu X, Tang Z, Wang X. 1999. A therizinosauroid dinosaur with integumentary structures from

1513 China. Nature 399:350-354. DOI: 10.1038/20670.

1514 Xu X, Zheng X, Sullivan C, Wang X, Xing L, Wang Y, Zhang X, O’Connor JK, Zhang F, Pan

1515 Y. 2015. A bizarre Jurassic maniraptoran theropod with preserved evidence of

1516 membranous wings. Nature 521:70-73. DOI: 10.1038/nature14423.

1517 Xu X, Zhou Z, Dudley R, Mackem S, Chuong C-M, Erickson GM, Varricchio DJ. 2014. An

1518 integrative approach to understanding bird origins. Science 346:1253293. DOI:

$1519 \quad 10.1126 /$ science.1253293.

1520 Yao X, Liao C-C, Sullivan C, Xu X. 2019. A new transitional therizinosaurian theropod from the

1521 Early Cretaceous Jehol Biota of China. Scientific Reports 9:1-12. DOI: 10.1038/s41598-

$1522 \quad 019-41560-z$

1523 Zanno LE. 2010a. Osteology of Falcarius utahensis (Dinosauria: Theropoda): characterizing the 1524 anatomy of basal therizinosaurs. Zoological Journal of the Linnean Society 158:196-230.

1525 DOI: $10.1111 /$ j.1096-3642.2009.00464.x.

1526 Zanno LE. 2010b. A taxonomic and phylogenetic re-evaluation of Therizinosauria (Dinosauria:

1527 Maniraptora). Journal of Systematic Palaeontology 8:503-543. DOI:

$1528 \quad 10.1080 / 14772019.2010 .488045$. 
1529 Zanno LE, Gillette DD, Albright LB, Titus AL. 2009. A new North American therizinosaurid 1530 and the role of herbivory in "predatory" dinosaur evolution. Proceedings of the Royal 1531 Society B: Biological Sciences 276:3505-3511. DOI: 10.1098/rspb.2009.1029.

1532 Zanno LE, Makovicky PJ. 2011. Herbivorous ecomorphology and specialization patterns in 1533 theropod dinosaur evolution. Proceedings of the National Academy of Sciences 108:2321534 237. DOI: $10.1073 /$ pnas. 1011924108.

1535 Zanno LE, Varricchio DJ, O’Connor PM, Titus AL, Knell MJ. 2011. A new troodontid theropod, 1536 Talos sampsoni gen. et sp. nov., from the Upper Cretaceous Western Interior Basin of 1537 North America. PLoS ONE 6:e24487. DOI: 10.1371/journal.pone.0024487.

1538 Zumwalt A. 2006. The effect of endurance exercise on the morphology of muscle attachment 1539 sites. Journal of Experimental Biology 209:444-454. DOI: 10.1242/jeb.02028. 


\section{Figure legends}

1541 Figure 1. Simplified phylogeny of non-avian maniraptorans among other theropods and extant 1542 relatives. Taxa along top indicate what each reconstruction represents, and asterisks $\left(^{*}\right)$ indicate 1543 novel pelvic muscle reconstructions. See Methods for details on phylogenetic treatment of study 1544 taxa. Phylogeny based on Hendrickx et al. (2015).

1546 Figure 2. Osteological correlates of pelvic musculature in Falcarius. Pelvis in left lateral view 1547 (A) with ilium CEUM 77189, pubis UMNH VP 14540 (reversed; courtesy of Natural History 1548 Museum of Utah), and ischium CEUM 74717 (reversed). Ilium CEUM 77189 in ventral view 1549 (B) and oblique view of cuppedicus fossa (C). Pelvis in medial view (D) with the same 1550 specimens as in lateral view. Anterolateral view of proximal end of pubis CEUM 52424 (E).

1551 Close-up of obturator process (F) of ischium CEUM 52482 (reversed; proximal to top). Pubis

1552 UMNH VP 14540 in anterior $(\mathrm{G})$ and posterior $(\mathrm{H})$ views with close-up of the apron $(\mathrm{I})$.

1553 Abbreviations: ace, acetabulum; bf, brevis fossa; cf, cuppedicus fossa; dist, distal ischial 1554 tubercle; isa, ischial apron; isp, ischiadic peduncle; op, obturator process; pa, pubic apron; pah, 1555 preacetabular hook; pb, pubic boot; pist, proximal ischial tubercle; pos, postacetabulum; pre, 1556 preacetabulum; pt, preacetabular tubercle; pup, pubic peduncle; rdg, ridge; str, striations.

Figure 3. Osteological correlates of pelvic musculature in Caenagnathidae indet. Ilium UALVP 59791 in left lateral (A), ventral (B), and medial (C) views. Pelvis in left lateral view (D) with ilium TMP 1979.020.0001, pubis UALVP 56638, and ischium TMP 1979.020.0001 (reversed). Ilium TMP 1979.020.0001 in ventral view (E). Pelvis in medial view (F) with the same specimens as in lateral view except for pubis TMP 1980.016.2095. Close-up of obturator process (G) of ischium TMP 1979.020.0001. Pubes UALVP 56638 in anterior (H) and posterior (J) views. Refer to Fig. 2 for anatomical abbreviations.

Figure 4. Osteological correlates of pelvic musculature in Sinovenator (A-J) and Jianianhualong (K-L). Ilia IVPP V12615 and IVPP V12583 in left lateral (A-B) and ventral (C-E) views (A, C, and $\mathrm{E}$ reversed). In the stippled line drawings, dashed lines indicate broken edges and grey represents matrix-obscured areas. Pubis IVPP V12583 in lateral (F, reversed), medial (G, reversed), anterior (H), and posterior (I) views. Pubes IVPP V12615 in posterior view (J). Pelvic region of Jianianhualong $(\mathrm{K})$ with close-up of left ischium DLXH 1218 (L). Refer to Fig. 2 for anatomical abbreviations.

1573

Figure 5. Osteological correlates of pelvic musculature in derived Troodontidae indet. Pelvis in left lateral view (A) with ilium and pubis UALVP 55804 (reversed) and ischium AMNH 6516. Pelvis UALVP 55804 (reversed) in ventral view (B). Pelvis in medial view (C) with the same specimens as in lateral view. Ischium UMNH VP 19479 (reversed) in dorsal (D) and lateral (E) views. Pubis UALVP 55804 in anterior view (F). Pubes UALVP 55804 in lateral (G, close-up in 
$1579 \mathrm{H}$ ), anterior (I), posterior (J, close-up in K), and medial (L, close-up in M) views. Refer to Fig. 2 for anatomical abbreviations.

1581

1582 Figure 6. Pelvic myology of non-avian maniraptorans. Pelvis of Falcarius in left lateral view

1583 (A), ilium in ventral view (B), pelvis in medial view (C), and pubes in anterior (D) and posterior

1584 (E) views. Pelvis of Caenagnathidae indet. in left lateral view (F), ilium in ventral view (G),

1585 pelvis in medial view (H), and pubes in anterior (I) and posterior (J) views. Pelvis of Sinovenator

1586 in left lateral view $(\mathrm{K})$, ilium in ventral view (L), pelvis in medial view (M), and pubes in

1587 anterior $(\mathrm{N})$ and posterior $(\mathrm{O})$ views. Pelvis of derived Troodontidae indet. in left lateral view

$1588(\mathrm{P})$, ilium in ventral view $(\mathrm{Q})$, pelvis in medial view $(\mathrm{R})$, and pubes in anterior $(\mathrm{S})$ and posterior

1589 (T) views. See Table 2 for muscle abbreviations.

1590

1591

1592

1593

Figure 7. Pelvic myology of other study taxa. Pelvis of Varanus in left lateral (A) and medial (B) views. Pelvis of Alligator in left lateral (C) and medial (D) views, and pubes in dorsal (E) and

1594 ventral $(\mathrm{F})$ views. Pelvis of Caiman in left lateral $(\mathrm{G})$ and medial $(\mathrm{H})$ views, and pubes in dorsal (I) and ventral (J) views. Pelvis of Allosaurus in left lateral view (K), ilium in ventral view (L), pelvis in medial view $(\mathrm{M})$, and pubes in anterior $(\mathrm{N})$ and posterior $(\mathrm{O})$ views. Pelvis of Albertosaurus in left lateral view (P), ilium in ventral view (Q), pelvis in medial view (R), and pubes in anterior $(\mathrm{S})$ and posterior $(\mathrm{T})$ views. Pelvis of Ornithomimidae indet. in left lateral view $(\mathrm{U})$, ilium in ventral view $(\mathrm{V})$, pelvis in medial view $(\mathrm{W})$, and pubes in anterior $(\mathrm{X})$ and posterior (Y) views. Pelvis of Saurornitholestes in left lateral view (Z), ilium in ventral view (AA), pelvis in medial view (BB), and pubes in anterior (CC) and posterior (DD) views. Pelvis of Struthio in left lateral (EE) and medial (FF) views. Pelvis of Dromaius in left lateral (GG) and medial (HH) views. Pelvis of Gallus in left lateral (II) and medial (JJ) views. See Table 2 for muscle abbreviations and refer to Supplemental Figures for individually labeled origins.

Figure 8. Area of attachment across all pelvic muscles and by conventional anatomical groups. (A) Equal-area chart showing the proportion of individual muscles to the total area of all muscles. (B) Paired bar charts representing anatomical groups with results from Corel DRAW! (left bars) and ImageJ (right bars). See Table 2 for muscle abbreviations.

Figure 9. Area of attachment by functional groups. (A) Antagonistic pairs of all taxa sampled. (B) Antagonistic pairs of taxa pruned to reflect general results of past studies. Abbreviations: Ab, abduction; Ad, adduction; E, extension; F, flexion; M, medial; L, lateral; LAR, long axis rotation. in representatives of non-theropod Sauria (Alligator, A), non-maniraptoran Theropoda 
1619 Figure 11. Sensitivity analysis. Comparison of Corel DRAW! and ImageJ under five tolerance levels performed on the Albertosaurus reconstruction (inset) shows no significant differences. Scatter plot (left) depicts individual muscle origin measurements, summarized in the box and

1622 whisker plot (right; coloured bars = interquartile range, black line $=$ mean). See Table 2 for

1623 muscle abbreviations.

1624

Figure 12. Phylogenetic Generalized Least Squares (PGLS) regressions on area of attachment and ilium length normalized to body mass (all log-transformed). (A) Individual regressions on each major group with colour-coded regression lines (dashed). (B) Regressions on non-avian theropods. (C) Regressions on bipedal taxa. Bivariate comparisons are grouped by rows according to the dependent variable: area of attachment of all hip muscles (upper), area of attachment of major extensors (middle), and length of the ilium (lower).

Figure 13. Area of attachment of major extensors. Muscles and groups plotted as a proportion of the total area of all pelvic muscle origins, and grey lines represent $5 \%$ increments. Cursoriality categories adapted from Carrano (1999). Classes based on Jenks Natural Break optimization of the major extensors for five groups. See Table 2 for muscle abbreviations.

Figure 14. Pelvic musculature and other putative correlates of cursoriality. (A) Pelvic muscle reconstructions in left lateral view grouped to show non-avian maniraptorans among other theropods and extant relatives. (B) Heat map comparing the area of attachment of major extensors (from Jenks Natural Breaks optimization in Fig. 13), proportional length of distal hind limb elements (sensu Carrano 1999), ankle joint morphology/degree of metatarsal fusion (hingelike $>$ ball-and-socket; tarsometatarsus $>$ arctometatarsus $>$ subarctometatarsus $>$ unspecialized), number of functional weight-bearing digits (fewer = higher), and foot symmetry. (C) Bar chart depicting a spectrum of inferred cursoriality averaged from the heat map above. 


\section{Table 1 (on next page)}

Pelvic material examined for osteological correlates of soft tissues. 
1 Table 1. Pelvic material examined for osteological correlates of soft tissues.

\begin{tabular}{|c|c|c|}
\hline Taxon & Specimen number(s) & Pelvic element(s) \\
\hline \multicolumn{3}{|l|}{ Non-maniraptoran Theropoda } \\
\hline Albertosaurus sarcophagus & CMN 11315 & $\begin{array}{l}\text { Ilia, fused pubes, } \\
\text { ischium }\end{array}$ \\
\hline Allosaurus fragilis & $\begin{array}{l}\text { BYUVP 4891, 5111, 5292, } \\
11430,13625,16774,17550 ; \\
\text { CMN } 38454\end{array}$ & Ilia, pubes, ischia \\
\hline Ceratosaurus sp. & BYUVP 12893 & Fused pubes, ischium \\
\hline Daspletosaurus torosus & UALVP 52981 & Articulated pelvis \\
\hline Dromiceiomimus brevitertius & ROM 797; UALVP 16182 & $\begin{array}{l}\text { Fused pubes (ROM); } \\
\text { Semi-articulated pelvis } \\
\text { (UALVP) }\end{array}$ \\
\hline Gorgosaurus libratus & UALVP 10 & $\begin{array}{l}\text { Articulated pelvis (fused } \\
\text { pubes broken midshaft) }\end{array}$ \\
\hline Ornithomimus edmontonicus & ROM 851 & Fused pubes \\
\hline Torvosaurus tanneri & $\begin{array}{l}\text { BYUVP 2013, 2014, 2015, } \\
4881,4977\end{array}$ & Ilia, pubes, ischia \\
\hline Ornithomimidae indet. & $\begin{array}{l}\text { CMN 8897, 12348; TMP } \\
\text { 1967.020.0230, 1967.020.0237, } \\
\text { 1981.016.0679, 1981.022.0025, } \\
\text { 1989.036.0103, 1992.050.0065, } \\
\text { 1994.012.0428, 1996.012.0019, } \\
\text { 2009.035.0001, 2013.012.0007; } \\
\text { UALVP 50646, 60331 }\end{array}$ & $\begin{array}{l}\text { Ilium, partial ischia } \\
\text { (CMN); ilium, pubes, } \\
\text { ischia, articulated pelvis } \\
\text { (TMP); partial ilium, } \\
\text { complete ischium } \\
\text { (UALVP) }\end{array}$ \\
\hline \multicolumn{3}{|l|}{ Therizinosauria } \\
\hline Falcarius utahensis & $\begin{array}{l}\text { UMNH VP } 12370,12371, \\
12374,14540,14659, \text { no } \# \\
\text { (small pubis) }\end{array}$ & Pubes, ischia \\
\hline Falcarius sp. & $\begin{array}{l}\text { CEUM 52424, 52482, 52520, } \\
53243,53252,53305,53312, \\
53349,53361,73681,73709, \\
73963,73964,74706,74717, \\
74727,74739,74763,74794, \\
74842,77035,77037,77045, \\
77051,77053,77081,77114, \\
77173,77189,77194,77195, \\
77233,77241,77290,78223\end{array}$ & Ilia, pubes, ischia \\
\hline \multicolumn{3}{|l|}{ Caenagnathidae } \\
\hline Anzu wyliei & CM 78000 & $\begin{array}{l}\text { Partial ilium, pubes, } \\
\text { ischia }\end{array}$ \\
\hline Chirostenotes pergracilis & $\begin{array}{l}\text { TMP 1979.020.0001, TMP } \\
2002.012 .0103\end{array}$ & Ilia, ischium \\
\hline Epichirostenotes curriei & ROM 43250 & Ilia, right ischium, pubes \\
\hline Caenagnathidae indet. & TMP 1980.016.2095, & Ilia, disarticulated and \\
\hline
\end{tabular}


Dromaeosauridae

Hesperonychus elizabethae

Saurornitholestes langstoni

Utahraptor ostrommaysorum

Dromaeosauridae indet.

Velociraptorinae indet.

Troodontidae

Jianianhualong tengi

Latenivenatrix mcmasterae

Saurornithoides mongoliensis

Sinovenator changii

Talos sampsoni

Aves

Apteryx haastii

Casuarius australis

Dromaius novaehollandiae

Gallus gallus

Rhea americana

Struthio camelus

Crocodylia

Alligator mississippiensis

Alligator sp.

Caiman crocodilus

Osteolaemus tetraspis

Squamata

Tupinambis teguixin

Varanus albigularis

Varanus jobiensis

Varanus komodoensis

Varanus niloticus

Varanus rudicollis

Varanus salvator
1981.023.0034-35,

1982.016.0275, 1992.036.0674,

1994.012.0603, 1998.093.0013;

UALVP 56638, 59791

UALVP 48778

MOR 660; UALVP 55700

BYUVP 14302, 19973, 20692

TMP 1986.077.0002

ROM 53573

DLXH 1218

UALVP 55804

AMNH FR 6516

IVPP V12583, V12615

UMNH VP 19479

RM 8369

UAMZ 1369

ROM R6843, R7654; UAMZ BFIC2014.260

RM 8355

RM 8499

ROM R1080, R1162, R1933,

R2136, R2305; UAMZ 7159

ROM R343

UAMZ HER-R654

RM 5242

RM 5216

ROM R436

RM 5220

RM 5219

ROM R7565

RM 5221

ROM R7318

RM 5222, 5223, 5224 fused pubes (TMP);

partial ilium, fused pubes

(UALVP)

Partial articulated pelvis

Ilium (MOR); articulated pelvis (UALVP)

Partial ilia, pubis

Ischium

Cast of articulated pelvis

Semi-articulated pelvis

Ilia, partial pubes

Ischia

Ilia, pubes

Partial ilium, partial

pubes, partial ischia

Articulated pelvis

Articulated pelvis

Articulated pelves

Articulated pelvis

Disarticulated pelvis

Disarticulated and

articulated pelves

Semi-articulated pelvis

Articulated pelvis

Disarticulated pelvis

Articulated pelvis

Articulated pelvis

Disarticulated pelvis

Articulated pelvis

Disarticulated pelvis

Articulated pelvis

Articulated pelvis

Articulated pelves 


\section{Table 2 (on next page)}

Homologies and abbreviations of pelvic musculature by anatomical muscle group (adapted from Hutchinson, 2001a).

Note: -, absent; ${ }^{*}$, undivided; ${ }^{\dagger}$, origin located on soft tissue, not directly on pelvis. 
1 Table 2. Homologies and abbreviations of pelvic musculature by anatomical muscle group (adapted from Hutchinson, 2001a).

\begin{tabular}{|c|c|c|c|c|}
\hline Muscle & Lepidosauria & Crocodylia & $\begin{array}{l}\text { Non-avian } \\
\text { Theropoda }\end{array}$ & Aves \\
\hline \multicolumn{5}{|l|}{ Triceps femoris } \\
\hline \multirow[t]{3}{*}{ M. iliotibialis (IT)/Mm. iliotibiales cranialis et lateralis (IC+IL) } & IT & IT1 & IT1 & IC \\
\hline & $*$ & IT2 & IT2 & IL \\
\hline & $*$ & IT3 & IT3 & $*$ \\
\hline M. ambiens (AMB) & AMB & $\mathrm{AMB} 1+2$ & AMB & $\mathrm{AMB} 1+2$ \\
\hline M. iliofibularis & ILFB & ILFB & ILFB & ILFB \\
\hline \multicolumn{5}{|l|}{ Deep dorsal group } \\
\hline \multirow{5}{*}{$\begin{array}{l}\text { M. iliofemoralis (IF)/Mm. iliotrochantericus caudalis et iliofemoralis } \\
\text { externus (ITC+IFE) } \\
\text { M. puboischiofemoralis internus (PIFI)/Mm. iliofemoralis internus } \\
\text { (IFI) and iliotrochanterici cranialis et medius (ITCR+ITM) }\end{array}$} & IF & $\mathrm{IF}$ & ITC & ITC \\
\hline & $*$ & * & IFE & IFE \\
\hline & PIFI1+2 & PIFI1 & PIFI1 & IFI \\
\hline & PIFI3 & PIFI2 & PIFI2 & ITCR \\
\hline & $*$ & $*$ & $*$ & ITM \\
\hline \multicolumn{5}{|l|}{ Flexor cruris group } \\
\hline \multirow{3}{*}{ M. puboischiotibialis (PIT) } & PIT1 & - & - & - \\
\hline & $\mathrm{PIT}^{\dagger}$ & PIT & - & - \\
\hline & $\mathrm{PIT}^{\dagger}$ & FTI2 & - & - \\
\hline \multirow[t]{3}{*}{ M. flexor tibialis internus $(\mathrm{FTI}) / \mathrm{M}$. flexor cruris medialis $(\mathrm{FCM})$} & FTI1 & FTI1 & FTI1 & - \\
\hline & FTI2 & FTI3 & FTI3 & FCM \\
\hline & $*$ & $\mathrm{FTI}^{\dagger}{ }^{\dagger}$ & - & - \\
\hline $\begin{array}{l}\text { M. flexor tibialis externus (FTE)/M. flexor cruris lateralis pars pelvica } \\
\text { (FCLP) }\end{array}$ & $\mathrm{FTE}^{\dagger}$ & FTE & FTE & FCLP \\
\hline M. pubotibialis (PUT) & PUT & - & - & - \\
\hline \multirow{5}{*}{$\begin{array}{l}\text { M. adductor femoris (ADD)/Mm. puboischiofemorales medialis et } \\
\text { lateralis (PIFM+PIFL) } \\
\text { M. puboischiofemoralis externus (PIFE)/Mm. obturatorii lateralis et } \\
\text { medialis (OL+OM) }\end{array}$} & ADD & ADD1 & ADD1 & PIFM \\
\hline & $*$ & ADD2 & ADD2 & PIFL \\
\hline & PIFE & PIFE1 & PIFE1 & $\mathrm{OL}$ \\
\hline & $*$ & PIFE2 & PIFE2 & $\mathrm{OM}$ \\
\hline & $*$ & PIFE3 & PIFE3 & - \\
\hline M. ischiotrochantericus (ISTR)/M. ischiofemoralis (ISF) & ISTR & ISTR & ISTR & ISF \\
\hline M. caudofemoralis brevis (CFB)/M. caudofemoralis pars pelvica (CFP) & CFB & CFB & CFB & CFP \\
\hline
\end{tabular}




\section{PeerJ}

2 Note: - , absent; ${ }^{*}$, undivided; ${ }^{\dagger}$, origin located on soft tissue, not directly on pelvis. 


\section{Table 3 (on next page)}

Individual pelvic muscle origin areas $\left(\mathrm{cm}^{2}\right)$ for each taxon measured in both programs (Corel DRAW!, Image).

Numbered columns correspond to taxa in Fig. 1: 1, Varanus; 2, Alligator; 3, Caiman; 4, Allosaurus; 5, Albertosaurus; 6, Ornithomimidae indet.; 7, Falcarius; 8, Caenagnathidae indet.; 9, Saurornitholestes; 10, Sinovenator; 11, derived Troodontidae indet.; 12, Struthio;

13, Dromaius; 14, Gallus. Note: *, undivided; ${ }^{\dagger}$, origin located on soft tissue (not directly on pelvis). See Table 2 for muscle abbreviations. 
1 Table 3. Individual pelvic muscle origin areas $\left(\mathrm{cm}^{2}\right)$ for each taxon measured in both programs (Corel DRAW!, ImageJ). Numbered

2 columns correspond to taxa in Fig. 1: 1, Varanus; 2, Alligator; 3, Caiman; 4, Allosaurus; 5, Albertosaurus; 6, Ornithomimidae indet.;

3 7, Falcarius; 8, Caenagnathidae indet.; 9, Saurornitholestes; 10, Sinovenator; 11, derived Troodontidae indet.; 12, Struthio; 13,

4 Dromaius; 14, Gallus.

\begin{tabular}{|c|c|c|c|c|c|c|c|c|c|c|c|c|c|c|c|c|c|}
\hline $\begin{array}{c}\text { Muscl } \\
\text { e }\end{array}$ & 1 & & 2 & 3 & & 4 & 5 & 6 & 7 & 8 & 9 & 10 & 11 & & 12 & 13 & 14 \\
\hline \multirow[t]{3}{*}{ IT } & $\begin{array}{l}1.6400, \\
1.5928\end{array}$ & IT1 & $\begin{array}{l}0.3517, \\
0.3542\end{array}$ & $\begin{array}{c}0.145 \\
4, \\
0.143 \\
0\end{array}$ & IT1 & $\begin{array}{l}55.5300 \\
52.8585\end{array}$ & $\begin{array}{l}46.2600 \\
42.0757\end{array}$ & $\begin{array}{l}32.0000, \\
30.8872\end{array}$ & $\begin{array}{l}9.9360, \\
9.9736\end{array}$ & $\begin{array}{l}7.0950, \\
7.6908\end{array}$ & $\begin{array}{l}1.6960, \\
1.6466\end{array}$ & $\begin{array}{c}0.186 \\
4, \\
0.184 \\
6\end{array}$ & $\begin{array}{l}5.9820 \\
5.9757\end{array}$ & IC & $\begin{array}{l}5.2640 \\
4.7024\end{array}$ & $\begin{array}{l}5.4600, \\
5.2366\end{array}$ & $\begin{array}{c}0.131 \\
3 \\
0.098 \\
2\end{array}$ \\
\hline & & IT2 & $\begin{array}{l}2.4520, \\
2.4262\end{array}$ & $\begin{array}{c}0.474 \\
1, \\
0.474 \\
8\end{array}$ & IT2 & $\begin{array}{l}97.1300 \\
91.6356\end{array}$ & $\begin{array}{c}106.960 \\
0 \\
95.9770\end{array}$ & $\begin{array}{l}40.4900 \\
36.5978\end{array}$ & $\begin{array}{l}7.6660, \\
7.6134\end{array}$ & $\begin{array}{l}4.7660 \\
4.8012\end{array}$ & $\begin{array}{l}2.4310 \\
2.3680\end{array}$ & $\begin{array}{c}0.222 \\
7 \\
0.204 \\
5\end{array}$ & $\begin{array}{l}8.8970 \\
7.8217\end{array}$ & IL & $\begin{array}{l}19.1300, \\
17.2724\end{array}$ & $\begin{array}{l}8.7410, \\
7.9932\end{array}$ & $\begin{array}{c}0.912 \\
4, \\
0.800 \\
3\end{array}$ \\
\hline & & IT3 & $\begin{array}{l}0.2799 \\
0.2809\end{array}$ & $\begin{array}{c}0.044 \\
4, \\
0.045 \\
1\end{array}$ & IT3 & $\begin{array}{c}57.5700 \\
54.0924\end{array}$ & $\begin{array}{l}50.0000 \\
47.1902\end{array}$ & $\begin{array}{l}20.0600 \\
17.8012\end{array}$ & $\begin{array}{l}3.9640 \\
3.9783\end{array}$ & $\begin{array}{l}1.6730 \\
1.5734\end{array}$ & $\begin{array}{l}1.8130 \\
1.8660\end{array}$ & $\begin{array}{c}0.161 \\
4, \\
0.157 \\
6\end{array}$ & $\begin{array}{l}8.0940 \\
8.1602\end{array}$ & & & & \\
\hline \multirow[t]{2}{*}{ AMB } & $\begin{array}{l}0.9300 \\
0.9248\end{array}$ & $\begin{array}{c}\text { AMB } \\
1\end{array}$ & $\begin{array}{l}1.4922, \\
1.4224\end{array}$ & $\begin{array}{c}0.147 \\
4, \\
0.298 \\
3\end{array}$ & AMB & $\begin{array}{l}26.2600 \\
26.3178\end{array}$ & $\begin{array}{l}33.0100 \\
33.5779\end{array}$ & $\begin{array}{l}7.7840 \\
7.9078\end{array}$ & $\begin{array}{l}4.4920 \\
4.6759\end{array}$ & $\begin{array}{l}5.6800 \\
5.7987\end{array}$ & $\begin{array}{l}1.5420 \\
1.5525\end{array}$ & $\begin{array}{l}0.107 \\
1, \\
0.105 \\
4\end{array}$ & $\begin{array}{l}3.4340 \\
3.1558\end{array}$ & $\begin{array}{c}\text { AMB } \\
1\end{array}$ & $\begin{array}{c}4.6970 \\
4.5010\end{array}$ & $\begin{array}{c}0.5416 \\
0.5251\end{array}$ & $\begin{array}{c}0.047 \\
6, \\
0.033 \\
7\end{array}$ \\
\hline & & $\begin{array}{c}\text { AMB } \\
2\end{array}$ & $\begin{array}{l}0.5623, \\
0.5528\end{array}$ & $*$ & & & & & & & & & & $\underset{2}{\mathbf{A M B}}$ & $\begin{array}{c}33.9200, \\
33.3790\end{array}$ & $*$ & $*$ \\
\hline ILFB & $\begin{array}{l}0.9831 \\
0.9917\end{array}$ & ILFB & $\begin{array}{l}0.4943, \\
0.4898\end{array}$ & $\begin{array}{c}0.058 \\
4, \\
0.058 \\
2\end{array}$ & ILFB & $\begin{array}{c}220.650 \\
0 \\
219.062 \\
6\end{array}$ & $\begin{array}{c}286.430 \\
0 \\
284.145 \\
0\end{array}$ & $\begin{array}{c}139.200 \\
0 \\
140.479 \\
6\end{array}$ & $\begin{array}{c}31.160 \\
0 \\
31.177 \\
1\end{array}$ & $\begin{array}{c}38.260 \\
0 \\
38.644 \\
4\end{array}$ & $\begin{array}{l}8.6000 \\
8.6188\end{array}$ & $\begin{array}{c}1.601 \\
0 \\
1.593 \\
9\end{array}$ & $\begin{array}{l}60.7500 \\
62.4600\end{array}$ & ILFB & $\begin{array}{c}124.500 \\
0, \\
121.690 \\
5\end{array}$ & $\begin{array}{l}54.2400 \\
53.7954\end{array}$ & $\begin{array}{c}1.020 \\
0 \\
1.020 \\
9\end{array}$ \\
\hline \multirow[t]{2}{*}{ IF } & $\begin{array}{l}3.2590 \\
3.2196\end{array}$ & IF & $\begin{array}{l}4.9550, \\
4.9495\end{array}$ & $\begin{array}{c}1.232 \\
0 \\
1.223 \\
9\end{array}$ & ITC & $\begin{array}{c}250.870 \\
0 \\
251.228 \\
7\end{array}$ & $\begin{array}{c}326.920 \\
0 \\
327.263 \\
0\end{array}$ & $\begin{array}{c}203.100 \\
0 \\
205.199 \\
7\end{array}$ & $\begin{array}{c}68.970 \\
0 \\
68.931 \\
1\end{array}$ & $\begin{array}{c}88.570 \\
0 \\
89.430 \\
7\end{array}$ & $\begin{array}{c}25.190 \\
0 \\
25.243 \\
3\end{array}$ & $\begin{array}{c}3.351 \\
0 \\
3.326 \\
1\end{array}$ & $\begin{array}{l}66.1900 \\
68.1188\end{array}$ & ITC & $\begin{array}{l}68.2400, \\
66.9022\end{array}$ & $\begin{array}{l}23.7000 \\
23.4878\end{array}$ & $\begin{array}{c}5.235 \\
0 \\
5.299 \\
0\end{array}$ \\
\hline & & & & & IFE & $\begin{array}{c}40.9300 \\
40.4700\end{array}$ & $\begin{array}{l}59.4800 \\
59.3447\end{array}$ & $\begin{array}{l}33.2800 \\
33.7780\end{array}$ & $\begin{array}{l}4.7840 \\
4.8695\end{array}$ & $\begin{array}{l}8.5820 \\
8.8027\end{array}$ & $\begin{array}{l}1.1360 \\
1.1367\end{array}$ & $\begin{array}{c}0.387 \\
4, \\
0.391 \\
8\end{array}$ & $\begin{array}{l}14.5600 \\
14.9618\end{array}$ & IFE & $\begin{array}{l}3.5170 \\
3.4440\end{array}$ & $\begin{array}{l}2.7120 \\
2.6996\end{array}$ & $\begin{array}{c}0.254 \\
2, \\
0.256 \\
2\end{array}$ \\
\hline PIFI1+2 & $\begin{array}{c}12.440 \\
0 \\
12.337 \\
1\end{array}$ & PIFI1 & $\begin{array}{l}5.0000, \\
5.0035\end{array}$ & $\begin{array}{c}1.057 \\
0, \\
1.050 \\
8\end{array}$ & PIFI1 & $\begin{array}{l}32.7620 \\
29.4096\end{array}$ & $\begin{array}{l}40.1300 \\
38.7543\end{array}$ & $\begin{array}{l}10.2700 \\
10.4166\end{array}$ & $\begin{array}{l}9.0860 \\
9.2023\end{array}$ & $\begin{array}{l}5.2260 \\
5.3039\end{array}$ & $\begin{array}{l}3.8130 \\
3.8179\end{array}$ & $\begin{array}{c}0.581 \\
8 \\
0.562 \\
9\end{array}$ & $\begin{array}{l}7.8920 \\
7.1780\end{array}$ & IFI & $\begin{array}{l}24.8800, \\
24.5188\end{array}$ & $\begin{array}{l}10.6000 \\
10.5831\end{array}$ & $\begin{array}{c}0.160 \\
7 \\
0.158 \\
5\end{array}$ \\
\hline PIFI3 & 17.480 & PIFI2 & $\dagger$ & $\dagger$ & PIFI2 & 76.7100 & 139.640 & 37.2570 & 48.260 & 36.950 & 6.0878, & 0.649 & 12.8270 & ITCR & 10.4200, & 17.7500, & 0.332 \\
\hline
\end{tabular}




\begin{tabular}{|c|c|c|c|c|c|c|c|c|c|c|c|c|c|c|c|c|c|}
\hline & $\begin{array}{c}0 \\
17.298 \\
9\end{array}$ & & & & & 74.2587 & $\begin{array}{c}0, \\
139.441 \\
0\end{array}$ & 34.4643 & $\begin{array}{c}0 \\
48.468 \\
6\end{array}$ & $\begin{array}{c}0, \\
37.297 \\
6\end{array}$ & 6.0420 & $\begin{array}{c}9, \\
0.632 \\
6\end{array}$ & 12.6053 & & 10.2395 & 17.8404 & $\begin{array}{c}4, \\
0.324 \\
6\end{array}$ \\
\hline & & & & & & & & & & & & & & ITM & $\begin{array}{l}5.1550 \\
5.1196\end{array}$ & $\begin{array}{c}14.5300 \\
14.4034\end{array}$ & $\begin{array}{c}0.122 \\
9 \\
0.116 \\
7\end{array}$ \\
\hline PIT1 & $\begin{array}{l}1.0703 \\
1.0527\end{array}$ & PIT & $\begin{array}{l}0.3484 \\
0.3562\end{array}$ & $\begin{array}{c}0.043 \\
7 \\
0.042 \\
4\end{array}$ & & & & & & & & & & & & & \\
\hline FTI1 & $\begin{array}{l}0.0975, \\
0.0917\end{array}$ & FTI1 & $\begin{array}{l}0.1089 \\
0.1025\end{array}$ & $\begin{array}{c}0.053 \\
7 \\
0.047 \\
7\end{array}$ & FTI1 & $\begin{array}{c}4.4580 \\
1.7834\end{array}$ & $\begin{array}{c}2.6000 \\
1.1192\end{array}$ & $\begin{array}{l}1.3600 \\
1.1719\end{array}$ & $\begin{array}{l}0.2051, \\
0.2206\end{array}$ & $\begin{array}{l}0.1120 \\
0.1002\end{array}$ & $\begin{array}{c}0.2715 \\
0.2738\end{array}$ & $\begin{array}{c}0.038 \\
0, \\
0.033 \\
6\end{array}$ & $\begin{array}{l}0.9766 \\
0.8363\end{array}$ & & & & \\
\hline \multirow[t]{2}{*}{ FTI2 } & $\begin{array}{l}0.1463 \\
0.1412\end{array}$ & FTI3 & $\begin{array}{c}0.2941 \\
0.2876\end{array}$ & $\begin{array}{c}0.071 \\
4, \\
0.061 \\
7\end{array}$ & FTI3 & $\begin{array}{c}10.8050 \\
9.3902\end{array}$ & $\begin{array}{l}8.4900 \\
6.7431\end{array}$ & $\begin{array}{l}3.8110 \\
3.1756\end{array}$ & $\begin{array}{l}0.5151 \\
0.4786\end{array}$ & $\begin{array}{l}0.4788, \\
0.4205\end{array}$ & $\begin{array}{l}0.2018 \\
0.2147\end{array}$ & $\begin{array}{c}0.085 \\
3, \\
0.081 \\
5\end{array}$ & $\begin{array}{l}2.0560 \\
1.9346\end{array}$ & FCM & $\begin{array}{c}33.1700 \\
32.7531\end{array}$ & $\begin{array}{c}60.5900 \\
59.8530\end{array}$ & $\begin{array}{c}0.324 \\
8 \\
0.330 \\
9\end{array}$ \\
\hline & & FTI2 & $\begin{array}{l}0.2269 \\
0.2242\end{array}$ & $\begin{array}{c}0.061 \\
7 \\
0.062 \\
7\end{array}$ & & & & & & & & & & & & & \\
\hline FTE & $\dagger$ & FTE & $\begin{array}{c}0.3097 \\
0.3133\end{array}$ & $\begin{array}{c}0.065 \\
4, \\
0.066 \\
4\end{array}$ & FTE & $\begin{array}{c}109.140 \\
0 \\
108.788 \\
3\end{array}$ & $\begin{array}{l}87.4100 \\
87.6565\end{array}$ & $\begin{array}{l}56.0700 \\
56.7627\end{array}$ & $\begin{array}{c}9.9390 \\
10.023 \\
4\end{array}$ & $\begin{array}{c}11.520 \\
0, \\
11.773 \\
4\end{array}$ & $\begin{array}{l}1.3100 \\
1.3011\end{array}$ & $\begin{array}{c}0.252 \\
4, \\
0.253 \\
3\end{array}$ & $\begin{array}{l}14.8400 \\
15.2328\end{array}$ & $\begin{array}{c}\text { FCL } \\
\mathbf{P}\end{array}$ & $\begin{array}{l}11.5400 \\
10.8545\end{array}$ & $\begin{array}{l}5.1080 \\
4.1161\end{array}$ & $\begin{array}{c}0.374 \\
9, \\
0.381 \\
2\end{array}$ \\
\hline PUT & $\begin{array}{l}0.2832 \\
0.2829\end{array}$ & & & & & & & & & & & & & & & & \\
\hline \multirow[t]{2}{*}{ ADD } & $\begin{array}{l}2.9480 \\
2.9011\end{array}$ & $\begin{array}{c}\text { ADD } \\
1\end{array}$ & $\begin{array}{l}1.1800 \\
1.1320\end{array}$ & $\begin{array}{c}0.194 \\
5 \\
0.162 \\
0\end{array}$ & $\begin{array}{c}\text { ADD } \\
1\end{array}$ & $\begin{array}{l}21.4400 \\
20.3833\end{array}$ & $\begin{array}{l}70.1600 \\
70.5402\end{array}$ & $\begin{array}{l}11.2000 \\
11.4542\end{array}$ & $\begin{array}{c}11.490 \\
0, \\
11.383 \\
8\end{array}$ & $\begin{array}{l}4.3730 \\
4.4071\end{array}$ & $\begin{array}{l}3.8960 \\
3.8026\end{array}$ & $\begin{array}{c}0.329 \\
7, \\
0.319 \\
9\end{array}$ & $\begin{array}{l}18.5000 \\
18.7969\end{array}$ & PIFM & $\begin{array}{l}34.6600 \\
33.6699\end{array}$ & $\begin{array}{l}32.2500 \\
31.2045\end{array}$ & $\begin{array}{c}0.762 \\
9 \\
0.750 \\
2\end{array}$ \\
\hline & & $\begin{array}{c}\text { ADD } \\
2\end{array}$ & $\begin{array}{c}2.1050 \\
1.9424\end{array}$ & $\begin{array}{c}0.368 \\
9 \\
0.353 \\
3\end{array}$ & $\begin{array}{l}\text { ADD } \\
2\end{array}$ & $\begin{array}{l}15.5780 \\
11.3672\end{array}$ & $\begin{array}{c}20.9200 \\
15.7738\end{array}$ & $\begin{array}{l}5.4710 \\
4.0141\end{array}$ & $\begin{array}{l}3.5520, \\
3.2151\end{array}$ & $\begin{array}{l}2.1880 \\
1.7322\end{array}$ & $\begin{array}{l}1.6358 \\
1.6140\end{array}$ & $\begin{array}{c}0.271 \\
9 \\
0.243 \\
7\end{array}$ & $\begin{array}{l}8.7980 \\
7.1172\end{array}$ & PIFL & * & $*$ & $\begin{array}{c}0.558 \\
1, \\
0.557 \\
7\end{array}$ \\
\hline \multirow[t]{3}{*}{ PIFE } & $\begin{array}{c}23.987 \\
0, \\
23.772 \\
7\end{array}$ & $\begin{array}{c}\text { PIFE } \\
1\end{array}$ & $\begin{array}{c}11.053 \\
0, \\
10.736 \\
9\end{array}$ & $\begin{array}{c}3.216 \\
9 \\
3.158 \\
7\end{array}$ & $\begin{array}{c}\text { PIFE } \\
1\end{array}$ & $\begin{array}{l}72.7600 \\
67.0230\end{array}$ & $\begin{array}{c}127.740 \\
0 \\
112.763 \\
3\end{array}$ & $\begin{array}{l}39.2900 \\
35.5202\end{array}$ & $\begin{array}{c}38.640 \\
0, \\
37.232 \\
4\end{array}$ & $\begin{array}{c}19.809 \\
0, \\
18.515 \\
6\end{array}$ & $\begin{array}{l}8.3580 \\
7.8680\end{array}$ & $\begin{array}{c}3.103 \\
5 \\
2.899 \\
6\end{array}$ & $\begin{array}{l}27.1930 \\
25.7227\end{array}$ & OL & $\begin{array}{l}5.5530 \\
4.2878\end{array}$ & - & $\begin{array}{c}0.055 \\
0 \\
0.047 \\
9\end{array}$ \\
\hline & & $\begin{array}{c}\text { PIFE } \\
2\end{array}$ & $\begin{array}{l}8.5360 \\
8.3300\end{array}$ & $\begin{array}{c}2.549 \\
9 \\
2.508 \\
1\end{array}$ & $\begin{array}{c}\text { PIFE } \\
2\end{array}$ & $\begin{array}{c}107.022 \\
0 \\
100.722 \\
6\end{array}$ & $\begin{array}{c}136.660 \\
0, \\
123.984 \\
4\end{array}$ & $\begin{array}{l}49.8200 \\
46.7320\end{array}$ & $\begin{array}{c}32.349 \\
0, \\
29.599 \\
6\end{array}$ & $\begin{array}{c}31.629 \\
0, \\
31.378 \\
9\end{array}$ & $\begin{array}{l}9.9870 \\
8.7183\end{array}$ & $\begin{array}{c}6.000 \\
5 \\
5.625 \\
5\end{array}$ & $\begin{array}{c}107.330 \\
0 \\
104.897 \\
6\end{array}$ & OM & $\begin{array}{c}219.700 \\
0 \\
213.680 \\
2\end{array}$ & $\begin{array}{c}118.260 \\
0 \\
116.725 \\
8\end{array}$ & $\begin{array}{c}9.004 \\
0, \\
9.114 \\
4\end{array}$ \\
\hline & & $\begin{array}{c}\text { PIFE } \\
\mathbf{3}\end{array}$ & $\begin{array}{l}8.7910 \\
8.5178\end{array}$ & $\begin{array}{c}1.535 \\
0, \\
1.515 \\
5\end{array}$ & $\begin{array}{c}\text { PIFE } \\
3\end{array}$ & $\begin{array}{c}4.5720 \\
3.8392\end{array}$ & $\begin{array}{l}43.8100 \\
42.4911\end{array}$ & $\begin{array}{c}10.3600 \\
9.3188\end{array}$ & $\begin{array}{l}9.5260 \\
9.4732\end{array}$ & $\begin{array}{l}2.8430 \\
2.7976\end{array}$ & $\begin{array}{l}2.4950 \\
2.5057\end{array}$ & $\begin{array}{l}0.431 \\
1, \\
0.423 \\
4\end{array}$ & $\begin{array}{l}17.3000 \\
17.6725\end{array}$ & & & & \\
\hline ISTR & 4.5300 & ISTR & 5.1060 & 0.689 & ISTR & 13.8900 & 30.2600 & 5.2110 & 3.2980 & 1.8270 & 1.2260 & 0.178 & 5.3410 & ISF & 18.9800, & 0.8023 & 4.953 \\
\hline
\end{tabular}




\begin{tabular}{|c|c|c|c|c|c|c|c|c|c|c|c|c|c|c|c|c|c|}
\hline & 4.4808 & & 4.9072 & $\begin{array}{c}6, \\
0.642 \\
1\end{array}$ & & 14.1762 & 30.4392 & 5.3750 & 3.3710 & 1.8755 & 1.2374 & $\begin{array}{c}4, \\
0.176 \\
7\end{array}$ & 5.6510 & & 17.2033 & 0.7917 & $\begin{array}{c}0, \\
5.015 \\
9\end{array}$ \\
\hline CFB & $\begin{array}{l}0.1671, \\
0.1254\end{array}$ & CFB & $\begin{array}{l}0.8096 \\
0.7836\end{array}$ & $\begin{array}{c}0.126 \\
8 \\
0.124 \\
5\end{array}$ & CFB & $\begin{array}{c}250.060 \\
0, \\
230.280 \\
7\end{array}$ & $\begin{array}{c}335.710 \\
0 \\
314.047 \\
6\end{array}$ & $\begin{array}{c}164.450 \\
0 \\
157.639 \\
5\end{array}$ & $\begin{array}{c}18.266 \\
0, \\
17.738 \\
7\end{array}$ & $\begin{array}{c}23.430 \\
0 \\
23.733 \\
2\end{array}$ & $\begin{array}{c}10.251 \\
0 \\
10.113 \\
9\end{array}$ & $\begin{array}{c}1.609 \\
2, \\
1.516 \\
3\end{array}$ & $\begin{array}{l}64.0600 \\
62.0356\end{array}$ & CFP & $\begin{array}{c}141.400 \\
0, \\
138.622 \\
0\end{array}$ & $\begin{array}{c}90.1900 \\
89.0167\end{array}$ & $\begin{array}{c}2.654 \\
0, \\
2.683 \\
7\end{array}$ \\
\hline
\end{tabular}

5 Note: *, undivided; ${ }^{\dagger}$, origin located on soft tissue (not directly on pelvis). See Table 2 for muscle abbreviations. 


\section{Table 4 (on next page)}

Relative proportion of individual origin area to total area of all origins for each taxon in both programs (Corel DRAW!, Image)).

Numbered columns correspond to taxa in Fig. 1: 1, Varanus; 2, Alligator; 3, Caiman; 4, Allosaurus; 5, Albertosaurus; 6, Ornithomimidae indet.; 7, Falcarius; 8, Caenagnathidae indet.; 9, Saurornitholestes; 10, Sinovenator; 11, derived Troodontidae indet.; 12, Struthio;

13, Dromaius; 14, Gallus. Note: *, undivided; ${ }^{\dagger}$, origin located on soft tissue (not directly on pelvis). See Table 2 for muscle abbreviations. 
1 Table 4. Relative proportion of individual origin area to total area of all origins for each taxon in both programs (Corel DRAW!,

2 ImageJ). Numbered columns correspond to taxa in Fig. 1: 1, Varanus; 2, Alligator; 3, Caiman; 4, Allosaurus; 5, Albertosaurus; 6,

3 Ornithomimidae indet.; 7, Falcarius; 8, Caenagnathidae indet.; 9, Saurornitholestes; 10, Sinovenator; 11, derived Troodontidae indet.;

4 12, Struthio; 13, Dromaius; 14, Gallus

\begin{tabular}{|c|c|c|c|c|c|c|c|c|c|c|c|c|c|c|c|c|c|}
\hline Muscle & 1 & & 2 & 3 & & 4 & 5 & 6 & 7 & 8 & 9 & 10 & 11 & & 12 & 13 & 14 \\
\hline \multirow[t]{3}{*}{ IT } & $\begin{array}{l}0.0234, \\
0.0230\end{array}$ & IT1 & $\begin{array}{l}0.0065, \\
0.0067\end{array}$ & $\begin{array}{l}0.0120 \\
0.0119\end{array}$ & IT1 & $\begin{array}{l}0.0378, \\
0.0376\end{array}$ & $\begin{array}{l}0.0237 \\
0.0225\end{array}$ & $\begin{array}{l}0.0368 \\
0.0364\end{array}$ & $\begin{array}{l}0.0314 \\
0.0320\end{array}$ & $\begin{array}{l}0.0240 \\
0.0260\end{array}$ & $\begin{array}{l}0.0184 \\
0.0183\end{array}$ & $\begin{array}{l}0.0095 \\
0.0099\end{array}$ & $\begin{array}{c}0.0131 \\
0.0133\end{array}$ & IC & $\begin{array}{c}0.0069 \\
0.0063\end{array}$ & $\begin{array}{c}0.0123 \\
0.0119\end{array}$ & $\begin{array}{c}0.0049 \\
0.0036\end{array}$ \\
\hline & & IT2 & $\begin{array}{l}0.0450 \\
0.0457\end{array}$ & $\begin{array}{l}0.0391, \\
0.0394\end{array}$ & IT2 & $\begin{array}{c}0.0662 \\
0.0651\end{array}$ & $\begin{array}{l}0.0548, \\
0.0512\end{array}$ & $\begin{array}{l}0.0465 \\
0.0431\end{array}$ & $\begin{array}{c}0.0243, \\
0.0244\end{array}$ & $\begin{array}{l}0.0162, \\
0.0162\end{array}$ & $\begin{array}{l}0.0264, \\
0.0263\end{array}$ & $\begin{array}{l}0.0114 \\
0.0109\end{array}$ & $\begin{array}{c}0.0196, \\
0.0174\end{array}$ & IL & $\begin{array}{c}0.0250 \\
0.0233\end{array}$ & $\begin{array}{r}0.0196 \\
0.0182\end{array}$ & $\begin{array}{c}0.0339 \\
0.0297\end{array}$ \\
\hline & & IT3 & $\begin{array}{l}0.0051 \\
0.0053\end{array}$ & $\begin{array}{l}0.0037 \\
0.0037\end{array}$ & IT3 & $\begin{array}{c}0.0392, \\
0.0384\end{array}$ & $\begin{array}{l}0.0256 \\
0.0252\end{array}$ & $\begin{array}{l}0.0230 \\
0.0210\end{array}$ & $\begin{array}{c}0.0125, \\
0.0128\end{array}$ & $\begin{array}{l}0.0057 \\
0.0053\end{array}$ & $\begin{array}{l}0.0197, \\
0.0207\end{array}$ & $\begin{array}{c}0.0083, \\
0.0084\end{array}$ & $\begin{array}{c}0.0178, \\
0.0181\end{array}$ & & & & \\
\hline \multirow[t]{2}{*}{ AMB } & $\begin{array}{c}0.0133, \\
0.0134\end{array}$ & AMB1 & $\begin{array}{l}0.0274, \\
0.0268\end{array}$ & $\begin{array}{l}0.0121, \\
0.0248\end{array}$ & AMB & $\begin{array}{l}0.0179 \\
0.0187\end{array}$ & $\begin{array}{l}0.0169 \\
0.0179\end{array}$ & $\begin{array}{l}0.0089 \\
0.0093\end{array}$ & $\begin{array}{c}0.0142 \\
0.0150\end{array}$ & $\begin{array}{l}0.0193 \\
0.0196\end{array}$ & $\begin{array}{l}0.0168, \\
0.0173\end{array}$ & $\begin{array}{l}0.0055 \\
0.0056\end{array}$ & $\begin{array}{c}0.0075 \text {, } \\
0.0070\end{array}$ & AMB1 & $\begin{array}{c}0.0061 \\
0.0061\end{array}$ & $\begin{array}{c}0.0012, \\
0.0012\end{array}$ & $\begin{array}{r}0.0018 \\
0.0012\end{array}$ \\
\hline & & AMB2 & $\begin{array}{c}0.0103, \\
0.0104\end{array}$ & * & & & & & & & & & & AMB2 & $\begin{array}{c}0.0444, \\
0.0449\end{array}$ & * & * \\
\hline ILFB & $\begin{array}{l}0.0141, \\
0.0143\end{array}$ & ILFB & $\begin{array}{l}0.0091 \\
0.0092\end{array}$ & $\begin{array}{l}0.0048, \\
0.0048\end{array}$ & ILFB & $\begin{array}{l}0.1503, \\
0.1557\end{array}$ & $\begin{array}{l}0.1467 \\
0.1517\end{array}$ & $\begin{array}{l}0.1599, \\
0.1655\end{array}$ & $\begin{array}{c}0.0986 \\
0.1000\end{array}$ & $\begin{array}{l}0.1297 \\
0.1305\end{array}$ & $\begin{array}{l}0.0935 \text {, } \\
0.09558\end{array}$ & $\begin{array}{l}0.0819 \\
0.0851\end{array}$ & $\begin{array}{c}0.1335, \\
0.1387\end{array}$ & ILFB & $\begin{array}{c}0.1628 \\
0.1638\end{array}$ & $\begin{array}{c}0.1218 \\
0.1227\end{array}$ & $\begin{array}{c}0.0379 \text {, } \\
0.0378\end{array}$ \\
\hline \multirow[t]{2}{*}{ IF } & $\begin{array}{l}0.0466, \\
0.0465\end{array}$ & IF & $\begin{array}{l}0.0910 \\
0.0932\end{array}$ & $\begin{array}{l}0.1015 \\
0.1017\end{array}$ & ITC & $\begin{array}{l}0.1709 \\
0.1785\end{array}$ & $\begin{array}{l}0.1674 \\
0.1747\end{array}$ & $\begin{array}{l}0.2333, \\
0.2418\end{array}$ & $\begin{array}{l}0.2182, \\
0.2212\end{array}$ & $\begin{array}{l}0.3002, \\
0.3021\end{array}$ & $\begin{array}{l}0.2740 \\
0.2807\end{array}$ & $\begin{array}{l}0.1714 \\
0.1776\end{array}$ & $\begin{array}{c}0.1455 \\
0.1513\end{array}$ & ITC & $\begin{array}{c}0.0892 \\
0.0901\end{array}$ & $\begin{array}{c}0.0532 \\
0.0536\end{array}$ & $\begin{array}{c}0.1946, \\
0.1963\end{array}$ \\
\hline & & & & & IFE & $\begin{array}{l}0.0279 \\
0.0288\end{array}$ & $\begin{array}{l}0.0305 \\
0.0317\end{array}$ & $\begin{array}{c}0.0382, \\
0.0398\end{array}$ & $\begin{array}{c}0.0151 \\
0.0156\end{array}$ & $\begin{array}{l}0.0291 \\
0.0297\end{array}$ & $\begin{array}{l}0.0124, \\
0.0126\end{array}$ & $\begin{array}{l}0.0198 \\
0.0209\end{array}$ & $\begin{array}{c}0.0320 \\
0.0332\end{array}$ & IFE & $\begin{array}{c}0.0046 \\
0.0046\end{array}$ & $\begin{array}{c}0.0061, \\
0.0062\end{array}$ & $\begin{array}{r}0.0094 \\
0.0095\end{array}$ \\
\hline PIFI1+2 & $\begin{array}{l}0.1778, \\
0.1782\end{array}$ & PIFI1 & $\begin{array}{l}0.0918 \\
0.0942\end{array}$ & $\begin{array}{l}0.0871 \\
0.0873\end{array}$ & PIFI1 & $\begin{array}{c}0.0223, \\
0.0209\end{array}$ & $\begin{array}{l}0.0206 \\
0.0207\end{array}$ & $\begin{array}{l}0.0118 \\
0.0123\end{array}$ & $\begin{array}{l}0.0287 \\
0.0295\end{array}$ & $\begin{array}{l}0.0177 \\
0.0179\end{array}$ & $\begin{array}{l}0.0415, \\
0.0424\end{array}$ & $\begin{array}{l}0.0298 \\
0.0301\end{array}$ & $\begin{array}{c}0.0173 \\
0.0159\end{array}$ & IFI & $\begin{array}{c}0.0325 \\
0.0330\end{array}$ & $\begin{array}{c}0.0238 \\
0.0241\end{array}$ & $\begin{array}{c}0.0060 \\
0.0059\end{array}$ \\
\hline \multirow[t]{2}{*}{ PIFI3 } & $\begin{array}{c}0.2499 \\
0.2499\end{array}$ & PIFI2 & $\dagger$ & $\dagger$ & PIFI2 & $\begin{array}{l}0.0522, \\
0.0528\end{array}$ & $\begin{array}{l}0.0715 \\
0.0744\end{array}$ & $\begin{array}{l}0.0428, \\
0.0406\end{array}$ & $\begin{array}{c}0.1527 \\
0.1555\end{array}$ & $\begin{array}{l}0.1252 \\
0.1260\end{array}$ & $\begin{array}{l}0.0662, \\
0.0672\end{array}$ & $\begin{array}{l}0.0332, \\
0.0338\end{array}$ & $\begin{array}{c}0.0282, \\
0.0280\end{array}$ & ITCR & $\begin{array}{c}0.0136 \\
0.0138\end{array}$ & $\begin{array}{c}0.0398 \\
0.0407\end{array}$ & $\begin{array}{c}0.0124, \\
0.0120\end{array}$ \\
\hline & & & & & & & & & & & & & & ITM & $\begin{array}{c}0.0067 \\
0.0069\end{array}$ & $\begin{array}{c}0.0326 \\
0.0329\end{array}$ & $\begin{array}{c}0.0046 \\
0.0043\end{array}$ \\
\hline PIT1 & $\begin{array}{c}0.0153, \\
0.0152\end{array}$ & PIT & $\begin{array}{c}0.0064 \\
0.0067\end{array}$ & $\begin{array}{l}0.0036 \\
0.0035\end{array}$ & & & & & & & & & & & & & \\
\hline FTI1 & $\begin{array}{l}0.0014 \\
0.0013\end{array}$ & FTI1 & $\begin{array}{l}0.0020 \\
0.0019\end{array}$ & $\begin{array}{l}0.0044 \\
0.0040\end{array}$ & FTI1 & $\begin{array}{l}0.0030 \\
0.0013\end{array}$ & $\begin{array}{l}0.0013 \\
0.0006\end{array}$ & $\begin{array}{c}0.0016 \\
0.0014\end{array}$ & $\begin{array}{l}0.0006 \\
0.0007\end{array}$ & $\begin{array}{l}0.0004 \\
0.0003\end{array}$ & $\begin{array}{l}0.0030 \\
0.0030\end{array}$ & $\begin{array}{c}0.0019 \\
0.0018\end{array}$ & $\begin{array}{l}0.0021, \\
0.0019\end{array}$ & & & & \\
\hline \multirow[t]{2}{*}{ FTI2 } & $\begin{array}{l}0.0021, \\
0.0020\end{array}$ & FTI3 & $\begin{array}{l}0.0054 \\
0.0054\end{array}$ & $\begin{array}{l}0.0059 \\
0.0051\end{array}$ & FTI3 & $\begin{array}{l}0.0074 \\
0.0067\end{array}$ & $\begin{array}{l}0.0043 \\
0.0036\end{array}$ & $\begin{array}{l}0.0044, \\
0.0037\end{array}$ & $\begin{array}{c}0.0016, \\
0.0015\end{array}$ & $\begin{array}{l}0.0016, \\
0.0014\end{array}$ & $\begin{array}{l}0.0022, \\
0.0024\end{array}$ & $\begin{array}{l}0.0044, \\
0.0044\end{array}$ & $\begin{array}{c}0.0045, \\
0.0043\end{array}$ & FCM & $\begin{array}{c}0.0434 \\
0.0441\end{array}$ & $\begin{array}{c}0.1360 \\
0.1366\end{array}$ & $\begin{array}{l}0.0121, \\
0.0123\end{array}$ \\
\hline & & FTI2 & $\begin{array}{l}0.0042 \\
0.0042\end{array}$ & $\begin{array}{l}0.0051 \\
0.0052\end{array}$ & & & & & & & & & & & & & \\
\hline FTE & $\dagger$ & FTE & $\begin{array}{l}0.0057 \\
0.0059\end{array}$ & $\begin{array}{l}0.0054 \\
0.0055\end{array}$ & FTE & $\begin{array}{c}0.0743 \\
0.0773\end{array}$ & $\begin{array}{l}0.0448 \\
0.0468\end{array}$ & $\begin{array}{l}0.0644, \\
0.0669\end{array}$ & $\begin{array}{l}0.0314 \\
0.0322\end{array}$ & $\begin{array}{l}0.0390 \\
0.0398\end{array}$ & $\begin{array}{l}0.0142, \\
0.0145\end{array}$ & $\begin{array}{l}0.0129 \\
0.0135\end{array}$ & $\begin{array}{c}0.0326, \\
0.0338\end{array}$ & FCLP & $\begin{array}{c}0.0151 \\
0.0146\end{array}$ & $\begin{array}{c}0.0115 \\
0.0094\end{array}$ & $\begin{array}{c}0.0139 \\
0.0141\end{array}$ \\
\hline PUT & $\begin{array}{l}0.0040, \\
0.0041\end{array}$ & & & & & & & & & & & & & & & & \\
\hline \multirow[t]{2}{*}{ ADD } & $\begin{array}{l}0.0421 \text {, } \\
0.0419\end{array}$ & ADD1 & $\begin{array}{l}0.0217 \\
0.0213\end{array}$ & $\begin{array}{l}0.0160 \\
0.0135\end{array}$ & ADD1 & $\begin{array}{c}0.0146 \\
0.0145\end{array}$ & $\begin{array}{l}0.0359 \\
0.0377\end{array}$ & $\begin{array}{l}0.0129 \\
0.0135\end{array}$ & $\begin{array}{c}0.0363 \\
0.0365\end{array}$ & $\begin{array}{l}0.0148 \\
0.0149\end{array}$ & $\begin{array}{l}0.0424, \\
0.0423\end{array}$ & $\begin{array}{c}0.0169 \\
0.0171\end{array}$ & $\begin{array}{c}0.0407, \\
0.0417\end{array}$ & PIFM & $\begin{array}{c}0.0453 \\
0.0453\end{array}$ & $\begin{array}{c}0.0724, \\
0.0712\end{array}$ & $\begin{array}{r}0.0284 \\
0.0278\end{array}$ \\
\hline & & ADD2 & 0.0387 & 0.0304 & ADD2 & 0.0106, & 0.0107, & 0.0063 , & 0.0112 & 0.0074 & 0.0178 & 0.0139 & 0.0193, & PIFL & $*$ & * & 0.0207 , \\
\hline
\end{tabular}




\begin{tabular}{|c|c|c|c|c|c|c|c|c|c|c|c|c|c|c|c|c|c|}
\hline & & & 0.0366 & 0.0293 & & 0.0081 & 0.0084 & 0.0047 & 0.0103 & 0.0059 & 0.0179 & 0.0130 & 0.0158 & & & & 0.0207 \\
\hline \multirow[t]{3}{*}{ PIFE } & $\begin{array}{c}0.3429 \\
0.3435\end{array}$ & PIFE1 & $\begin{array}{c}0.2030 \\
0.2022\end{array}$ & $\begin{array}{c}0.2651 \text {, } \\
0.2624\end{array}$ & PIFE1 & $\begin{array}{c}0.0496 \\
0.0476\end{array}$ & $\begin{array}{c}0.0654 \\
0.0602\end{array}$ & $\begin{array}{c}0.0451 \\
0.0419\end{array}$ & $\begin{array}{c}0.1222, \\
0.1195\end{array}$ & $\begin{array}{c}0.0671 \\
0.0625\end{array}$ & $\begin{array}{c}0.0909 \\
0.0875\end{array}$ & $\begin{array}{c}0.1588 \\
0.1548\end{array}$ & $\begin{array}{c}0.0598 \\
0.0571\end{array}$ & OL & $\begin{array}{c}0.0073 \\
0.0058\end{array}$ & - & $\begin{array}{r}0.0020 \\
0.0018\end{array}$ \\
\hline & & PIFE2 & $\begin{array}{c}0.1568 \\
0.1568\end{array}$ & $\begin{array}{c}0.2101, \\
0.2083\end{array}$ & PIFE2 & $\begin{array}{c}0.0729 \\
0.0716\end{array}$ & $\begin{array}{c}0.0700 \\
0.0662\end{array}$ & $\begin{array}{c}0.0572 \\
0.0551\end{array}$ & $\begin{array}{c}0.1023, \\
0.0950\end{array}$ & $\begin{array}{c}0.1072 \\
0.1060\end{array}$ & $\begin{array}{c}0.1086 \\
0.0969\end{array}$ & $\begin{array}{r}0.3070 \\
0.3003\end{array}$ & $\begin{array}{c}0.2359 \\
0.2329\end{array}$ & OM & $\begin{array}{c}0.2873 \\
0.2877\end{array}$ & $\begin{array}{c}0.2655 \\
0.2663\end{array}$ & $\begin{array}{r}0.3347 \\
0.3377\end{array}$ \\
\hline & & PIFE3 & $\begin{array}{c}0.1614 \\
0.1604\end{array}$ & $\begin{array}{c}0.1265 \\
0.1259\end{array}$ & PIFE3 & $\begin{array}{c}0.0031 \\
0.0027\end{array}$ & $\begin{array}{c}0.0224 \\
0.0227\end{array}$ & $\begin{array}{c}0.0119 \\
0.0110\end{array}$ & $\begin{array}{c}0.0301, \\
0.0304\end{array}$ & $\begin{array}{c}0.0096 \\
0.0094\end{array}$ & $\begin{array}{c}0.0271 \\
0.0279\end{array}$ & $\begin{array}{c}0.0221, \\
0.0226\end{array}$ & $\begin{array}{c}0.0380 \\
0.0392\end{array}$ & & & & \\
\hline ISTR & $\begin{array}{c}0.0647 \\
0.0647\end{array}$ & ISTR & $\begin{array}{c}0.0938 \\
0.0924\end{array}$ & $\begin{array}{c}0.0568 \\
0.0533\end{array}$ & ISTR & $\begin{array}{c}0.0095 \\
0.0101\end{array}$ & $\begin{array}{c}0.0155 \\
0.0162\end{array}$ & $\begin{array}{c}0.0060 \\
0.0063\end{array}$ & $\begin{array}{c}0.0104 \\
0.0108\end{array}$ & $\begin{array}{c}0.0062 \\
0.0063\end{array}$ & $\begin{array}{c}0.0133 \\
0.0138\end{array}$ & $\begin{array}{c}0.0091 \\
0.0094\end{array}$ & $\begin{array}{l}0.0117 \\
0.0125\end{array}$ & ISF & $\begin{array}{c}0.0248 \\
0.0232\end{array}$ & $\begin{array}{c}0.0018 \\
0.0018\end{array}$ & $\begin{array}{r}0.1841, \\
0.1858\end{array}$ \\
\hline CFB & $\begin{array}{c}0.0024 \\
0.0018\end{array}$ & CFB & $\begin{array}{c}0.0149 \\
0.0148\end{array}$ & $\begin{array}{l}0.0104, \\
0.0103\end{array}$ & CFB & $\begin{array}{c}0.1703 \text {, } \\
0.1637 \\
\end{array}$ & $\begin{array}{c}0.1719 \\
0.1676\end{array}$ & $\begin{array}{c}0.1889 \\
0.1857\end{array}$ & $\begin{array}{c}0.0578, \\
0.0569\end{array}$ & $\begin{array}{c}0.0794 \\
0.0802\end{array}$ & $\begin{array}{c}0.1115 \\
0.1125\end{array}$ & $\begin{array}{c}0.0823, \\
0.0809\end{array}$ & $\begin{array}{r}0.1408 \\
0.1378 \\
\end{array}$ & CFP & $\begin{array}{c}0.1849 \\
0.1866 \\
\end{array}$ & $\begin{array}{c}0.2025 \text {, } \\
0.2031\end{array}$ & $\begin{array}{r}0.0987 \\
0.0994 \\
\end{array}$ \\
\hline
\end{tabular}

5 Note: *, undivided; ${ }^{\dagger}$, origin located on soft tissue (not directly on pelvis). See Table 2 for muscle abbreviations. 


\section{Table 5 (on next page)}

Inferred muscle functions around the hip (h) and knee (k) joints including flexion (F), extension $(E)$, abduction $(A b)$, adduction $(A d)$, lateral rotation $(L)$, and medial rotation (M).

Functions are averaged for each muscle and are derived from previous studies cited in the main text. Numbered columns correspond to taxa in Fig. 1: 1, Varanus; 2, Alligator; 3 , Caiman; 4, Allosaurus; 5, Albertosaurus; 6, Ornithomimidae indet.; 7, Falcarius; 8 , Caenagnathidae indet.; 9, Saurornitholestes; 10, Sinovenator; 11, derived Troodontidae indet.; 12, Struthio; 13, Dromaius; 14 , Gallus. Note: *, undivided; ${ }^{\dagger}$, origin located on soft tissue (not directly on pelvis). See Table 2 for muscle abbreviations. 
1 Table 5. Inferred muscle functions around the hip (h) and knee (k) joints including flexion (F), extension (E), abduction (Ab),

2 adduction $(\mathrm{Ad})$, lateral rotation $(\mathrm{L})$, and medial rotation $(\mathrm{M})$. Functions are averaged for each muscle and are derived from previous

3 studies cited in the main text. Numbered columns correspond to taxa in Fig. 1: 1, Varanus; 2, Alligator; 3, Caiman; 4, Allosaurus; 5,

4 Albertosaurus; 6, Ornithomimidae indet.; 7, Falcarius; 8, Caenagnathidae indet.; 9, Saurornitholestes; 10, Sinovenator; 11, derived

5 Troodontidae indet.; 12, Struthio; 13, Dromaius; 14, Gallus.

\begin{tabular}{|c|c|c|c|c|c|c|c|c|c|c|c|c|}
\hline Muscle & 1 & & $2-3$ & & 4 & 5 & $6-8$ & 9-11 & & 12 & 13 & 14 \\
\hline \multirow[t]{3}{*}{ IT } & $\mathrm{hE}, \mathrm{Ab} ; \mathrm{kE}$ & IT1 & $\mathrm{hF}, \mathrm{Ab} ; \mathrm{kE}$ & IT1 & $\begin{array}{c}\mathrm{hF}, \mathrm{Ab}, \mathrm{M} ; \\
\mathrm{kE}\end{array}$ & $\begin{array}{c}\mathrm{hF}, \mathrm{Ab}, \mathrm{M} ; \\
\mathrm{kE}\end{array}$ & $\begin{array}{c}\mathrm{hF}, \mathrm{Ab}, \mathrm{M} ; \\
\mathrm{kE}\end{array}$ & $\begin{array}{c}\mathrm{hF}, \mathrm{Ab}, \mathrm{M} ; \\
\mathrm{kE}\end{array}$ & IC & $\begin{array}{c}\mathrm{hF}, \mathrm{Ad}, \mathrm{M}, \\
\mathrm{kF} / \mathrm{E}\end{array}$ & $\begin{array}{c}\mathrm{hF}, \mathrm{Ad}, \mathrm{M}, \\
\mathrm{kF} / \mathrm{E}\end{array}$ & $\mathrm{hF} ; \mathrm{kE}$ \\
\hline & & IT2 & $\begin{array}{l}\mathrm{hF} / \mathrm{E}, \mathrm{Ab} \\
\mathrm{kE}\end{array}$ & IT2 & $\begin{array}{c}\mathrm{hF} / \mathrm{E}, \mathrm{Ab} \\
\mathrm{M} / \mathrm{L} ; \mathrm{kE}\end{array}$ & $\begin{array}{c}\mathrm{hF} / \mathrm{E}, \mathrm{Ab} \\
\mathrm{M} / \mathrm{L} ; \mathrm{kE}\end{array}$ & $\begin{array}{c}\mathrm{hF} / \mathrm{E}, \mathrm{Ab} \\
\mathrm{M} / \mathrm{L} ; \mathrm{kE}\end{array}$ & $\begin{array}{c}\mathrm{hF} / \mathrm{E}, \mathrm{Ab} \\
\mathrm{M} / \mathrm{L} ; \mathrm{kE}\end{array}$ & IL & $\begin{array}{c}\mathrm{hF} / \mathrm{E}, \mathrm{Ab} \\
\mathrm{M} / \mathrm{L} ; \mathrm{kE}\end{array}$ & $\begin{array}{l}\mathrm{hE}, \mathrm{Ab} \\
\mathrm{M} / \mathrm{L} ; \mathrm{kE}\end{array}$ & $\begin{array}{c}\mathrm{hF} / \mathrm{E}, \mathrm{Ab} ; \\
\mathrm{kE}\end{array}$ \\
\hline & & IT3 & $\begin{array}{c}\mathrm{hE}, \mathrm{Ab}, \mathrm{L} \\
\mathrm{kE}\end{array}$ & IT3 & $\begin{array}{c}\mathrm{hE}, \mathrm{Ab}, \mathrm{L} \\
\mathrm{kE}\end{array}$ & $\begin{array}{c}\mathrm{hE}, \mathrm{Ab}, \mathrm{L} \\
\mathrm{kE}\end{array}$ & $\begin{array}{c}\mathrm{hE}, \mathrm{Ab}, \mathrm{L} ; \\
\mathrm{kE}\end{array}$ & $\begin{array}{c}\mathrm{hE}, \mathrm{Ab}, \mathrm{L} \\
\mathrm{kE}\end{array}$ & & & & \\
\hline \multirow[t]{2}{*}{ AMB } & $\mathrm{kE}$ & AMB1 & $\mathrm{hF} / \mathrm{E}, \mathrm{M} ; \mathrm{kE}$ & AMB & $\mathrm{hF} / \mathrm{E}, \mathrm{M} ; \mathrm{kE}$ & $\mathrm{hF} / \mathrm{E}, \mathrm{M} ; \mathrm{kE}$ & $\mathrm{hF} / \mathrm{E}, \mathrm{M} ; \mathrm{kE}$ & $\mathrm{hF} / \mathrm{E}, \mathrm{M} ; \mathrm{kE}$ & AMB1 & $\begin{array}{l}\mathrm{hF} / \mathrm{E}, \mathrm{Ad}, \\
\mathrm{L} ; \mathrm{kF}\end{array}$ & hAd, M; kF & $\mathrm{hF}, \mathrm{Ad} ; \mathrm{kE}$ \\
\hline & & AMB2 & $\mathrm{hF} / \mathrm{E}, \mathrm{M} ; \mathrm{kE}$ & & & & & & AMB2 & $\begin{array}{l}\mathrm{hF}, \mathrm{Ad} \\
\mathrm{M} / \mathrm{L} ; \mathrm{kE}\end{array}$ & $*$ & $*$ \\
\hline ILFB & $\mathrm{hE}, \mathrm{Ab} ; \mathrm{kF}$ & ILFB & $\begin{array}{c}\mathrm{hE}, \mathrm{Ab}, \mathrm{L} ; \\
\mathrm{kF}\end{array}$ & ILFB & $\begin{array}{l}\mathrm{hE}, \mathrm{Ab}, \mathrm{L} ; \\
\mathrm{kF}\end{array}$ & $\begin{array}{l}\mathrm{hE}, \mathrm{Ab}, \mathrm{L} ; \\
\mathrm{kF}\end{array}$ & $\begin{array}{c}\mathrm{hE}, \mathrm{Ab}, \mathrm{L} ; \\
\mathrm{kF}\end{array}$ & $\begin{array}{c}\mathrm{hE}, \mathrm{Ab}, \mathrm{L} \\
\mathrm{kF}\end{array}$ & ILFB & $\begin{array}{c}\mathrm{hE}, \mathrm{Ab}, \mathrm{M} ; \\
\mathrm{kF}\end{array}$ & $\mathrm{hE}, \mathrm{Ab} ; \mathrm{kF}$ & $\mathrm{hE}, \mathrm{Ab} ; \mathrm{kF}$ \\
\hline \multirow[t]{2}{*}{ IF } & $\mathrm{hE}, \mathrm{Ab}$ & IF & $\mathrm{hF} / \mathrm{E}, \mathrm{Ab}, \mathrm{L}$ & ITC & $\mathrm{hF}, \mathrm{Ab}, \mathrm{M}$ & $\mathrm{hF}, \mathrm{Ab}, \mathrm{M}$ & $\mathrm{hF}, \mathrm{Ab}, \mathrm{M}$ & $\begin{array}{c}\mathrm{hF} / \mathrm{E}, \mathrm{Ab} \\
\mathrm{M}\end{array}$ & ITC & $\begin{array}{c}\mathrm{hF} / \mathrm{E}, \\
\mathrm{Ab} / \mathrm{Ad}, \mathrm{M}\end{array}$ & $\begin{array}{c}\mathrm{hF}, \mathrm{Ab} / \mathrm{Ad} \\
\mathrm{M}\end{array}$ & $\mathrm{hF}, \mathrm{Ab}, \mathrm{M}$ \\
\hline & & & & IFE & $\mathrm{hF} / \mathrm{E}, \mathrm{Ab}, \mathrm{L}$ & $\mathrm{hF} / \mathrm{E}, \mathrm{Ab}, \mathrm{L}$ & $\mathrm{hF} / \mathrm{E}, \mathrm{Ab}, \mathrm{L}$ & $\mathrm{hF} / \mathrm{E}, \mathrm{Ab}, \mathrm{L}$ & IFE & $\begin{array}{c}\mathrm{hF}, \mathrm{Ab} \\
\mathrm{M} / \mathrm{L}\end{array}$ & $\begin{array}{c}\mathrm{hF}, \mathrm{Ab} \\
\mathrm{M} / \mathrm{L}\end{array}$ & $\mathrm{hF}, \mathrm{Ab}$ \\
\hline PIFI1+2 & $\mathrm{hF}, \mathrm{Ab}, \mathrm{M}$ & PIFI1 & $\mathrm{hF}, \mathrm{Ad}$ & PIFI1 & $\mathrm{hF}, \mathrm{Ab}, \mathrm{M}$ & $\mathrm{hF}, \mathrm{Ab}, \mathrm{M}$ & $\mathrm{hF}, \mathrm{Ab}, \mathrm{M}$ & $\mathrm{hF}, \mathrm{Ab}, \mathrm{M}$ & IFI & $\begin{array}{c}\mathrm{hF}, \mathrm{Ad} \\
\mathrm{M} / \mathrm{L}\end{array}$ & $\begin{array}{l}\mathrm{hF}, \mathrm{Ad}, \\
\mathrm{M} / \mathrm{L}\end{array}$ & $\mathrm{hF}, \mathrm{Ad}$ \\
\hline \multirow[t]{2}{*}{ PIFI3 } & $\mathrm{hF}, \mathrm{L}$ & PIFI2 & $\dagger$ & PIFI2 & $\mathrm{hF}, \mathrm{Ab}, \mathrm{M}$ & $\mathrm{hF}, \mathrm{Ab}, \mathrm{M}$ & $\mathrm{hF}, \mathrm{Ab}, \mathrm{M}$ & $\begin{array}{c}\mathrm{hF} / \mathrm{E}, \mathrm{Ab}, \\
\mathrm{M}\end{array}$ & ITCR & $\begin{array}{c}\mathrm{hF} / \mathrm{E} \\
\mathrm{Ab} / \mathrm{Ad}, \mathrm{M}\end{array}$ & $\begin{array}{c}\mathrm{hF}, \mathrm{Ab} / \mathrm{Ad} \\
\mathrm{M}\end{array}$ & $\mathrm{hF}, \mathrm{M}$ \\
\hline & & & & & & & & & ITM & $\begin{array}{c}\mathrm{hF} / \mathrm{E} \\
\mathrm{Ab} / \mathrm{Ad}, \mathrm{M}\end{array}$ & $\begin{array}{c}\mathrm{hF}, \mathrm{Ab} / \mathrm{Ad} \\
\mathrm{M}\end{array}$ & $\mathrm{hF}, \mathrm{Ab}, \mathrm{M}$ \\
\hline PIT1 & $\mathrm{hF}, \mathrm{Ad} ; \mathrm{kF}$ & PIT & $\begin{array}{l}\mathrm{hE}, \mathrm{Ad}, \\
\mathrm{M} / \mathrm{L} ; \mathrm{kF}\end{array}$ & & & & & & & & & \\
\hline FTI1 & $\mathrm{hE}, \mathrm{Ad} ; \mathrm{kF}$ & FTI1 & $\begin{array}{l}\mathrm{hE}, \mathrm{Ad}, \\
\mathrm{M} / \mathrm{L} ; \mathrm{kF}\end{array}$ & FTI1 & $\begin{array}{l}\mathrm{hE}, \mathrm{Ad}, \\
\mathrm{M} / \mathrm{L} ; \mathrm{kF}\end{array}$ & $\begin{array}{l}\mathrm{hE}, \mathrm{Ad}, \\
\mathrm{M} / \mathrm{L} ; \mathrm{kF}\end{array}$ & $\mathrm{hE}, \mathrm{M} / \mathrm{L} ; \mathrm{kF}$ & $\mathrm{hE}, \mathrm{M} / \mathrm{L} ; \mathrm{kF}$ & & & & \\
\hline \multirow[t]{2}{*}{ FTI2 } & $\mathrm{hE}, \mathrm{Ad} ; \mathrm{kF}$ & FTI3 & $\mathrm{hE}, \mathrm{Ad} ; \mathrm{kF}$ & FTI3 & $\mathrm{hE} ; \mathrm{kF}$ & $\mathrm{hE} ; \mathrm{kF}$ & $\mathrm{hE}, \mathrm{Ad} ; \mathrm{kF}$ & $\mathrm{hE}, \mathrm{Ad} ; \mathrm{kF}$ & FCM & $\begin{array}{c}\mathrm{hE}, \mathrm{Ab}, \mathrm{M} ; \\
\mathrm{kF}\end{array}$ & $\begin{array}{c}\mathrm{hE}, \mathrm{Ab}, \mathrm{M} ; \\
\mathrm{kF}\end{array}$ & $\mathrm{hE}, \mathrm{Ab} ; \mathrm{kF}$ \\
\hline & & FTI2 & ? & & & & & & & & & \\
\hline FTE & $\dagger$ & FTE & $\begin{array}{l}\mathrm{hE}, \mathrm{Ab}, \mathrm{L} ; \\
\mathrm{kF}\end{array}$ & FTE & $\mathrm{hE}, \mathrm{Ab} ; \mathrm{kF}$ & $\mathrm{hE}, \mathrm{Ab} ; \mathrm{kF}$ & $\mathrm{hE}, \mathrm{Ab} ; \mathrm{kF}$ & $\mathrm{hE}, \mathrm{Ab} ; \mathrm{kF}$ & FCLP & $\begin{array}{c}\mathrm{hE}, \mathrm{Ab}, \mathrm{M} ; \\
\mathrm{kF}\end{array}$ & $\begin{array}{c}\mathrm{hE}, \mathrm{Ab}, \mathrm{M} ; \\
\mathrm{kF}\end{array}$ & $\mathrm{hE}, \mathrm{Ab} ; \mathrm{kF}$ \\
\hline PUT & $\mathrm{hF}, \mathrm{Ad} ; \mathrm{kF}$ & & & & & & & & & & & \\
\hline ADD & $\mathrm{hF}, \mathrm{Ad}$ & ADD1 & $\begin{array}{c}\mathrm{hF} / \mathrm{E}, \mathrm{Ad}, \\
\mathrm{M} / \mathrm{L}\end{array}$ & ADD1 & $\mathrm{hF} / \mathrm{E}, \mathrm{Ad}, \mathrm{L}$ & $\mathrm{hF} / \mathrm{E}, \mathrm{Ad}, \mathrm{L}$ & $\mathrm{hF} / \mathrm{E}, \mathrm{Ad}, \mathrm{L}$ & $\mathrm{hE}, \mathrm{Ad}, \mathrm{L}$ & PIFM & $\mathrm{hE}, \mathrm{Ab}, \mathrm{L}$ & $\mathrm{hE}, \mathrm{Ab}, \mathrm{L}$ & $\mathrm{hE}$ \\
\hline
\end{tabular}




\begin{tabular}{|c|c|c|c|c|c|c|c|c|c|c|c|c|}
\hline \multirow{4}{*}{ PIFE } & & ADD2 & hE, Ad, L & ADD2 & $\mathrm{hF} / \mathrm{E}, \mathrm{Ad}, \mathrm{L}$ & $\mathrm{hE}, \mathrm{Ad}, \mathrm{L}$ & $\mathrm{hE}, \mathrm{Ad}, \mathrm{L}$ & $\mathrm{hE}, \mathrm{Ad}, \mathrm{L}$ & PIFL & * & * & $\mathrm{hE}$ \\
\hline & $\mathrm{hF} / \mathrm{E}, \mathrm{Ad}, \mathrm{L}$ & PIFE1 & $\mathrm{hF}, \mathrm{Ad}, \mathrm{M}$ & PIFE1 & $\mathrm{hF}, \mathrm{Ad}, \mathrm{M}$ & $\mathrm{hF}, \mathrm{Ad}, \mathrm{M}$ & $\mathrm{hF}, \mathrm{Ad}, \mathrm{M}$ & $\mathrm{hF}, \mathrm{Ad}, \mathrm{M}$ & OL & $\mathrm{hF}, \mathrm{Ad}$ & - & $\mathrm{hF}, \mathrm{Ad}, \mathrm{L}$ \\
\hline & & PIFE2 & $\mathrm{hF}, \mathrm{Ad}, \mathrm{M}$ & PIFE2 & $\mathrm{hF}, \mathrm{Ad}, \mathrm{M}$ & $\mathrm{hF}, \mathrm{Ad}, \mathrm{M}$ & $\mathrm{hF}, \mathrm{Ad}, \mathrm{M}$ & $\mathrm{hF}, \mathrm{Ad}, \mathrm{M}$ & OM & $\begin{array}{c}\mathrm{hF}, \mathrm{Ab} / \mathrm{Ad}, \\
\mathrm{L}\end{array}$ & $\mathrm{hF}, \mathrm{Ad}, \mathrm{L}$ & $\mathrm{hF}, \mathrm{Ad}, \mathrm{L}$ \\
\hline & & PIFE3 & $\mathrm{hF}, \mathrm{Ad}, \mathrm{L}$ & PIFE3 & $\mathrm{hF} / \mathrm{E}, \mathrm{Ad}, \mathrm{L}$ & $\mathrm{hF} / \mathrm{E}, \mathrm{Ad}, \mathrm{L}$ & $\mathrm{hF} / \mathrm{E}, \mathrm{Ad}, \mathrm{L}$ & $\mathrm{hF} / \mathrm{E}, \mathrm{Ad}, \mathrm{L}$ & & & & \\
\hline ISTR & $\mathrm{hE}, \mathrm{L}$ & ISTR & $\mathrm{hF} / \mathrm{E}, \mathrm{Ad}, \mathrm{L}$ & ISTR & $\mathrm{hE}, \mathrm{Ad}, \mathrm{L}$ & $\mathrm{hE}, \mathrm{Ad}, \mathrm{L}$ & $\mathrm{hE}, \mathrm{Ad}, \mathrm{L}$ & $\mathrm{hE}, \mathrm{Ad}, \mathrm{L}$ & ISF & $\mathrm{hF} / \mathrm{E}, \mathrm{Ab}, \mathrm{L}$ & $\mathrm{hF} / \mathrm{E}, \mathrm{Ab}, \mathrm{L}$ & $\mathrm{hE}, \mathrm{L}$ \\
\hline CFB & $\mathrm{hE}, \mathrm{M}$ & CFB & $\mathrm{hE}, \mathrm{M}$ & CFB & $\mathrm{hE}, \mathrm{L}$ & $\mathrm{hE}, \mathrm{L}$ & $\mathrm{hE}, \mathrm{L}$ & $\mathrm{hE}, \mathrm{L}$ & CFP & $\mathrm{hE}, \mathrm{Ab}, \mathrm{L}$ & $\mathrm{hE}, \mathrm{Ab}, \mathrm{L}$ & $\mathrm{hE}$ \\
\hline
\end{tabular}

6 Note: *, undivided; ${ }^{\dagger}$, origin located on soft tissue (not directly on pelvis). See Table 2 for muscle abbreviations. 


\section{Table 6(on next page)}

Summary statistics of pelvic muscle origin areas $\left(\mathrm{cm}^{2}\right)$ using two-sample t-tests assuming equal variances.

Note: df, degrees of freedom; $\bar{x}$, mean. 
1 Table 6. Summary statistics of pelvic muscle origin areas $\left(\mathrm{cm}^{2}\right)$ using two-sample t-tests

2 assuming equal variances.

\begin{tabular}{llllll}
\hline Group & $\overline{\mathbf{x}_{\text {Corel DRAW! }}}$ & $\overline{\mathbf{x}_{\text {ImageJ }}}$ & t-value & df & p-value \\
\hline Varanus & 4.9973 & 4.9438 & 0.0189 & 26 & 0.9850 \\
Alligator & 2.7228 & 2.6557 & 0.0639 & 38 & 0.9494 \\
Caiman & 0.6387 & 0.6336 & 0.0174 & 36 & 0.9862 \\
Allosaurus & 77.2704 & 74.0573 & 0.1251 & 36 & 0.9012 \\
Albertosaurus & 102.7679 & 98.5962 & 0.1255 & 36 & 0.9008 \\
Ornithomimdae indet. & 45.8149 & 44.6682 & 0.0608 & 36 & 0.9519 \\
Falcarius & 16.6367 & 16.4014 & 0.0389 & 36 & 0.9692 \\
Caenagnathidae indet. & 15.5269 & 15.5830 & -0.0080 & 36 & 0.9937 \\
Saurornitholestes & 4.8390 & 4.7338 & 0.0550 & 36 & 0.9564 \\
Sinovenator & 1.0289 & 0.9859 & 0.0875 & 36 & 0.9307 \\
Troodontidae indet. & 23.9485 & 23.7018 & 0.0263 & 36 & 0.9792 \\
Struthio & 44.9839 & 43.6965 & 0.0624 & 32 & 0.9506 \\
Dromaius & 29.6983 & 29.2182 & 0.0370 & 28 & 0.9708 \\
Gallus & 1.5825 & 1.5876 & -0.0059 & 32 & 0.9953 \\
All taxa & 26.9389 & 26.1350 & 0.1723 & 506 & 0.8633 \\
\hline
\end{tabular}

3 Note: df, degrees of freedom; $\bar{x}$, mean. 


\section{Table 7 (on next page)}

Measurements of select pelvic elements, hip musculature, and limb elements or other sources used for body mass estimates (given to 1 significant digit).

Note: *underestimated because the anterior portion of ilium is broken; ${ }^{\dagger}$ body mass doubled based on hip size (subjective estimate); ${ }^{\ddagger}$ species mean chosen to match sex of specimen (ilium). 
1 Table 7. Measurements of select pelvic elements, hip musculature, and limb elements or other sources used for body mass estimates

2 (given to 1 significant digit).

\begin{tabular}{|c|c|c|c|c|c|c|c|c|}
\hline Taxon & $\begin{array}{l}\text { Specimen } \\
\text { (ilium) }\end{array}$ & $\begin{array}{l}\text { Length of ilium, } \\
\text { anteroposterior } \\
(\mathrm{cm})\end{array}$ & $\begin{array}{l}\text { Area of } \\
\text { all } \\
\text { pelvic } \\
\text { muscles } \\
\left(\mathrm{cm}^{2}\right)\end{array}$ & $\begin{array}{l}\text { Area of } \\
\text { major } \\
\text { extensors } \\
\left(\mathrm{cm}^{2}\right)\end{array}$ & $\begin{array}{l}\text { Specimen } \\
\text { (femur, if not } \\
\text { same as ilium) }\end{array}$ & $\begin{array}{l}\text { Data } \\
\text { source }\end{array}$ & $\begin{array}{l}\text { Body } \\
\text { mass } \\
\text { estimate } \\
(\mathrm{kg})\end{array}$ & $\begin{array}{l}\text { Range } \\
( \pm 25 \%)\end{array}$ \\
\hline Varanus & ROM R7565 & 9.8 & 70.0 & 4.0 & - & $\begin{array}{l}\text { Specimen } \\
\text { card }\end{array}$ & 45.0 & $\mathrm{n} / \mathrm{a}$ \\
\hline Alligator & ROM R343 & 9.0 & 54.5 & 6.8 & - & $\begin{array}{l}\text { Calculated } \\
\text { by ilium } \\
\text { length } \\
\text { (Dodson, } \\
1975 \text { ) }\end{array}$ & 43.8 & $\begin{array}{l}32.8- \\
54.7\end{array}$ \\
\hline Caiman & ROM (no \#) & 6.1 & 12.1 & 1.0 & - & $\begin{array}{l}\text { Calculated } \\
\text { by ilium } \\
\text { length } \\
\text { (Dodson, } \\
\text { 1975) }\end{array}$ & 13.4 & $\begin{array}{l}10.1- \\
16.8\end{array}$ \\
\hline Allosaurus & CMN 38454 & 54.8 & 1468.1 & 776.1 & MOR 693 & $\begin{array}{l}\text { Bates et } \\
\text { al., } 2009\end{array}$ & 1083.7 & $\begin{array}{l}812.8- \\
1354.7\end{array}$ \\
\hline Albertosaurus & CMN 11315 & 67.5 & 1952.6 & 910.6 & - & $\begin{array}{l}\text { Pers. obs. } \\
\text { (PJC) }\end{array}$ & 1561.5 & $\begin{array}{l}1171.1- \\
1951.9\end{array}$ \\
\hline $\begin{array}{l}\text { Ornithomimdae } \\
\text { indet. }\end{array}$ & $\begin{array}{l}\text { TMP } \\
1981.022 .0025\end{array}$ & 47.8 & 870.5 & 433.2 & ROM 852 & $\begin{array}{l}\text { Campione } \\
\text { \& Evans, } \\
2020\end{array}$ & 130.5 & $\begin{array}{l}97.9- \\
163.1\end{array}$ \\
\hline Falcarius & CEUM 77189 & 28.1 & 316.1 & 76.2 & $\begin{array}{l}\text { UMNH VP } \\
12361\end{array}$ & $\begin{array}{l}\text { Campione } \\
\text { \& Evans, } \\
2020\end{array}$ & 86.9 & $\begin{array}{l}65.2- \\
108.6\end{array}$ \\
\hline $\begin{array}{l}\text { Caenagnathidae } \\
\text { indet. }\end{array}$ & $\begin{array}{l}\text { TMP } \\
1979.020 .0001\end{array}$ & $25.5^{*}$ & 295.0 & 85.9 & - & $\begin{array}{l}\text { Funston, } \\
2020\end{array}$ & 66.8 & $\begin{array}{l}50.1- \\
83.5\end{array}$ \\
\hline
\end{tabular}




\begin{tabular}{|c|c|c|c|c|c|c|c|c|}
\hline Saurornitholestes & UALVP 55700 & 19.2 & 91.9 & 26.4 & $\begin{array}{l}\text { TMP } \\
1988.121 .0039\end{array}$ & $\begin{array}{l}\text { Campione } \\
\text { \& Evans, } \\
2020\end{array}$ & 18.7 & $\begin{array}{l}14.0- \\
23.4\end{array}$ \\
\hline Sinovenator & $\begin{array}{l}\text { IVPP } \\
\text { V12583/V12615 }\end{array}$ & 6.9 & 19.5 & 4.1 & IVPP V12615 & $\begin{array}{l}\text { Pers. obs. } \\
\text { (PJC) }\end{array}$ & 1.5 & $1.1-1.8$ \\
\hline $\begin{array}{l}\text { Troodontidae } \\
\text { indet. }\end{array}$ & UALVP 55804 & 30.3 & 455.0 & 163.1 & CMN 12340 & $\begin{array}{l}\text { Benson et } \\
\text { al., } 2014\end{array}$ & $119.5^{\dagger}$ & $\begin{array}{l}89.6- \\
149.3\end{array}$ \\
\hline Struthio & UAMZ 7159 & 62.7 & 764.7 & 368.4 & - & $\begin{array}{l}\text { Olson \& } \\
\text { Turvey, } \\
2013\end{array}$ & $115.0^{\ddagger}$ & $\begin{array}{l}86.3- \\
143.8\end{array}$ \\
\hline Dromaius & $\begin{array}{l}\text { UAMZ B- } \\
\text { FIC2014.260 }\end{array}$ & 46.4 & 445.5 & 219.4 & - & $\begin{array}{l}\text { Olson \& } \\
\text { Turvey, } \\
2013\end{array}$ & 36.9 & $\begin{array}{l}27.7- \\
46.1\end{array}$ \\
\hline Gallus & RM 8355 & 10.0 & 26.9 & 5.3 & - & $\begin{array}{l}\text { Allen et } \\
\text { al., } 2013\end{array}$ & 2.6 & $2.0-3.3$ \\
\hline
\end{tabular}

3 Note: *underestimated because the anterior portion of ilium is broken; †body mass doubled based on hip size (subjective estimate);

4 species mean chosen to match sex of specimen (ilium). 


\section{Table 8(on next page)}

Summary of Phylogenetic Generalized Least Squares (PGLS) regressions.

Study taxa are grouped according to the dependent variable (y) tested against body mass $(x)$, both of which were log-transformed before analysis. Because the linear regression equations can be expressed as $y=b x^{k}$, the slope $(k)$ can be directly compared to scaling factors, which state that area increases as (body mass) (2/3 $^{2 / n}$ length increases as (body mass) $)^{1 / 3}$. Note: $b$, intercept; $k$, slope; $n$, sample size; $R^{2}$, multiple $R$-squared value; $R^{2}{ }_{\text {adj' }}$ adjusted R-squared value. 
1 Table 8. Summary of Phylogenetic Generalized Least Squares (PGLS) regressions. Study taxa

2 are grouped according to the dependent variable (y) tested against body mass (x), both of which

3 were log-transformed before analysis. Because the linear regression equations can be expressed

4 as $\mathrm{y}=\mathrm{bx}^{\mathrm{k}}$, the slope $(\mathrm{k})$ can be directly compared to scaling factors, which state that area

5 increases as (body mass) $)^{2 / 3}$ and length increases as (body mass) $)^{1 / 3}$.

\begin{tabular}{|c|c|c|c|c|c|c|}
\hline Dependent variable & $\mathbf{n}$ & $\mathbf{R}^{2}$ & $\mathbf{R}_{\text {adj }}^{2}$ & $\mathbf{k}$ & $\mathbf{b}$ & p-value \\
\hline \multicolumn{7}{|l|}{ All hip muscles $\left(\mathrm{cm}^{2}\right)$} \\
\hline Non-theropod Sauria & 3 & 0.9919 & 0.9838 & 1.3166 & -0.3549 & 0.0574 \\
\hline Non-maniraptoran Theropoda & 3 & 0.9541 & 0.9083 & 0.3120 & 2.2460 & 0.1374 \\
\hline Non-avian Maniraptora & 5 & 0.9939 & 0.9919 & 0.7200 & 1.1132 & 0.0002 \\
\hline Aves & 3 & 0.9673 & 0.9345 & 0.8907 & 1.0964 & 0.1158 \\
\hline Non-avian Theropoda & 8 & 0.9378 & 0.9275 & 0.6739 & 1.1650 & $7.6860 \times 10^{-5}$ \\
\hline All bipeds & 11 & 0.9294 & 0.9215 & 0.7241 & 1.0187 & $1.7650 \times 10^{-6}$ \\
\hline All taxa & 14 & 0.9165 & 0.9095 & 0.8083 & 0.5138 & $7.9320 \times 10^{-8}$ \\
\hline \multicolumn{7}{|l|}{ Major extensors $\left(\mathrm{cm}^{2}\right)$} \\
\hline Non-theropod Sauria & 3 & 0.9533 & 0.9067 & 1.4593 & -1.7517 & 0.1386 \\
\hline Non-maniraptoran Theropoda & 3 & 0.9951 & 0.9901 & 0.2952 & 2.0020 & 0.0448 \\
\hline Non-avian Maniraptora & 5 & 0.9918 & 0.9891 & 0.8290 & 0.3274 & 0.0003 \\
\hline Aves & 3 & 0.9475 & 0.8950 & 1.1295 & 0.3170 & 0.1471 \\
\hline Non-avian Theropoda & 8 & 0.9022 & 0.8859 & 0.7878 & 0.5231 & 0.0003 \\
\hline All bipeds & 11 & 0.8897 & 0.8775 & 0.8679 & 0.2893 & $1.3310 \times 10^{-5}$ \\
\hline All taxa & 14 & 0.8611 & 0.8495 & 1.0258 & -0.9182 & $1.7270 \times 10^{-6}$ \\
\hline \multicolumn{7}{|l|}{ Ilium length $(\mathrm{cm})$} \\
\hline Non-theropod Sauria & 3 & 0.9854 & 0.9709 & 0.3455 & 0.4118 & 0.0770 \\
\hline Non-maniraptoran Theropoda & 3 & 0.7912 & 0.5825 & 0.1262 & 1.3804 & 0.3021 \\
\hline Non-avian Maniraptora & 5 & 0.9903 & 0.9870 & 0.3326 & 0.8077 & 0.0004 \\
\hline Aves & 3 & 0.9684 & 0.9368 & 0.4884 & 0.8168 & 0.1137 \\
\hline Non-avian Theropoda & 8 & 0.9166 & 0.9028 & 0.3108 & 0.8284 & 0.0002 \\
\hline All bipeds & 11 & 0.8753 & 0.8615 & 0.3498 & 0.7148 & $2.3300 \times 10^{-5}$ \\
\hline All taxa & 14 & 0.8779 & 0.8677 & 0.3898 & 0.3871 & $7.9110 \times 10^{-7}$ \\
\hline
\end{tabular}

6 Note: $b$, intercept; $k$, slope; $n$, sample size; $\mathrm{R}^{2}$, multiple R-squared value; $\mathrm{R}_{\text {adj, }}^{2}$ adjusted R-

7 squared value. 


\section{Table 9 (on next page)}

Phylogenetically corrected residual outputs from select Phylogenetic Generalized Least Squares (PGLS) regressions (Table 8).

Study taxa are grouped according to the dependent variable (y) tested against body mass $(x)$, both of which were log-transformed before analysis. Residuals were calculated as percentages of fitted values to adjust for body mass. 
1 Table 9. Phylogenetically corrected residual outputs from select Phylogenetic Generalized Least

2 Squares (PGLS) regressions (Table 8). Study taxa are grouped according to the dependent

3 variable (y) tested against body mass (x), both of which were log-transformed before analysis.

4 Residuals were calculated as percentages of fitted values to adjust for body mass.

\begin{tabular}{|c|c|c|c|c|c|c|}
\hline \multirow[t]{2}{*}{ Dependent variable } & \multicolumn{3}{|c|}{ Non-avian Theropoda } & \multicolumn{3}{|c|}{ All bipeds } \\
\hline & $\begin{array}{l}\text { Fitted } \\
\text { value }\end{array}$ & Residual & $\begin{array}{l}\text { Percentage } \\
\text { of fitted } \\
\text { value }(\%)\end{array}$ & $\begin{array}{l}\text { Fitted } \\
\text { value }\end{array}$ & Residual & $\begin{array}{l}\text { Percentage } \\
\text { of fitted } \\
\text { value }(\%)\end{array}$ \\
\hline \multicolumn{7}{|l|}{$\begin{array}{l}\text { All hip muscles } \\
\left(\mathrm{cm}^{2}\right)\end{array}$} \\
\hline Allosaurus & 3.2104 & 0.0281 & 0.8754 & 3.2162 & -0.0495 & -1.5384 \\
\hline Albertosaurus & 3.3173 & 0.0562 & 1.6945 & 3.3311 & 0.0765 & 2.2952 \\
\hline $\begin{array}{l}\text { Ornithomimidae } \\
\text { indet. }\end{array}$ & 2.5908 & 0.2015 & 7.7793 & 2.5506 & -0.2244 & -8.7994 \\
\hline Falcarius & 2.4718 & 0.0191 & 0.7732 & 2.4227 & -0.1377 & -5.6844 \\
\hline $\begin{array}{l}\text { Caenagnathidae } \\
\text { indet. }\end{array}$ & 2.3949 & -0.0103 & -0.4319 & 2.3402 & -0.05 & -2.1354 \\
\hline Saurornitholestes & 2.0225 & -0.1811 & -8.9553 & 1.94 & 0.1431 & 7.377 \\
\hline Sinovenator & 1.2775 & 0.0149 & 1.1652 & 1.1396 & -0.0443 & -3.891 \\
\hline $\begin{array}{l}\text { Troodontidae } \\
\text { indet. }\end{array}$ & 2.5649 & 0.0267 & 1.0397 & 2.5228 & 0.1723 & 6.8289 \\
\hline Struthio & & & & 2.5108 & 0.075 & 2.9879 \\
\hline Dromaius & & & & 2.1534 & 0.0083 & 0.3858 \\
\hline Gallus & & & & 1.3192 & 0.0663 & 5.024 \\
\hline \multicolumn{7}{|l|}{$\begin{array}{l}\text { Major extensors } \\
\left(\mathrm{cm}^{2}\right)\end{array}$} \\
\hline Allosaurus & 2.9139 & 0.0269 & 0.9234 & 2.9232 & -0.0333 & -1.1402 \\
\hline Albertosaurus & 3.0388 & 0.0688 & 2.264 & 3.0609 & 0.0563 & 1.8405 \\
\hline $\begin{array}{l}\text { Ornithomimidae } \\
\text { indet. }\end{array}$ & 2.1897 & 0.2986 & 13.6363 & 2.1254 & -0.3035 & -14.2809 \\
\hline Falcarius & 2.0506 & -0.0712 & -3.4704 & 1.9721 & -0.2135 & -10.8262 \\
\hline $\begin{array}{l}\text { Caenagnathidae } \\
\text { indet. }\end{array}$ & 1.9608 & -0.0532 & -2.7132 & 1.8732 & -0.0898 & -4.7928 \\
\hline Saurornitholestes & 1.5254 & -0.2659 & -17.4295 & 1.3936 & 0.2458 & 17.6412 \\
\hline Sinovenator & 0.6546 & 0.0221 & 3.3736 & 0.4342 & -0.1022 & -23.5423 \\
\hline $\begin{array}{l}\text { Troodontidae } \\
\text { indet. }\end{array}$ & 2.1594 & -0.0492 & -2.2805 & 2.0921 & 0.324 & 15.4869 \\
\hline Struthio & & & & 2.0777 & 0.0607 & 2.9195 \\
\hline Dromaius & & & & 1.6493 & 0.0472 & 2.863 \\
\hline Gallus & & & & 0.6495 & 0.0391 & 6.0274 \\
\hline \multicolumn{7}{|l|}{ Ilium length $(\mathrm{cm})$} \\
\hline Allosaurus & 1.7718 & 0.0345 & 1.9463 & 1.7765 & -0.0377 & -2.1216 \\
\hline
\end{tabular}




\begin{tabular}{lllllll}
\hline Albertosaurus & 1.8211 & 0.0345 & 1.895 & 1.832 & -0.0384 & -2.0965 \\
$\begin{array}{l}\text { Ornithomimidae } \\
\text { indet. }\end{array}$ & 1.486 & 0.0767 & $\mathbf{5 . 1 6 3 8}$ & 1.4549 & -0.1582 & $\mathbf{- 1 0 . 8 7 6 7}$ \\
$\begin{array}{l}\text { Falcarius } \\
\text { Caenagnathidae }\end{array}$ & 1.4312 & -0.0079 & -0.5517 & 1.3931 & -0.0638 & -4.5786 \\
$\begin{array}{l}\text { indet. } \\
\text { Saurornitholestes }\end{array}$ & 1.3957 & -0.0552 & -3.9533 & 1.3532 & -0.0393 & -2.9077 \\
Sinovenator & 0.8803 & -0.0527 & $\mathbf{- 5 . 9 8 8 6}$ & 0.7731 & -0.0162 & -2.0964 \\
Troodontidae & 1.4741 & -0.0031 & -0.2091 & 1.4414 & 0.1189 & $\mathbf{8 . 2 5 1 9}$ \\
indet. & & & & & & \\
Struthio & & & & 1.4357 & 0.0114 & 0.7943 \\
Dromaius & & & & 1.263 & -0.0562 & -4.4489 \\
Gallus & & & & 0.8599 & 0.0276 & 3.2115 \\
\hline
\end{tabular}


Figure 1

Simplified phylogeny of non-avian maniraptorans among other theropods and extant relatives.

Taxa along top indicate what each reconstruction represents, and asterisks $(*)$ indicate novel pelvic muscle reconstructions. See Methods for details on phylogenetic treatment of study taxa. Phylogeny based on Hendrickx et al. (2015).

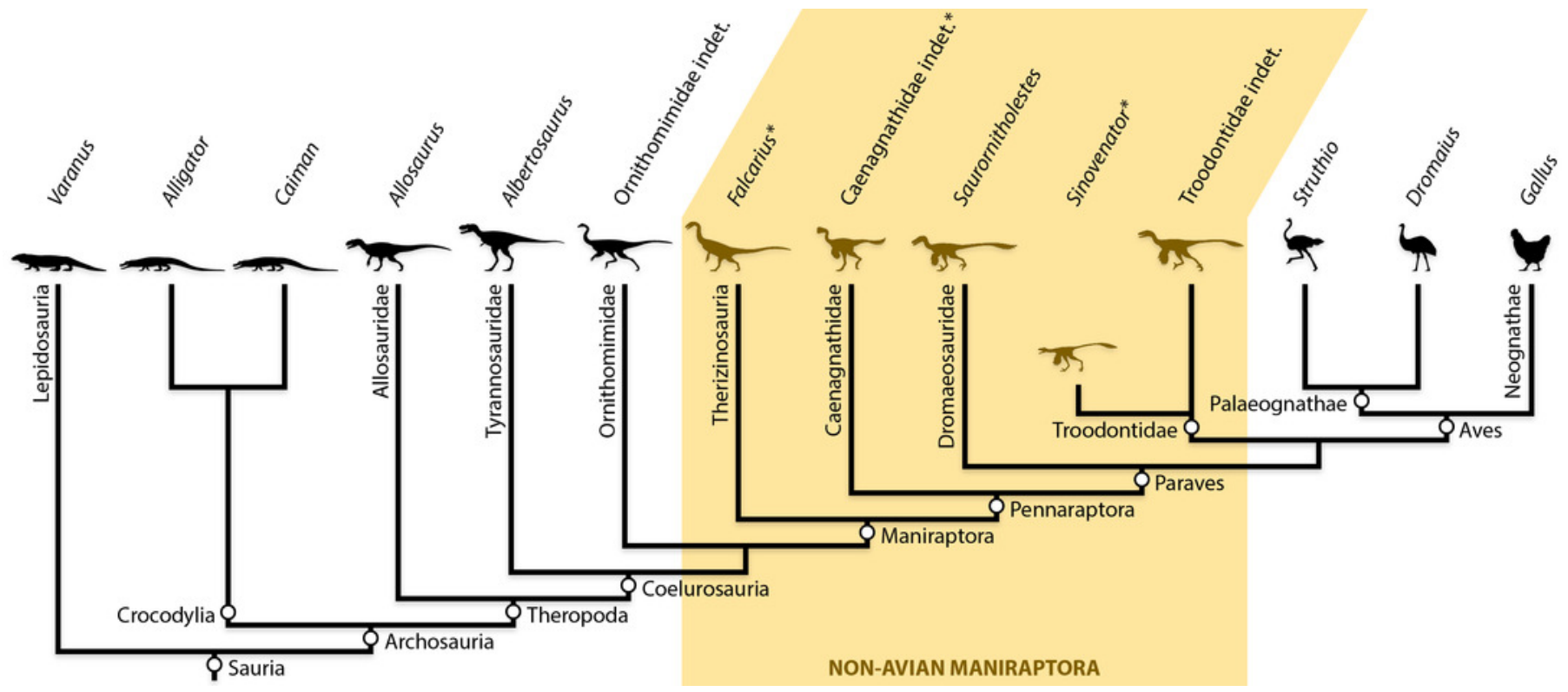




\section{Figure 2}

Osteological correlates of pelvic musculature in Falcarius.

Pelvis in left lateral view (A) with ilium CEUM 77189, pubis UMNH VP 14540 (reversed; courtesy of Natural History Museum of Utah), and ischium CEUM 74717 (reversed). Ilium CEUM 77189 in ventral view (B) and oblique view of cuppedicus fossa (C). Pelvis in medial view (D) with the same specimens as in lateral view. Anterolateral view of proximal end of pubis CEUM 52424 (E). Close-up of obturator process (F) of ischium CEUM 52482 (reversed; proximal to top). Pubis UMNH VP 14540 in anterior $(\mathrm{G})$ and posterior $(\mathrm{H})$ views with close-up of the apron (I). Abbreviations: ace, acetabulum; bf, brevis fossa; cf, cuppedicus fossa; dist, distal ischial tubercle; isa, ischial apron; isp, ischiadic peduncle; op, obturator process; pa, pubic apron; pah, preacetabular hook; pb, pubic boot; pist, proximal ischial tubercle; pos, postacetabulum; pre, preacetabulum; pt, preacetabular tubercle; pup, pubic peduncle; rdg, ridge; str, striations. 


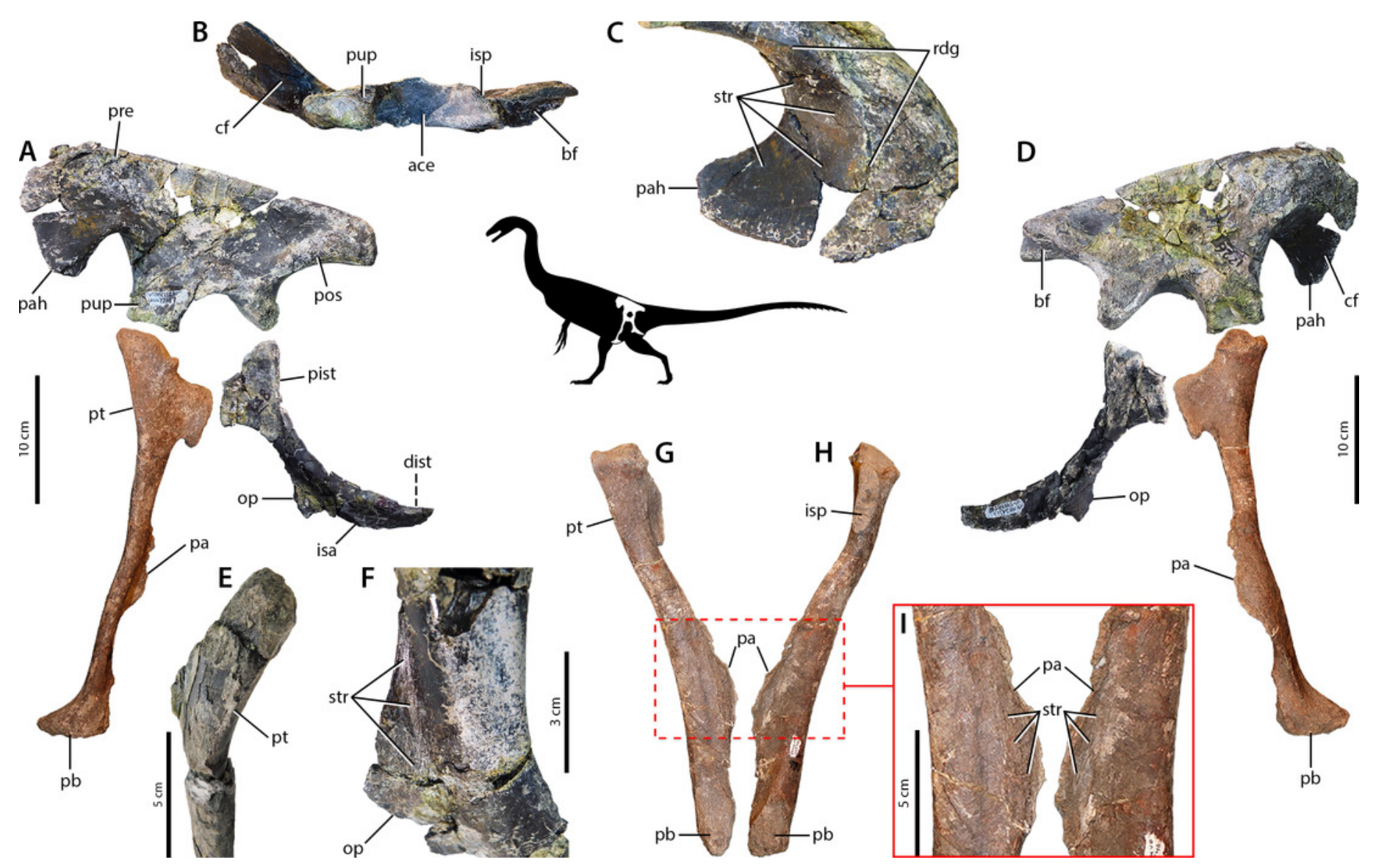




\section{Figure 3}

Osteological correlates of pelvic musculature in Caenagnathidae indet.

Ilium UALVP 59791 in left lateral (A), ventral (B), and medial (C) views. Pelvis in left lateral view (D) with ilium TMP 1979.020.0001, pubis UALVP 56638, and ischium TMP 1979.020.0001 (reversed). Ilium TMP 1979.020.0001 in ventral view (E). Pelvis in medial view (F) with the same specimens as in lateral view except for pubis TMP 1980.016.2095. Close-up of obturator process (G) of ischium TMP 1979.020.0001. Pubes UALVP 56638 in anterior $(H)$ and posterior (J) views. Refer to Fig. 2 for anatomical abbreviations.

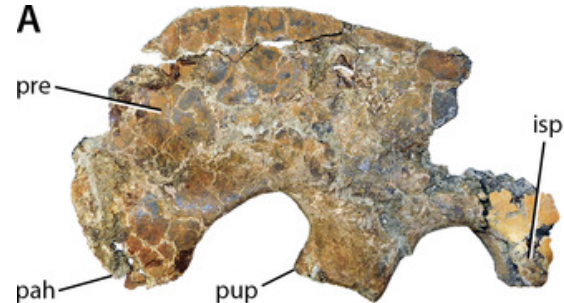

D


B

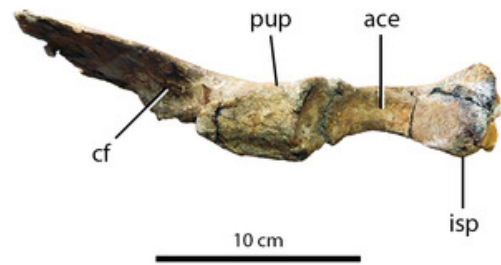

E
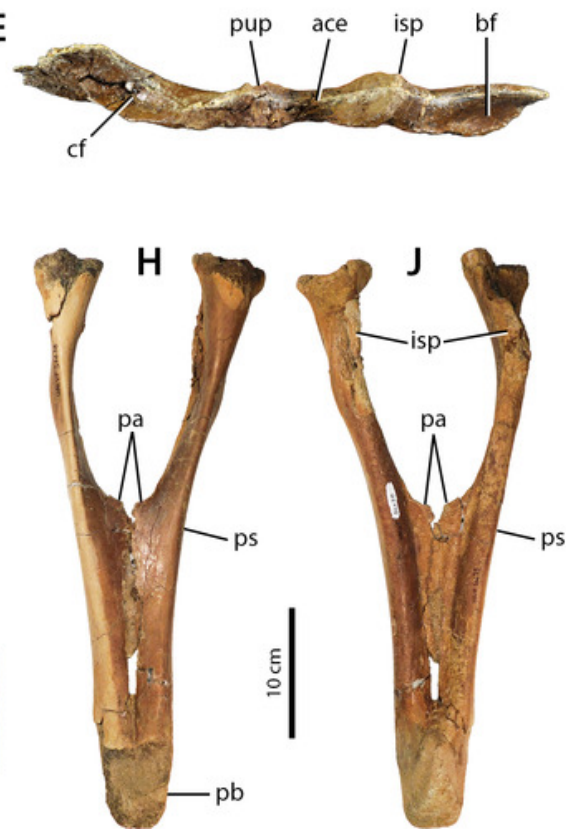

C

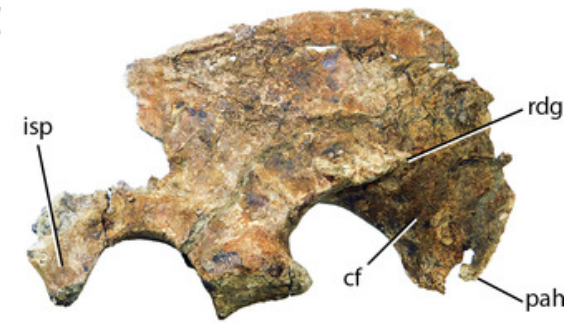

$\mathbf{F}$
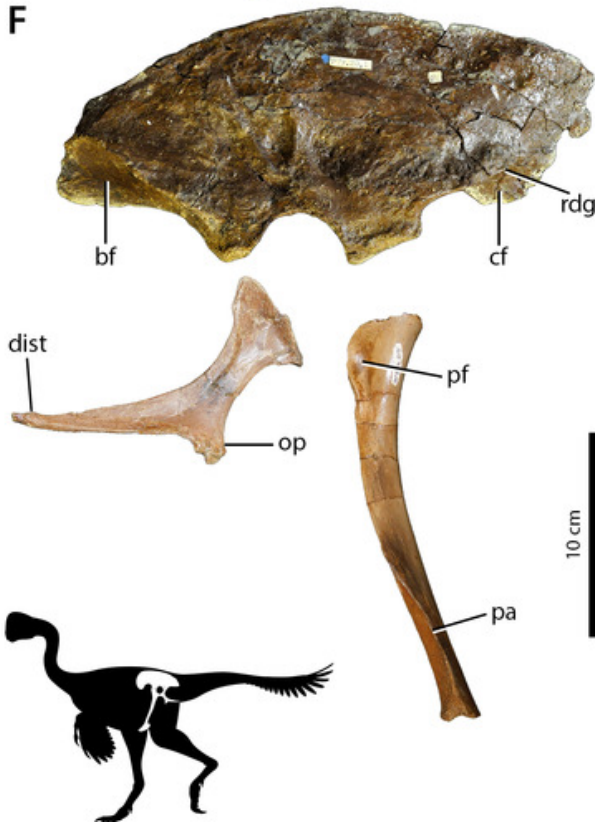
Figure 4

Osteological correlates of pelvic musculature in Sinovenator (A-J) and Jianianhualong $(\mathrm{K}-\mathrm{L})$.

Ilia IVPP V12615 and IVPP V12583 in left lateral (A-B) and ventral (C-E) views (A, C, and E reversed). In the stippled line drawings, dashed lines indicate broken edges and grey represents matrix-obscured areas. Pubis IVPP V12583 in lateral (F, reversed), medial (G, reversed), anterior (H), and posterior (I) views. Pubes IVPP V12615 in posterior view (J). Pelvic region of Jianianhualong (K) with close-up of left ischium DLXH 1218 (L). Refer to Fig. 2 for anatomical abbreviations.

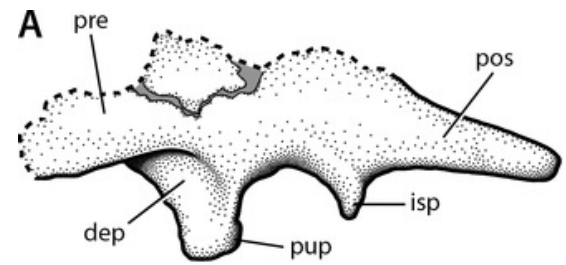

c
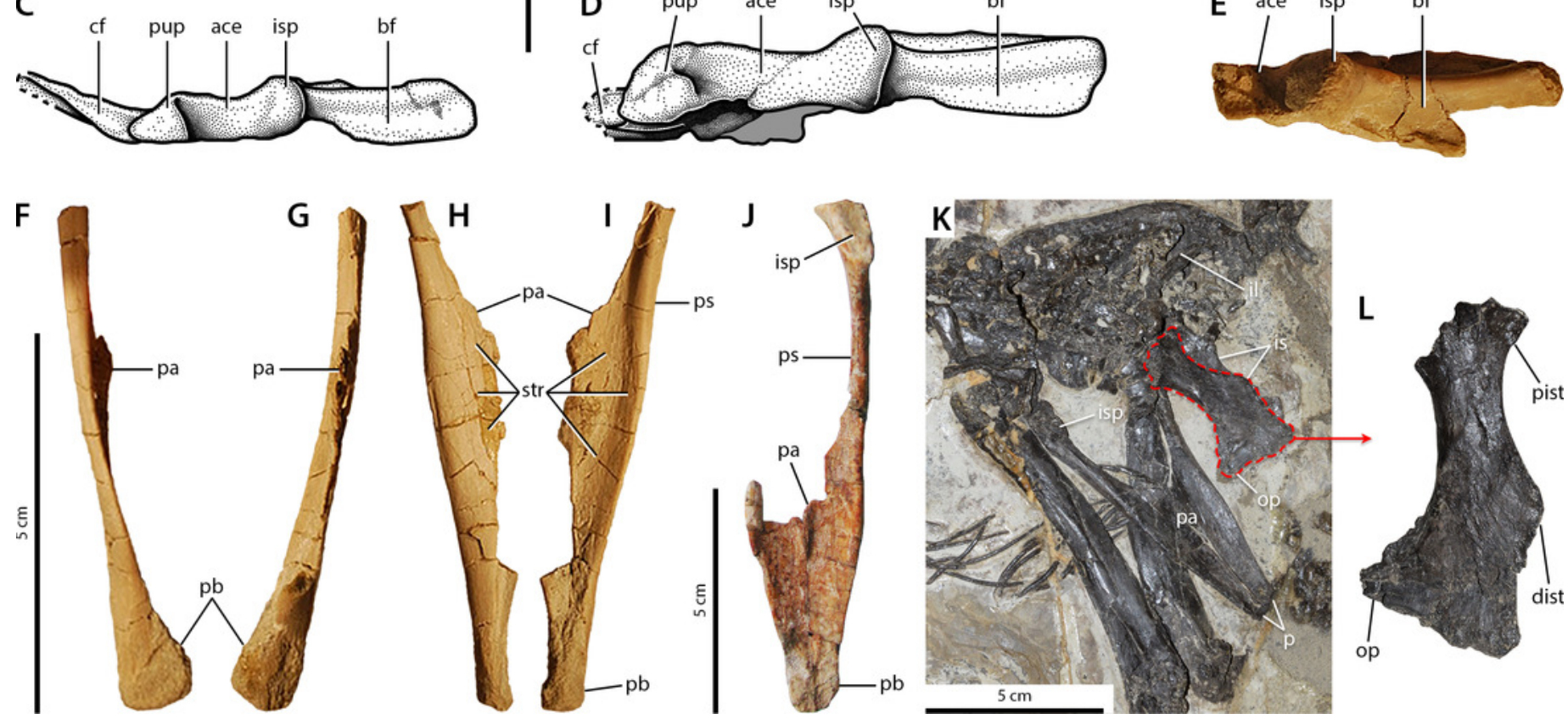


\section{Figure 5}

Osteological correlates of pelvic musculature in derived Troodontidae indet.

Pelvis in left lateral view (A) with ilium and pubis UALVP 55804 (reversed) and ischium AMNH 6516. Pelvis UALVP 55804 (reversed) in ventral view (B). Pelvis in medial view (C) with the same specimens as in lateral view. Ischium UMNH VP 19479 (reversed) in dorsal (D) and lateral (E) views. Pubis UALVP 55804 in anterior view (F). Pubes UALVP 55804 in lateral (G, close-up in $\mathrm{H})$, anterior (I), posterior (J, close-up in $\mathrm{K})$, and medial ( $\mathrm{L}$, close-up in $\mathrm{M})$ views. Refer to Fig. 2 for anatomical abbreviations.

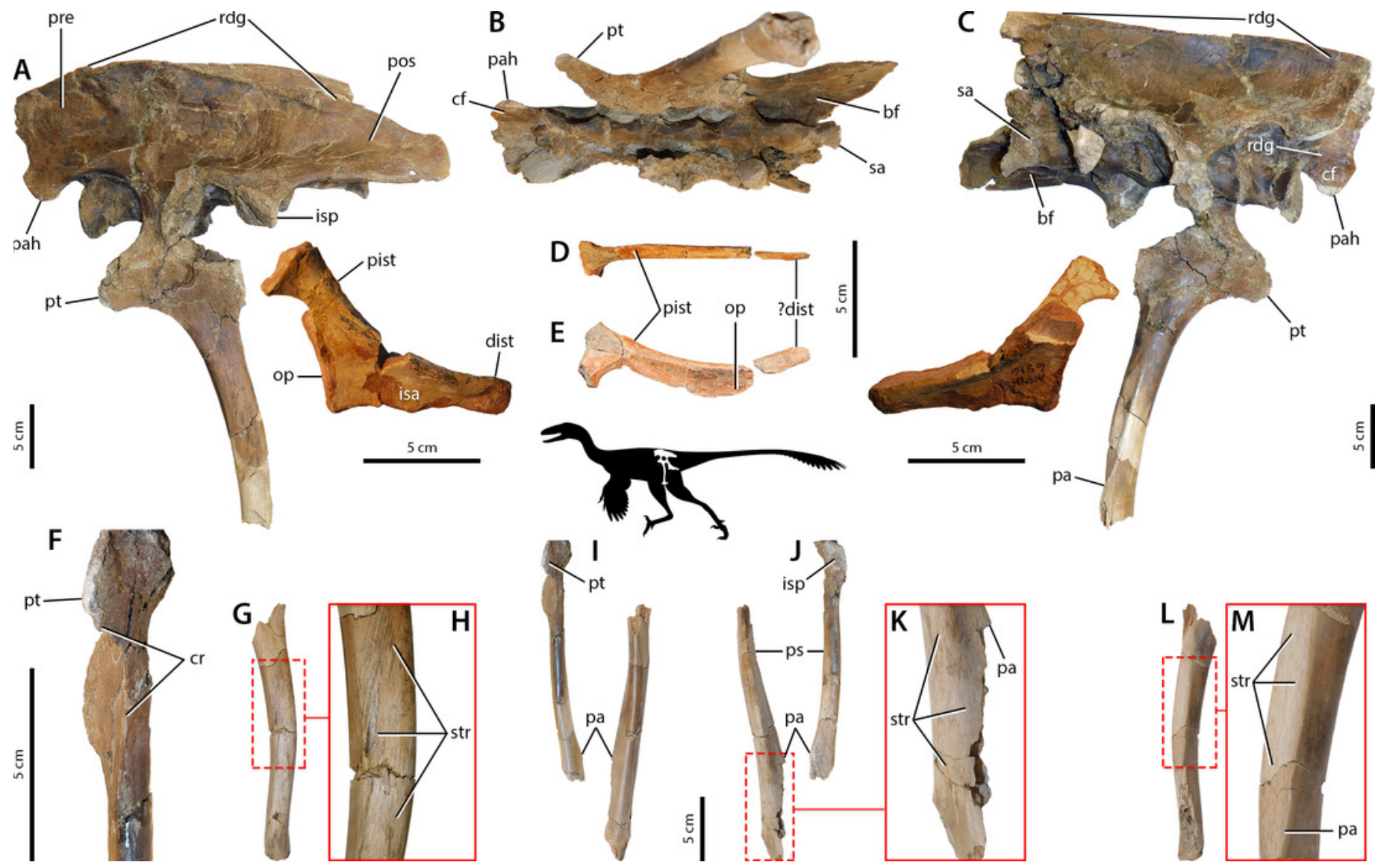




\section{Figure 6}

Pelvic myology of non-avian maniraptorans.

Pelvis of Falcarius in left lateral view (A), ilium in ventral view (B), pelvis in medial view (C), and pubes in anterior (D) and posterior (E) views. Pelvis of Caenagnathidae indet. in left lateral view $(F)$, ilium in ventral view $(G)$, pelvis in medial view $(H)$, and pubes in anterior (I) and posterior (J) views. Pelvis of Sinovenator in left lateral view (K), ilium in ventral view (L), pelvis in medial view $(\mathrm{M})$, and pubes in anterior $(\mathrm{N})$ and posterior $(\mathrm{O})$ views. Pelvis of derived Troodontidae indet. in left lateral view (P), ilium in ventral view (Q), pelvis in medial view (R), and pubes in anterior (S) and posterior ( $\mathrm{T}$ ) views. See Table 2 for muscle abbreviations. 


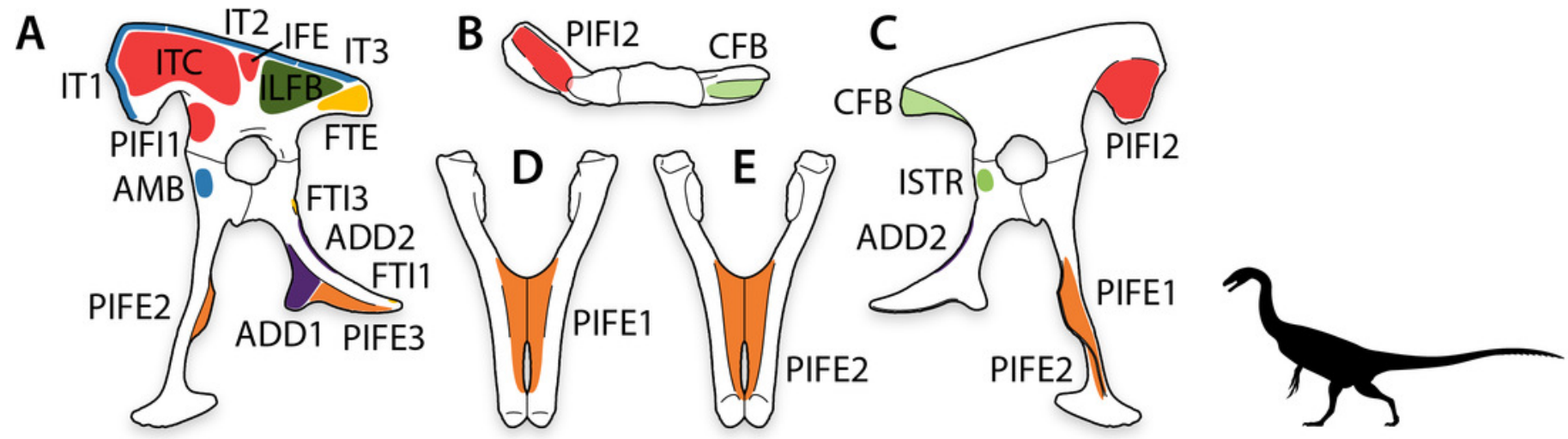

F

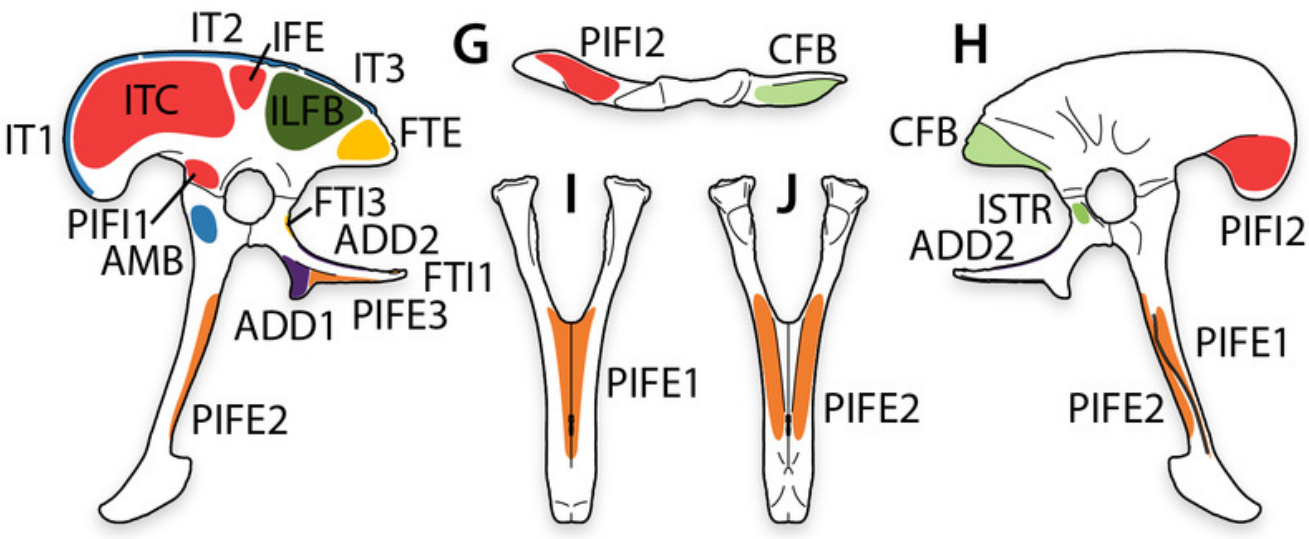

K
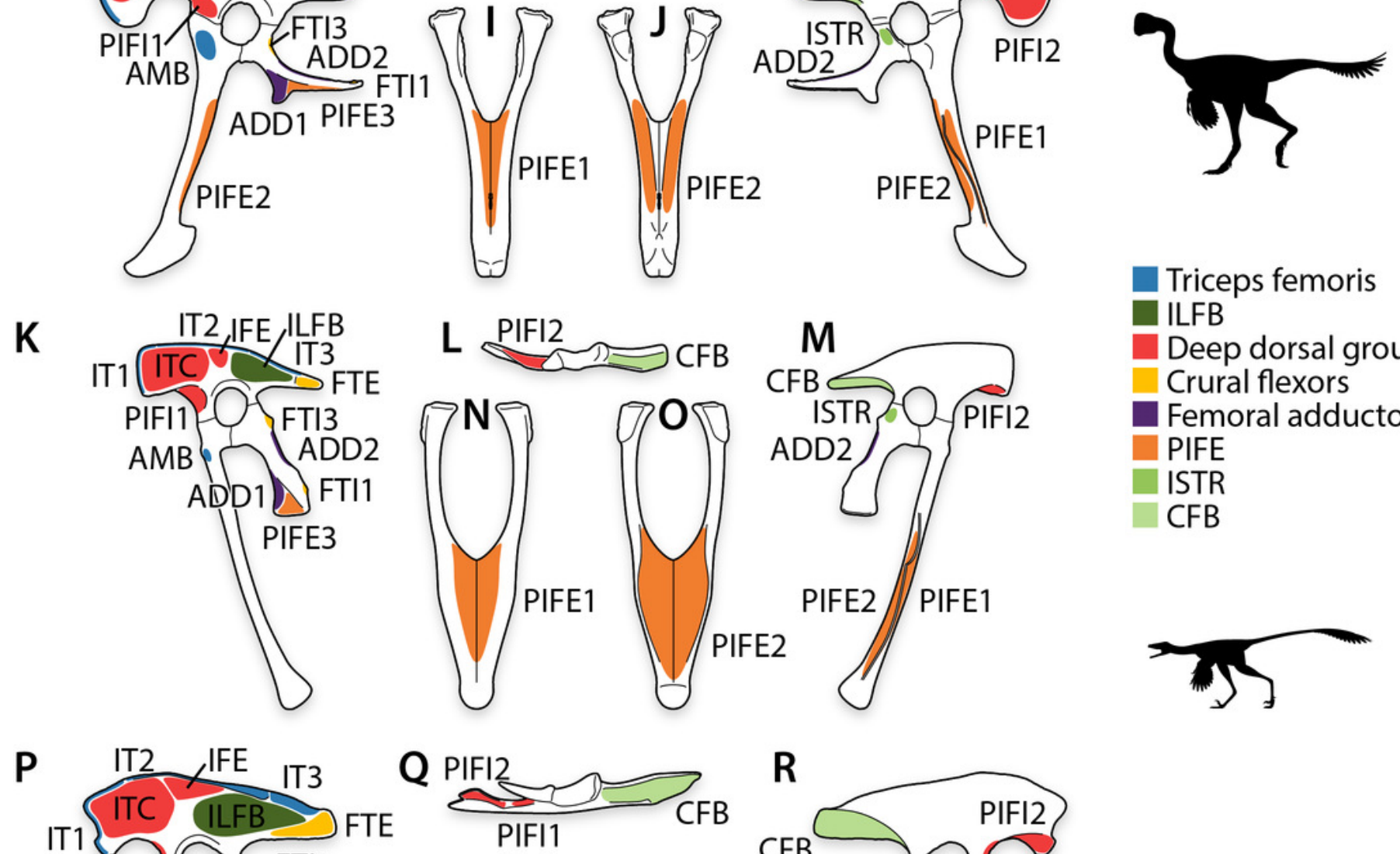

IT1 PIFI
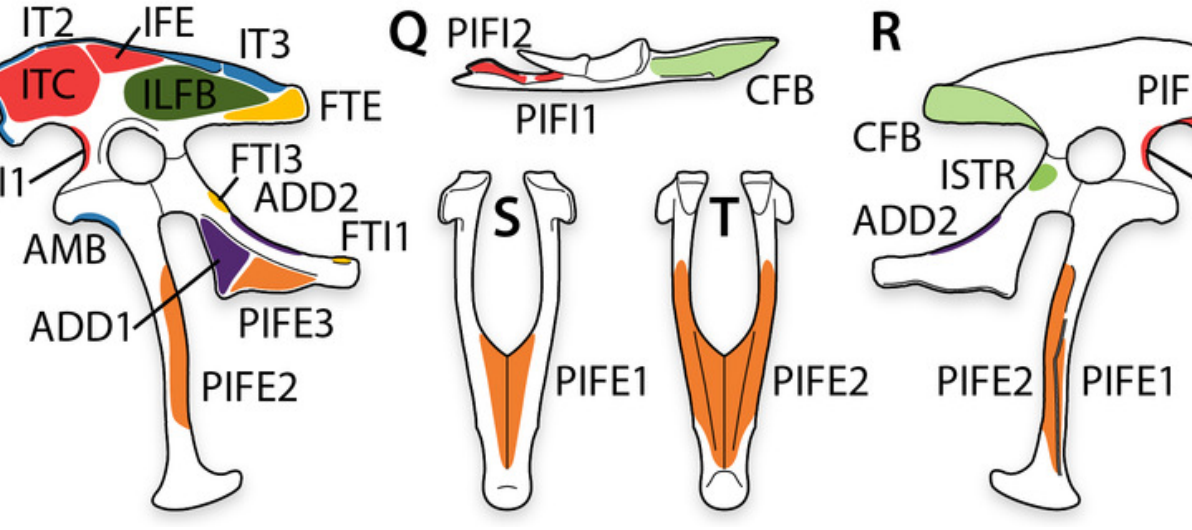

Triceps femoris

ILFB

Deep dorsal group Crural flexors

- Femoral adductors

PIFE

ISTR

CFB

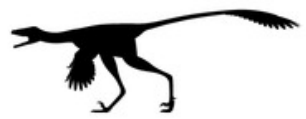




\section{Figure 7}

Pelvic myology of other study taxa.

Pelvis of Varanus in left lateral (A) and medial (B) views. Pelvis of Alligator in left lateral (C) and medial (D) views, and pubes in dorsal (E) and ventral (F) views. Pelvis of Caiman in left lateral (G) and medial (H) views, and pubes in dorsal (I) and ventral (J) views. Pelvis of Allosaurus in left lateral view (K), ilium in ventral view (L), pelvis in medial view (M), and pubes in anterior $(\mathrm{N})$ and posterior $(\mathrm{O})$ views. Pelvis of Albertosaurus in left lateral view $(\mathrm{P})$, ilium in ventral view $(\mathrm{Q})$, pelvis in medial view $(\mathrm{R})$, and pubes in anterior $(\mathrm{S})$ and posterior $(\mathrm{T})$ views. Pelvis of Ornithomimidae indet. in left lateral view (U), ilium in ventral view (V), pelvis in medial view $(\mathrm{W})$, and pubes in anterior $(\mathrm{X})$ and posterior $(\mathrm{Y})$ views. Pelvis of Saurornitholestes in left lateral view (Z), ilium in ventral view (AA), pelvis in medial view (BB), and pubes in anterior (CC) and posterior (DD) views. Pelvis of Struthio in left lateral (EE) and medial (FF) views. Pelvis of Dromaius in left lateral (GG) and medial (HH) views. Pelvis of Gallus in left lateral (II) and medial (JJ) views. See Table 2 for muscle abbreviations and refer to Supplemental Figures for individually labeled origins. 

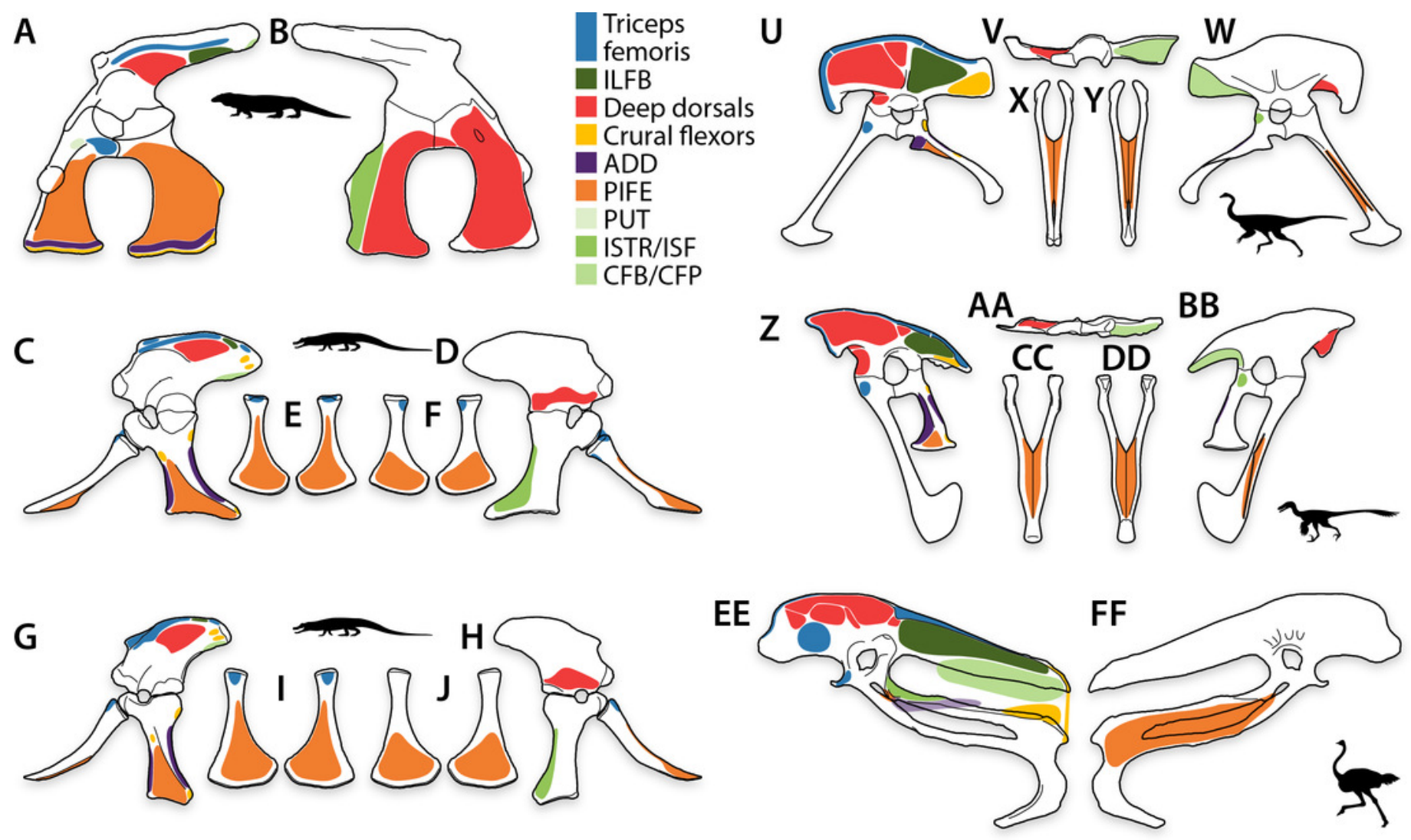

K
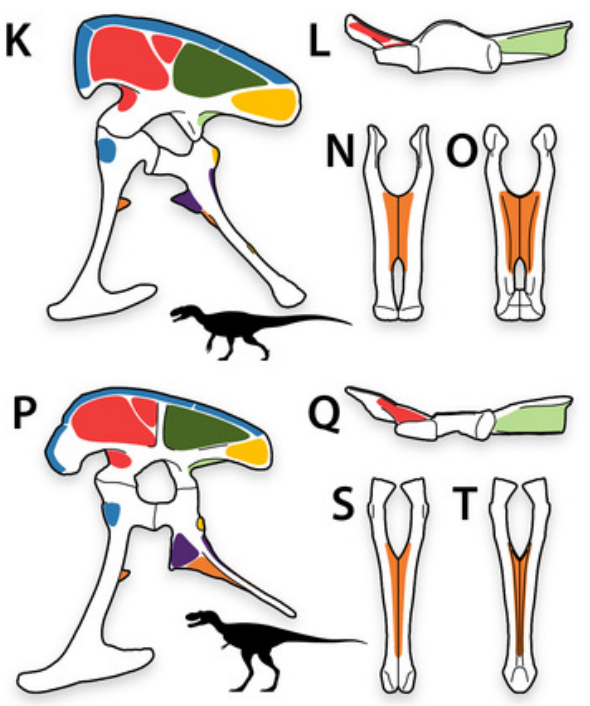
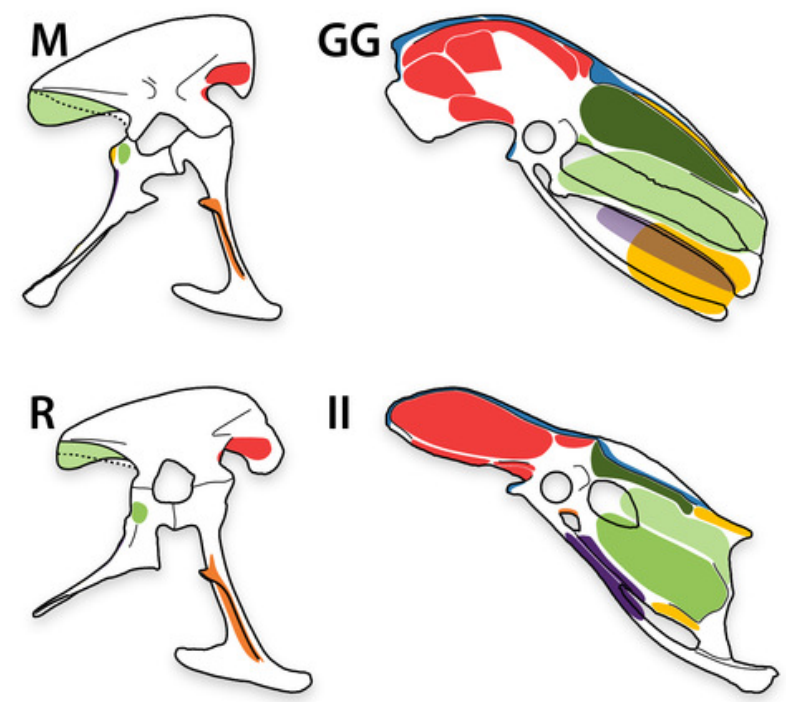
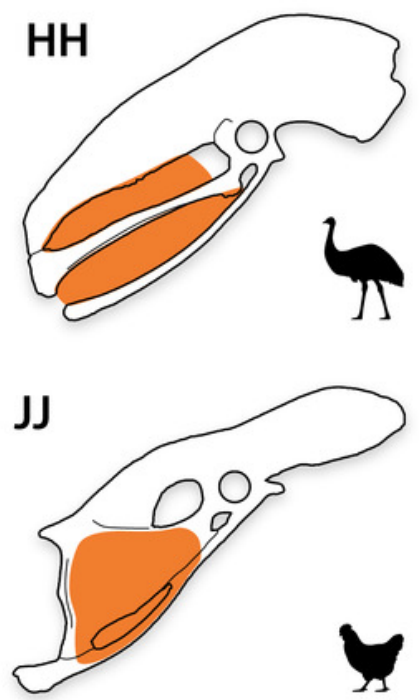


\section{Figure 8}

Area of attachment across all pelvic muscles and by conventional anatomical groups.

(A) Equal-area chart showing the proportion of individual muscles to the total area of all muscles. (B) Paired bar charts representing anatomical groups with results from Corel DRAW! (left bars) and Image (right bars). See Table 2 for muscle abbreviations.
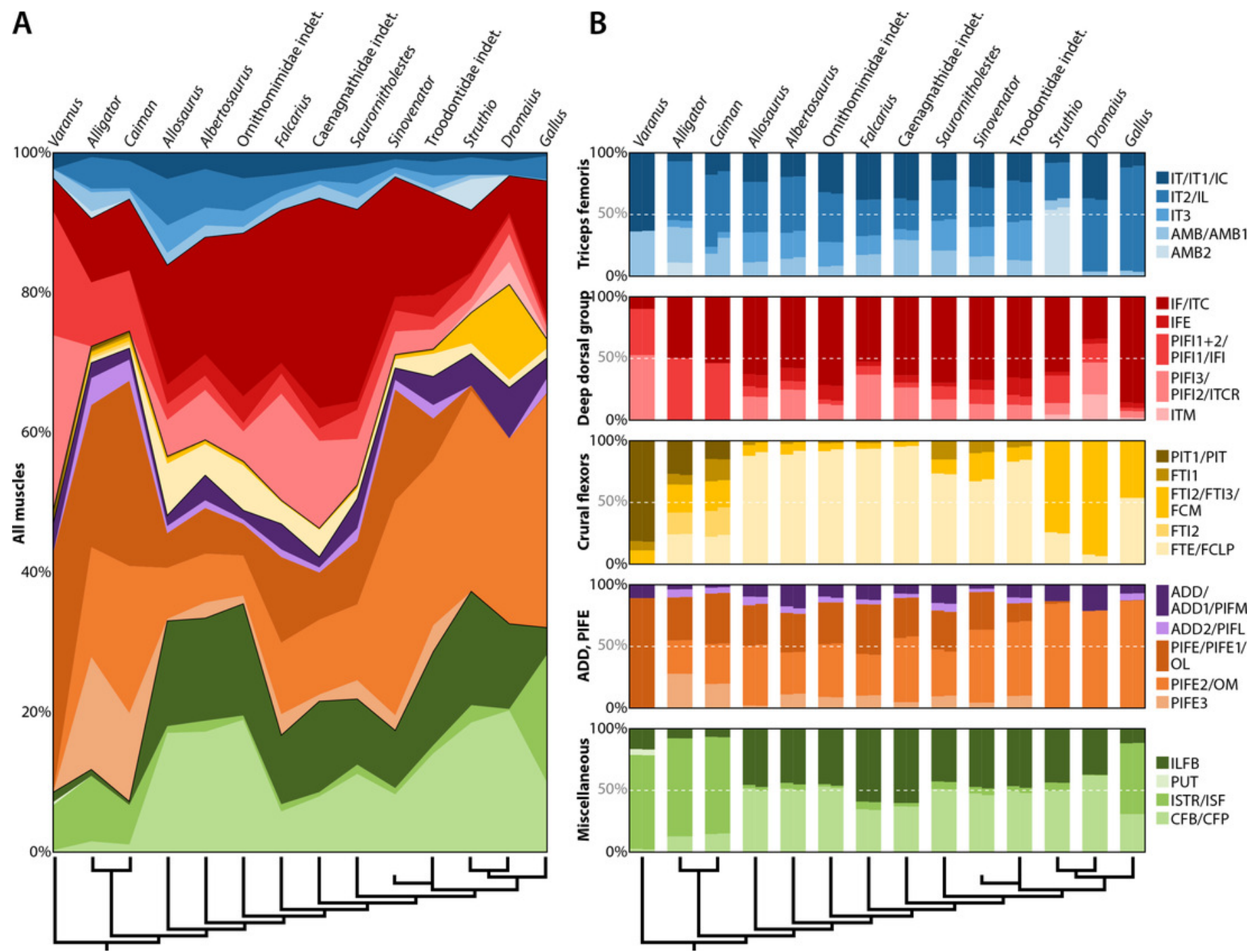
Figure 9

Area of attachment by functional groups.

(A) Antagonistic pairs of all taxa sampled. (B) Antagonistic pairs of taxa pruned to reflect general results of past studies. Abbreviations: Ab, abduction; Ad, adduction; $E$, extension; $F$, flexion; $M$, medial; L, lateral; LAR, long axis rotation.

A

A
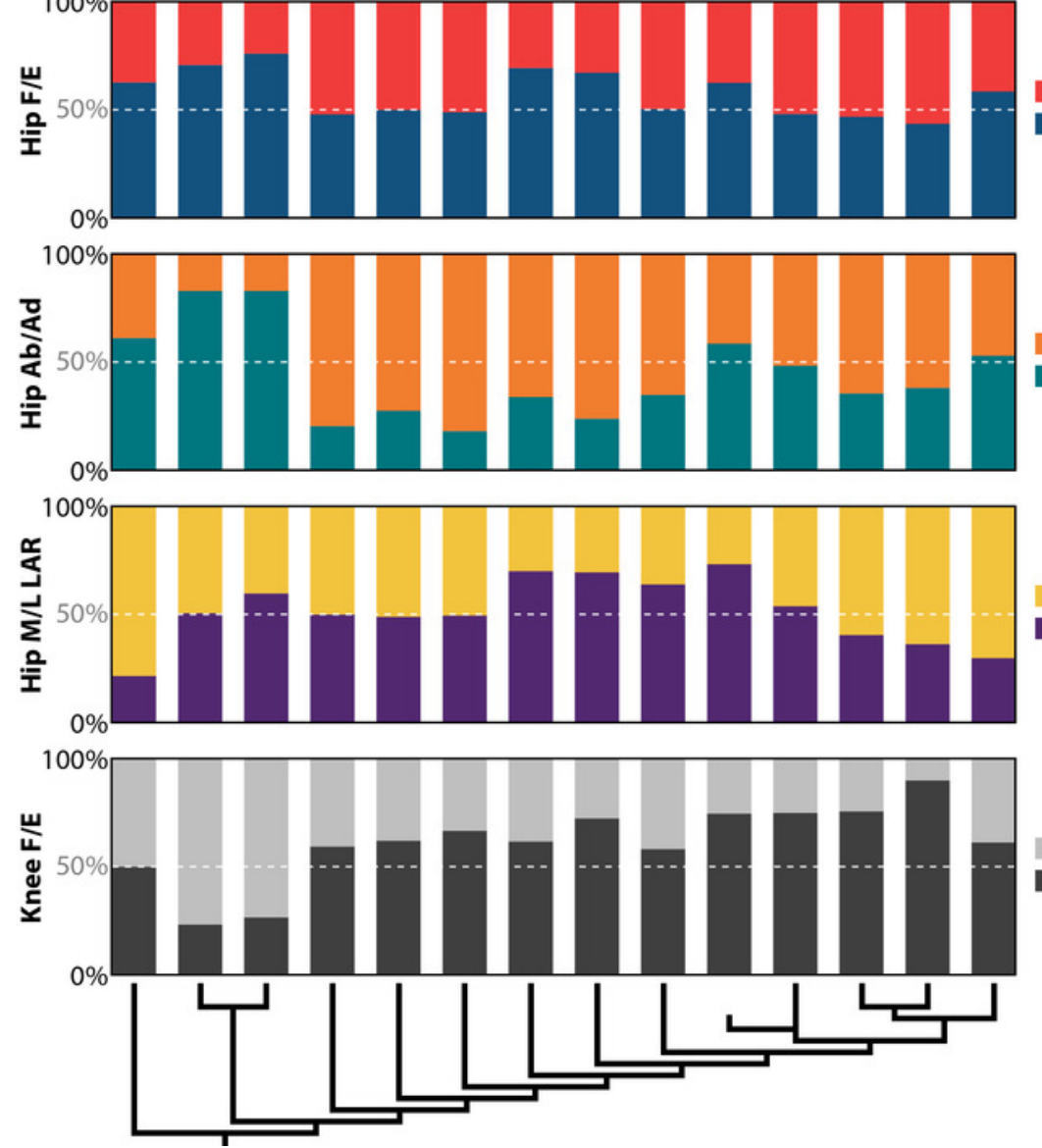

B

Extension

Elexion

Abduction

adduction

Lateral

- Medial

Extension

EFlexion

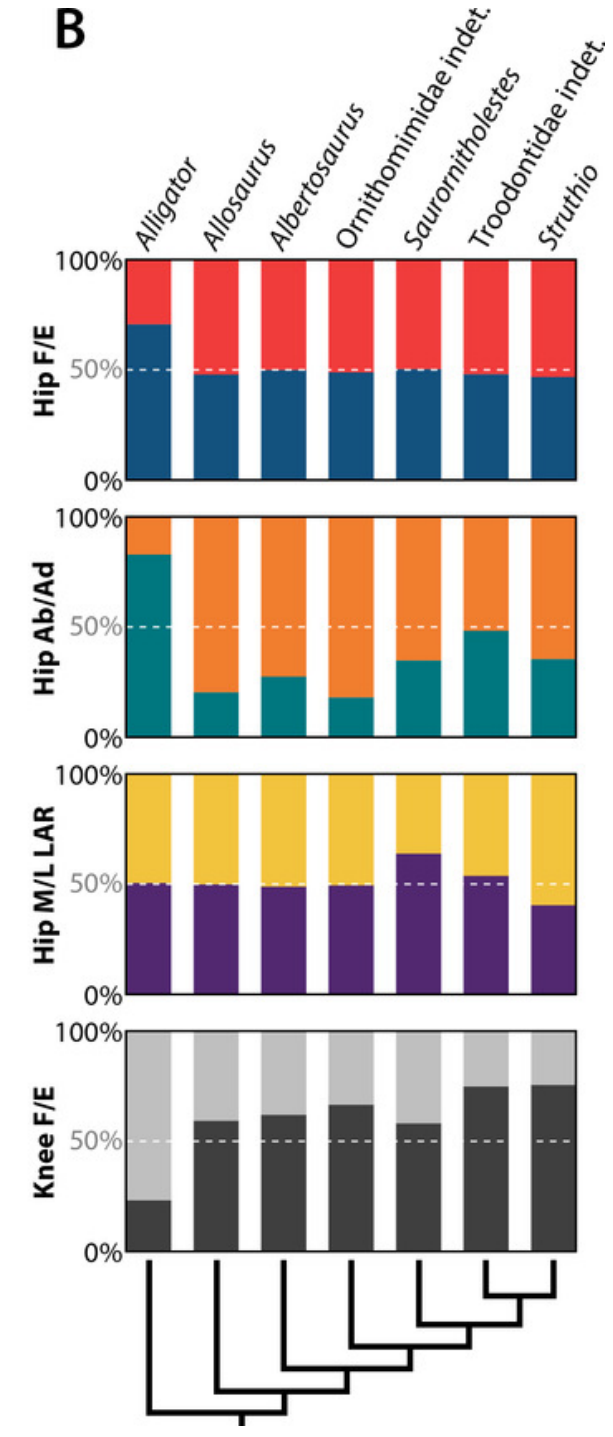


Figure 10

Pelvic myology by functional groups.

Antagonistic pairs demonstrate general patterns in representatives of non-theropod Sauria (Alligator, A), non-maniraptoran Theropoda (Allosaurus, B), non-avian Maniraptora (Saurornitholestes, C), and Aves (Gallus, D). Abbreviations: Ab, abduction; Ad, adduction; E, extension; F, flexion; M, medial; L, lateral; LAR, long axis rotation.




Figure 11

Sensitivity analysis.

Comparison of Corel DRAW! and ImageJ under five tolerance levels performed on the Albertosaurus reconstruction (inset) shows no significant differences. Scatter plot (left) depicts individual muscle origin measurements, summarized in the box and whisker plot (right; coloured bars = interquartile range, black line = mean). See Table 2 for muscle abbreviations.

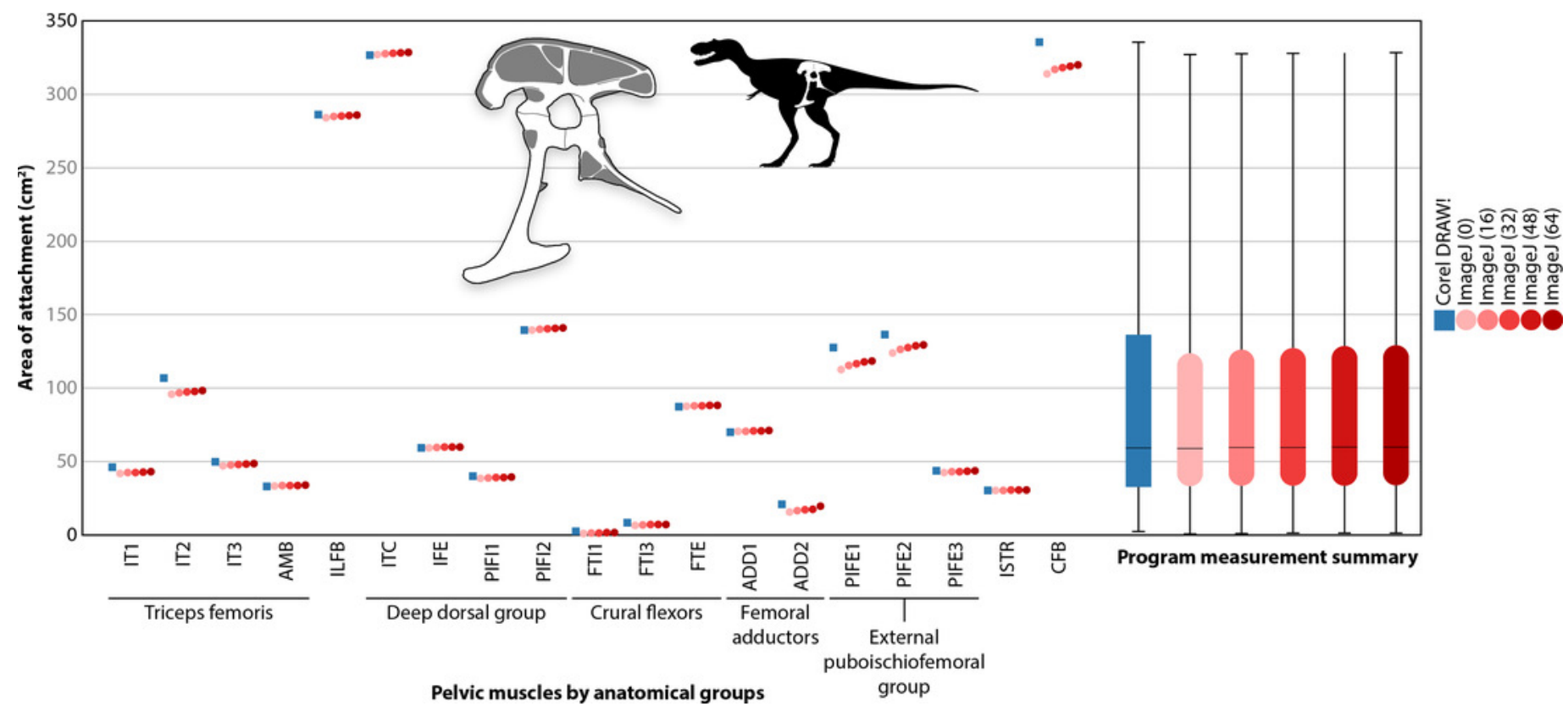




\section{Figure 12}

Phylogenetic Generalized Least Squares (PGLS) regressions on area of attachment and ilium length normalized to body mass (all log-transformed).

(A) Individual regressions on each major group with colour-coded regression lines (dashed).

(B) Regressions on non-avian theropods. (C) Regressions on bipedal taxa. Bivariate comparisons are grouped by rows according to the dependent variable: area of attachment of all hip muscles (upper), area of attachment of major extensors (middle), and length of the ilium (lower). 

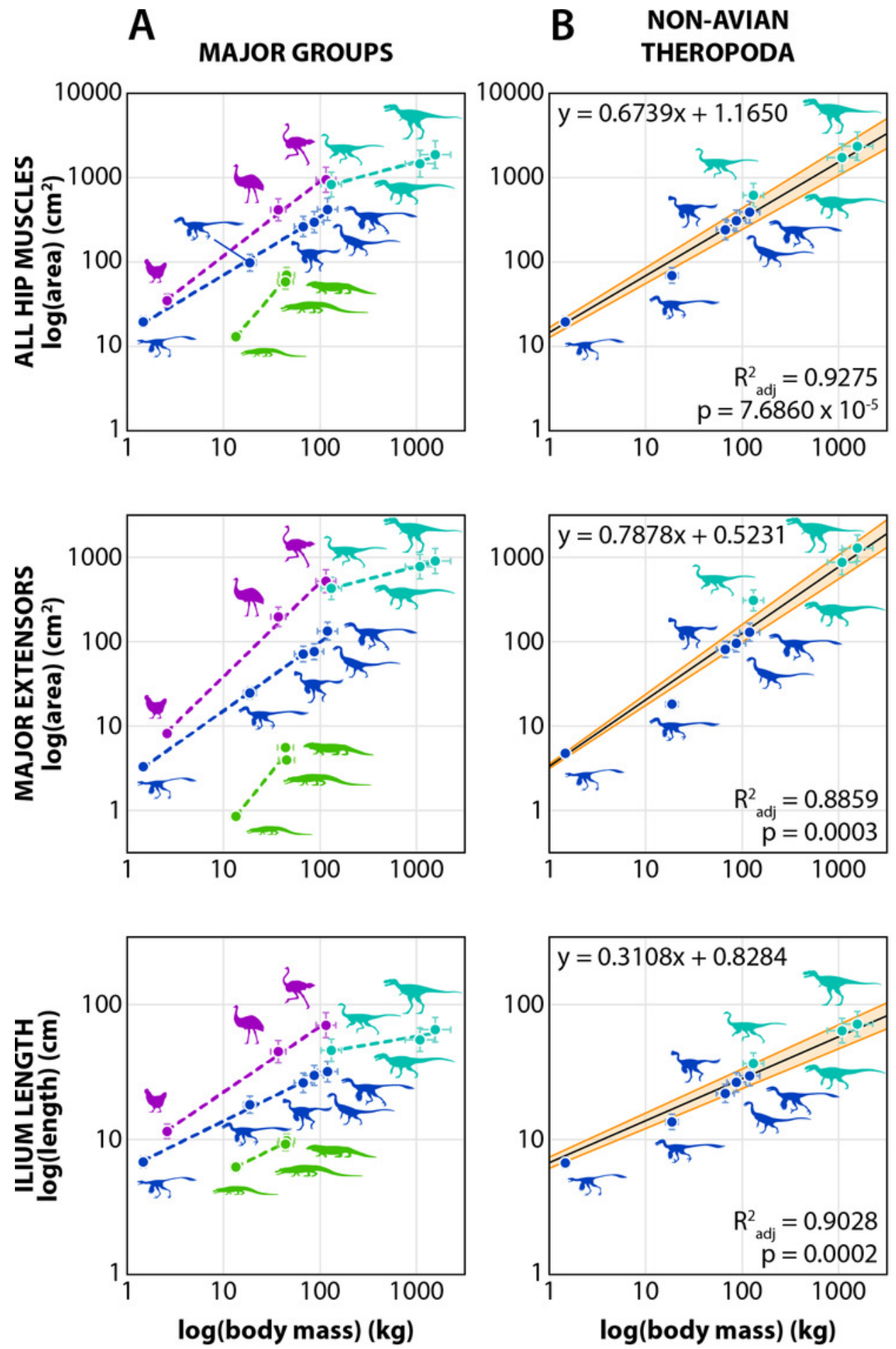

B NON-AVIAN

C
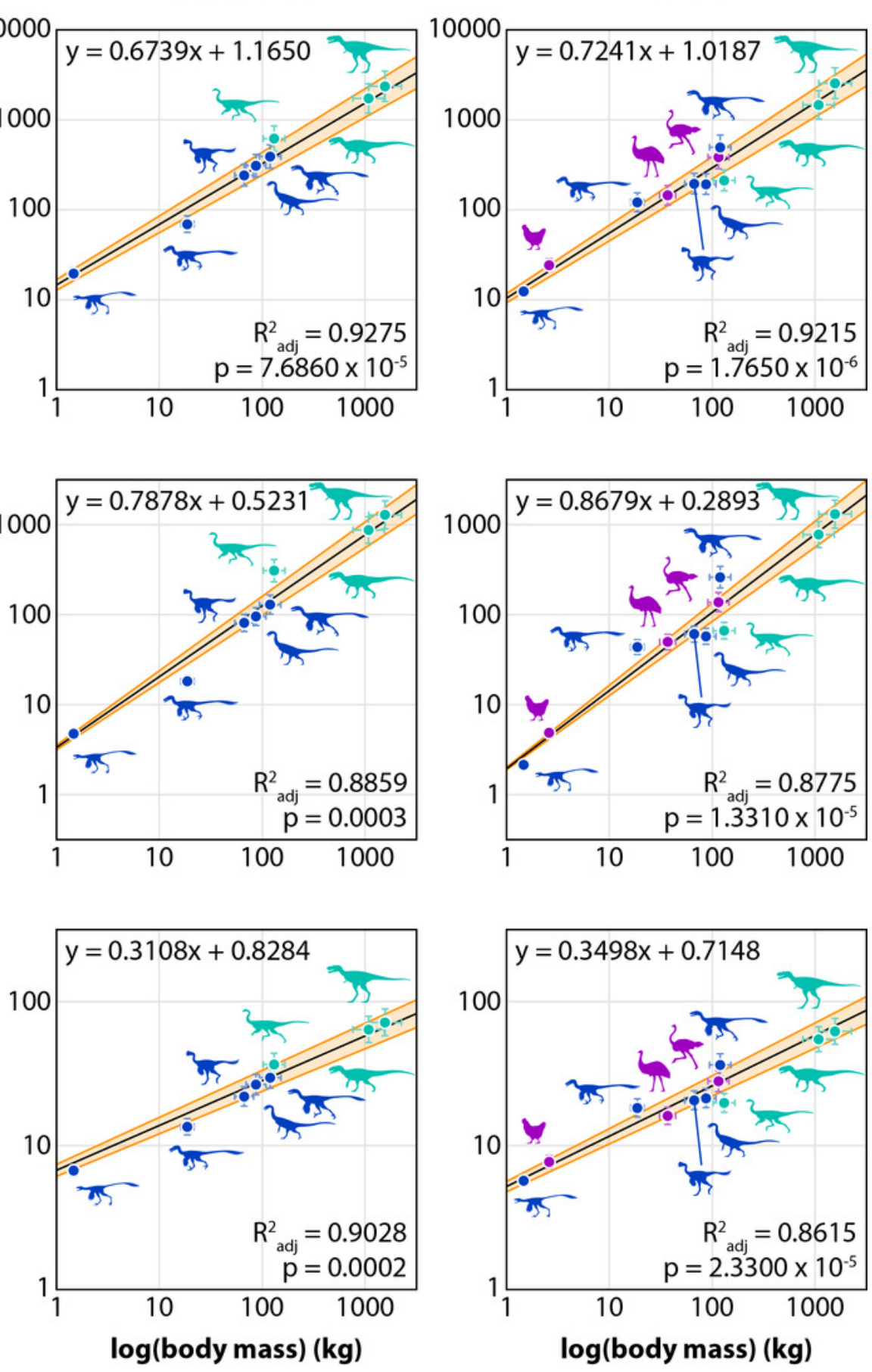

- Non-theropod Sauria

- Non-maniraptoran Theropoda

- Non-avian Maniraptora

- Aves
Regression line (taxon)

- Regression line

I $5 \%$ error bars

- $\pm 5 \%$ (adjusted to $\log \mathrm{BM}$ ) 


\section{Figure 13}

Area of attachment of major extensors.

Muscles and groups plotted as a proportion of the total area of all pelvic muscle origins, and grey lines represent 5\% increments. Cursoriality categories adapted from Carrano (1999).

Classes based on Jenks Natural Break optimization of the major extensors for five groups.

See Table 2 for muscle abbreviations. 

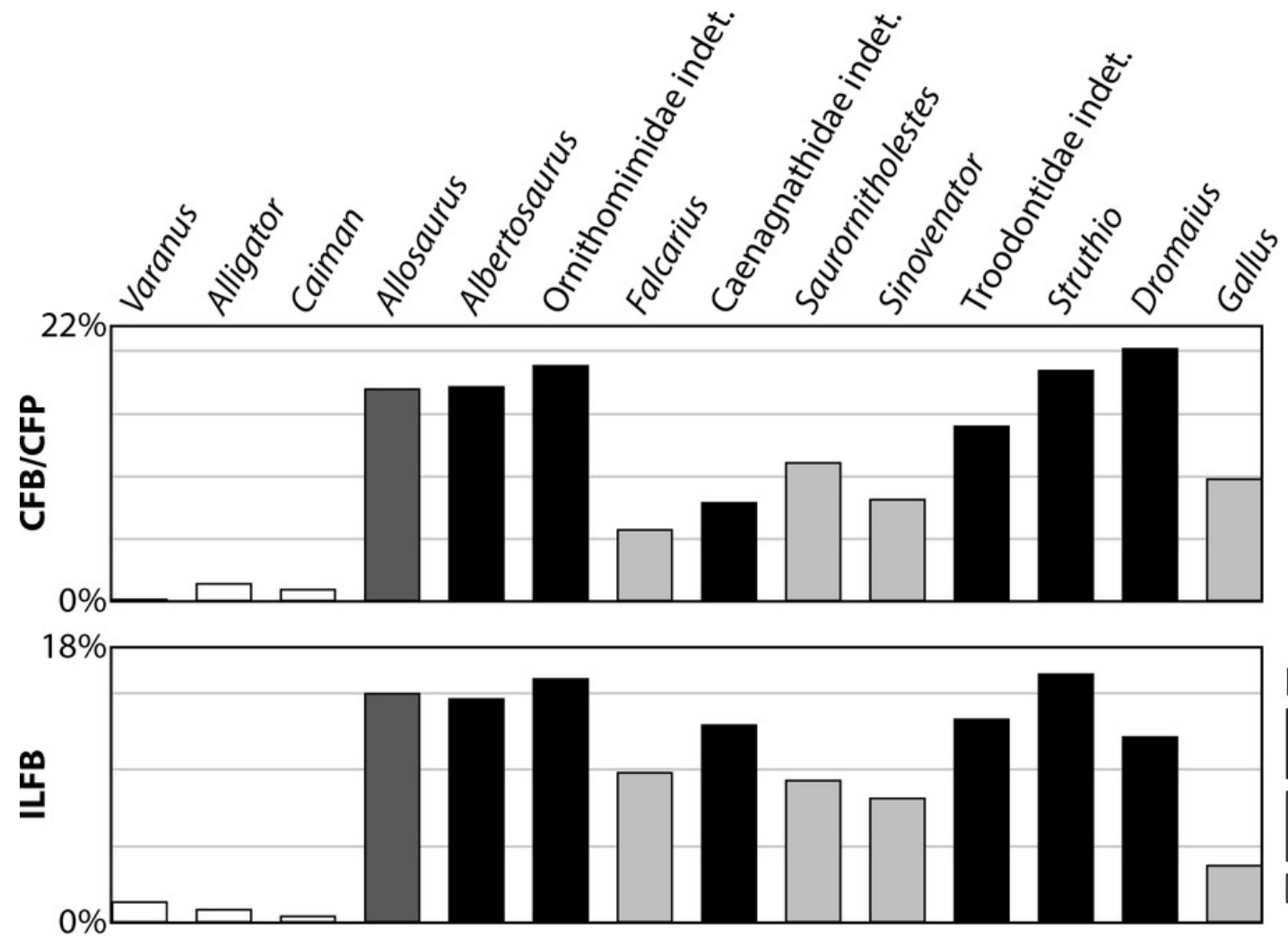

- Cursorial

Large-bodied intermediate

Small-bodied intermediate

$\square$ Non-cursorial

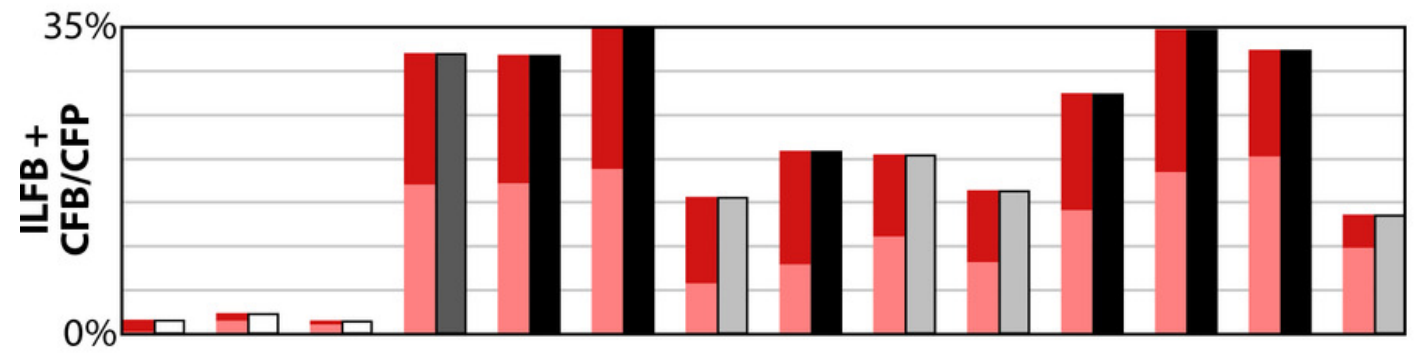

$\square$ ILFB

CFB/CFP

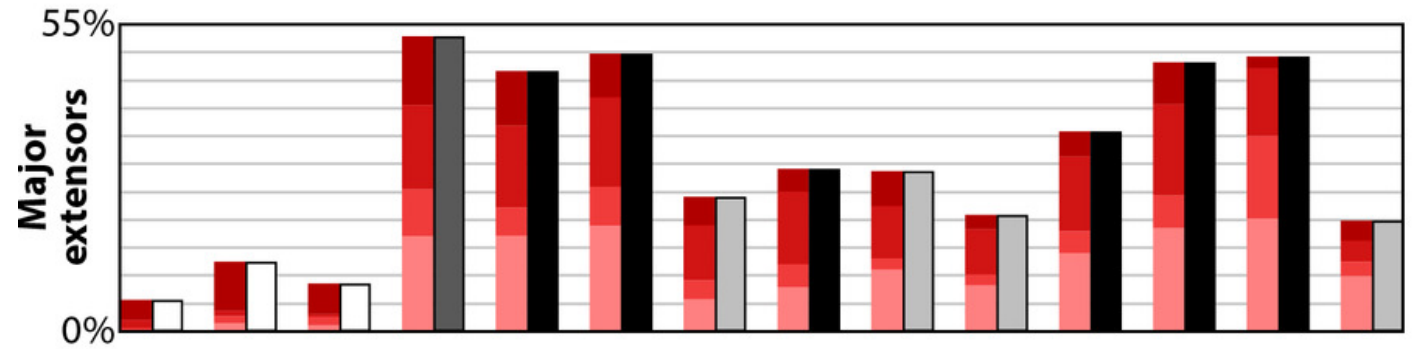

Triceps femoris extensors

aILFB

Crural flexors

CFB/CFP

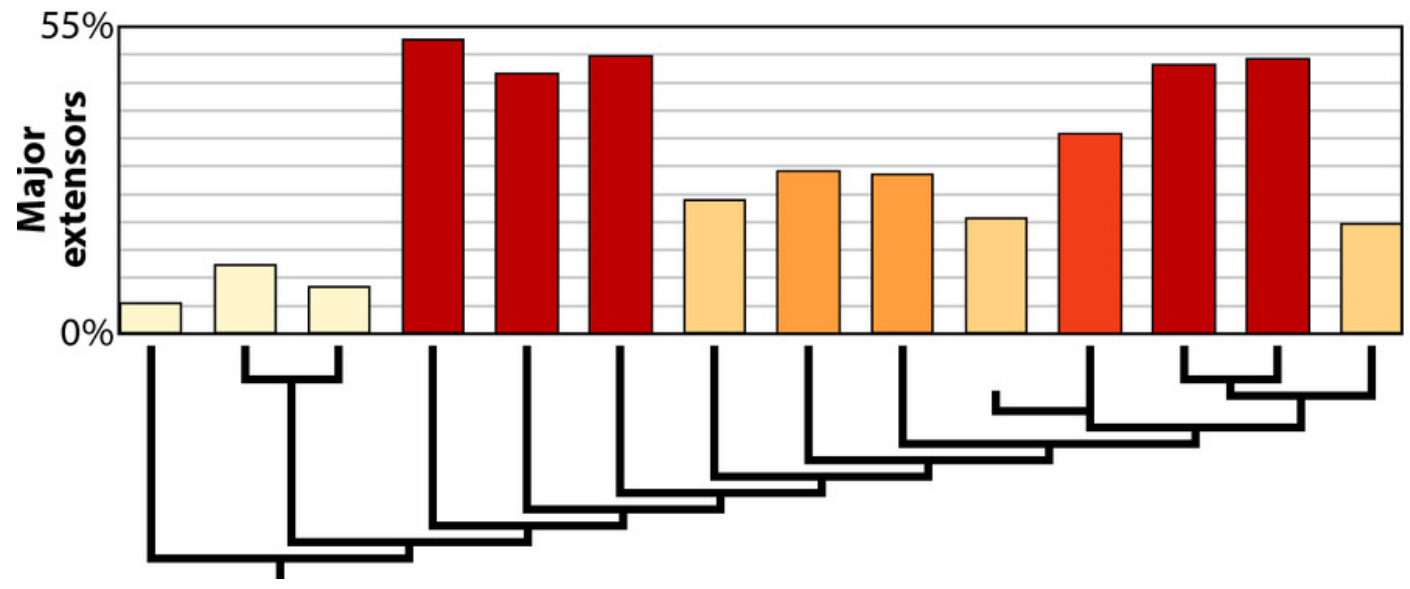

Class 5

$\square$ Class 4

$\square$ Class 3

$\square$ Class 2

$\square$ Class 1 


\section{Figure 14}

Pelvic musculature and other putative correlates of cursoriality.

(A) Pelvic muscle reconstructions in left lateral view grouped to show non-avian

maniraptorans among other theropods and extant relatives. (B) Heat map comparing the area of attachment of major extensors (from Jenks Natural Breaks optimization in Fig. 13), proportional length of distal hind limb elements (sensu Carrano 1999), ankle joint morphology/degree of metatarsal fusion (hinge-like > ball-and-socket; tarsometatarsus > arctometatarsus $>$ subarctometatarsus $>$ unspecialized), number of functional weightbearing digits (fewer = higher), and foot symmetry. (C) Bar chart depicting a spectrum of inferred cursoriality averaged from the heat map above. 


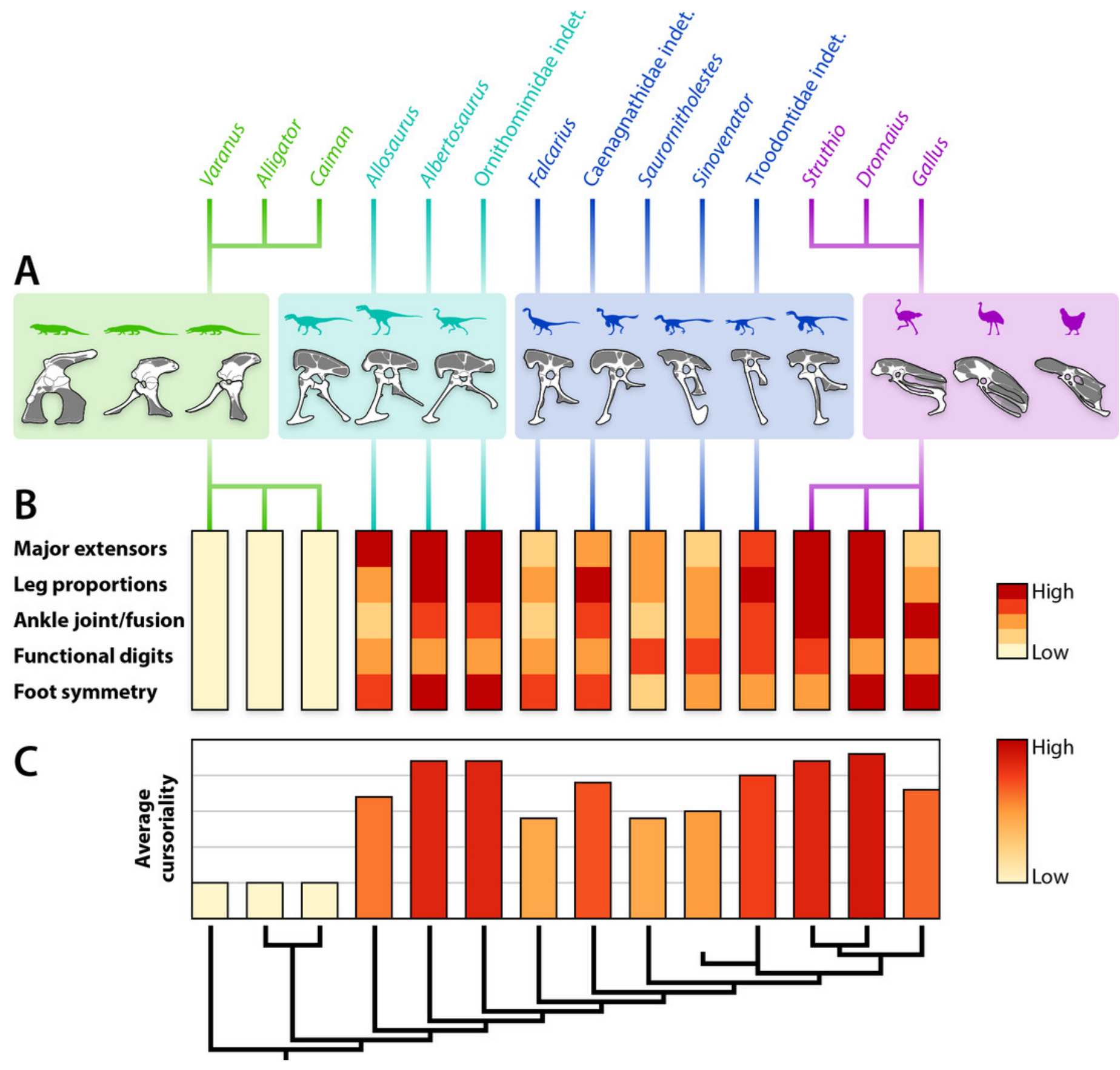

